\title{
Improving Microbial Safety of Food Products by Thermal and Non-thermal technology and Evaluate the Knowledge of Antibiotic Resistant Issue Among Local Produce Growers
}

Wentao Jiang

Follow this and additional works at: https://researchrepository.wvu.edu/etd

Part of the Food Microbiology Commons

\section{Recommended Citation}

Jiang, Wentao, "Improving Microbial Safety of Food Products by Thermal and Non-thermal technology and Evaluate the Knowledge of Antibiotic Resistant Issue Among Local Produce Growers" (2021). Graduate Theses, Dissertations, and Problem Reports. 10162.

https://researchrepository.wvu.edu/etd/10162

This Dissertation is protected by copyright and/or related rights. It has been brought to you by the The Research Repository @ WVU with permission from the rights-holder(s). You are free to use this Dissertation in any way that is permitted by the copyright and related rights legislation that applies to your use. For other uses you must obtain permission from the rights-holder(s) directly, unless additional rights are indicated by a Creative Commons license in the record and/ or on the work itself. This Dissertation has been accepted for inclusion in WVU Graduate Theses, Dissertations, and Problem Reports collection by an authorized administrator of The Research Repository @ WVU.

For more information, please contact researchrepository@mail.wvu.edu. 
Improving Microbial Safety of Food Products by Thermal and Nonthermal technology and Evaluate Knowledge of Antibiotic Resistant Issue among Local Produce Growers

Wentao Jiang

Davis College of Agriculture, Natural Resources and Design, wejiang@mix.wvu.edu

Follow this and additional works at: https://researchrepository.wvu.edu/etd

Part of the Microbiology Commons

Recommended Citation

This Dissertation is protected by copyright and/or related rights. It has been brought to you by the The Research Repository @ WVU with permission from the rights-holder(s). You are free to use this Dissertation in any way that is permitted by the copyright and related rights legislation that applies to your use. For other uses you must obtain permission from the rightsholder(s) directly, unless additional rights are indicated by a Creative Commons license in the record and/ or on the work itself. This Dissertation has been accepted for inclusion in WVU Graduate Theses, Dissertations, and Problem Reports collection by an authorized administrator of The Research Repository @ WVU. For more information, please contact researchrepository@mail.wvu.edu. 
Improving Microbial Safety of Food Products by Thermal and Non-thermal technology and Evaluate the Knowledge of Antibiotic Resistant Issue Among Local Produce Growers

\author{
Wentao Jiang \\ Dissertation submitted to the Davis College of Agriculture, Natural Resources and Design at West \\ Virginia University \\ in partial fulfillment of the requirements for the degree of \\ Doctor of Philosophy in \\ Animal and Nutritional Sciences \\ Canliang Shen, Ph.D.,Chair \\ Jacek Jaczynski, Ph.D. \\ Jianbo Yao, Ph.D. \\ Ida Holaskova, Ph.D. \\ Xiaoli Etienne, Ph.D. \\ Davis College of Agriculture, Natural Resources and Design
}

Morgantown, West Virginia

2021

Keywords: Food Safety, food borne illness, bacteria inactivation, antibiotic resistance

Copyright 2021 Wentao Jiang 


\begin{abstract}
Improving Microbial Safety of Food Products by Thermal and Non-thermal technology and Evaluate the Knowledge of Antibiotic Resistant Issue Among Local Produce Growers
\end{abstract}

Wentao Jiang

Microbial contamination of food products is one of the main transmission routes of disease in the world today, which is responsible for about two-thirds of all food-borne disease outbreaks although the hygiene process was improved recently. Improving microbial safety and implementing a good food management system are important elements to reduce microbial contamination and improve food safety and security. To improve microbial safety, I conducted inactivation studies on food pathogens and further explored antibiotic resistant risks. Initial research evaluated the efficacy of commercial antimicrobials distribution by comparing electrostatic sprayer with conventional sanitization process. The antibiotics applied by electrostatic spraying achieved significant additional reductions on the foodborne pathogen and more economically feasible compare to the conventional spraying method. Further exploration was carried out building inactivation model analysis on foodborne pathogens under thermal dynamic conditions. Thermal kinetics of foodborne pathogen on moisture enhanced meat were determined and a potential surrogate of Salmonella was identified. Finally, an investigation of the knowledge and attitude of antibiotic resistant issues among local food processors was conducted and results provided suggestions regarding antibiotic risks for local government agencies policy improvement. These studies combined to identify and improve microbial safety on food products by using technologies and statistical analysis. 


\section{Acknowledgment}

First and foremost, I want to express my heartiest gratitude and sincere thanks to my advisor Dr. Cangliang Shen. He took a chance on me as one of his graduate students, always guiding me with professional knowledge, and inspiring me in many ways. I don't think I could have finally made my Ph.D. journey without his support. His patient, enthusiasm, and affirmative, making me feel warm and strong when I face problems. I am thankful for the excellent example he has provided as a scientist and professor. I cannot use simple sentences to express my appreciation to Dr. Shen. I will always remember him in my heart in my future life.

I would like to thank all my committee members: Dr. Jacek Jaczynski, Dr. Jianbo Yao, Dr. Ida Holaskova, and Dr. Xiaoli Etienne, for their valuable comments, suggestions, and encouragement. Thanks to Dr. Yao who let me have a chance to study at WVU. He guided and encouraged me to learn molecular techniques which allow me to have much more possibilities in many areas. Thanks to Dr. Jaczynski who give me all advice on my lab work and guide me on how to think like an expert in the food industry. Thanks to Dr. Holaskova who help me with all modeling statistical support and encourage me to get the certificate of biostatistics. Thanks to Dr. Etienne who taught me how to build the economic analysis for my research. Also, thanks to Dr. Lilly Christa and Dr. Wen Sijin from the School of Public Health. Thanks to Dr. Lilly who help me with all my guidance of certificate of biostatistics. Thanks to Dr. Wen who let me join the real case in public health work. Thank you all!

I am especially grateful for the brilliant Shen group. My group member Kawang, Li, Lacey Lemonakis have been sources of friendships as well as good advice and collaboration. Especially Kawang, he is not only a lab mate but also a good friend. I very much appreciated his enthusiasm, intensity, and all his help. I want also to express my thanks to Mingxiang Zhang, who gave me a lot of support when the first year I came to WVU.

Last but not least, I am indebted to my wife, Yun Zhang. She gives me so much love and supports unconditionally. During the whole time of my WVU study, she always there encouraging me, trusting every decision I made. I owe her a lot and I can never pay her back. Thanks to my father Shuijian Jiang and my mother Xia Yang for all the support and love for me. 


\section{Contents}

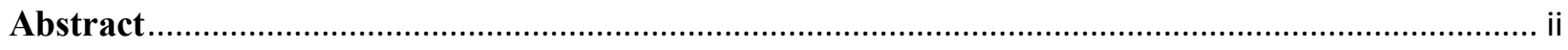

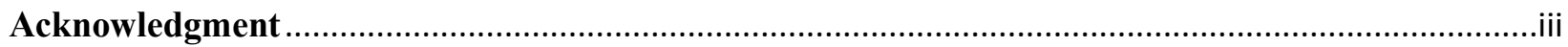

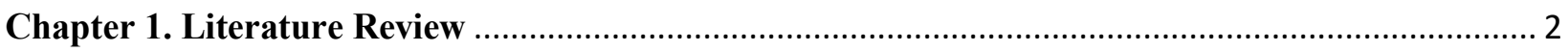

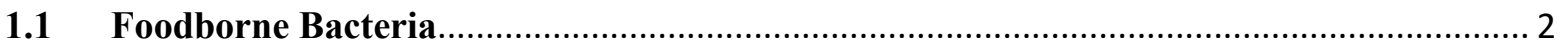

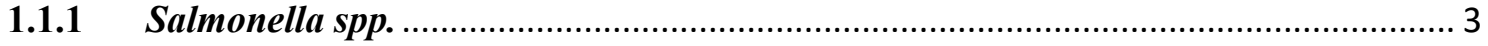

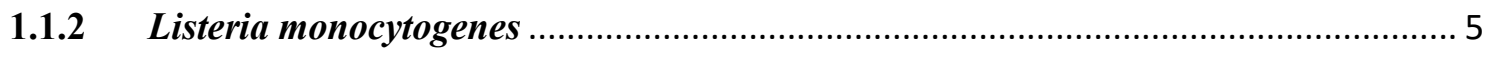

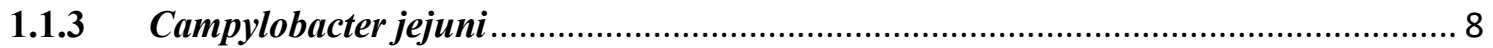

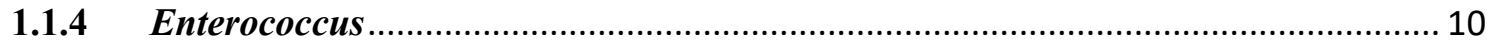

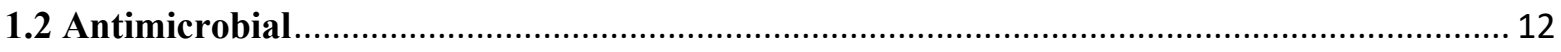

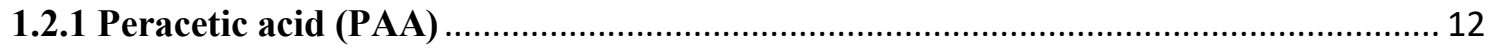

1.2.2 Lactic acid (LA) and lactic and citric acid blend (LCA) ...................................... 13

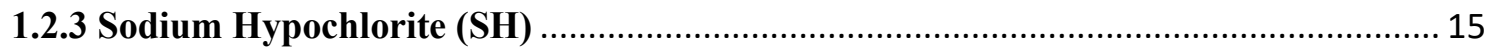

1.2.4 Antimicrobial treatments for egg and poultry industry ........................................ 17

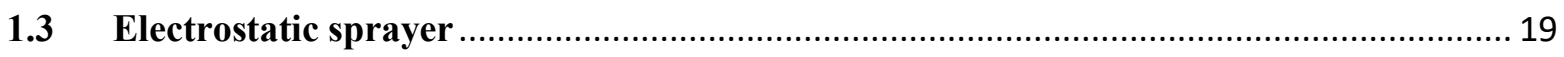

$1.4 \quad$ Thermal Inactivation of foodborne bacteria …...................................................... 22

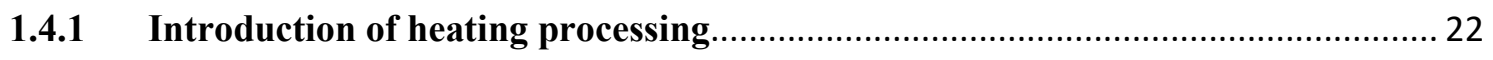

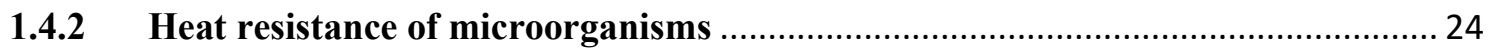

1.4.3 Mathematical thermal inactivation model …..................................................... 26

1.4.4 Thermal inactivation of bacteria in poultry meat products................................ 29

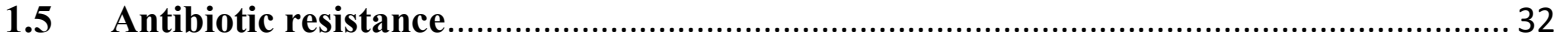

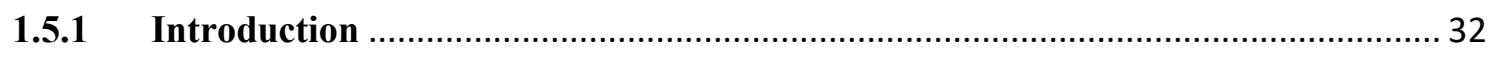

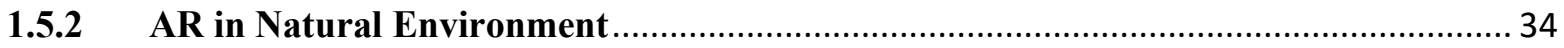

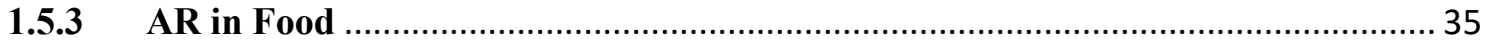

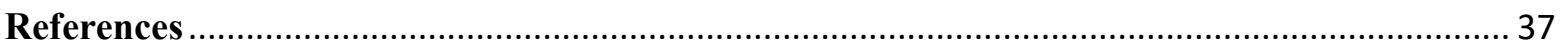

Chapter 2. Comparison of the Efficacy of Electrostatic versus Conventional Sprayer with Commercial Antimicrobials To Inactivate Salmonella, Listeria monocytogenes, and Campylobacter jejuni for Eggs and Economic Feasibility Analysis

2.1 Abstract 50 


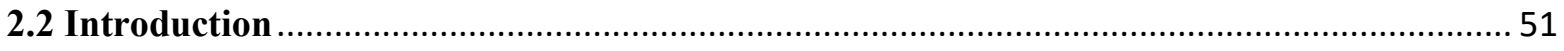

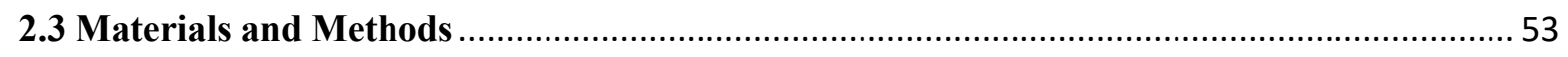

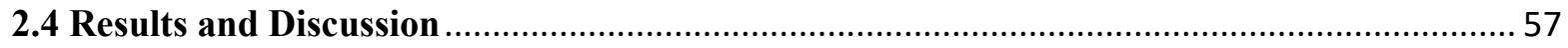

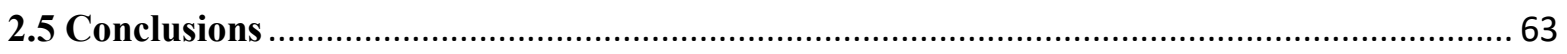

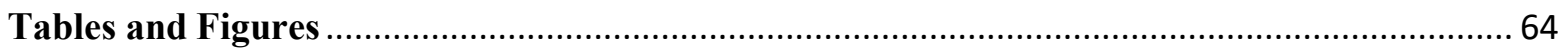

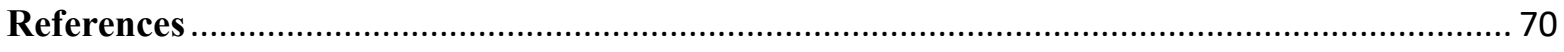

Chapter 3. Inactivation of Campylobacter jejuni in Moisture Enhanced Non-Intact Chicken Patties by Double Pan-broiling as Affected by Cooking Set-Up Temperature and Pump Rate ................... 74

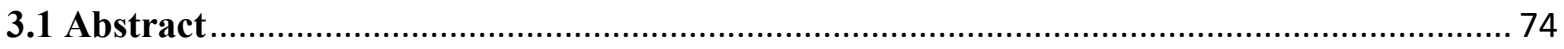

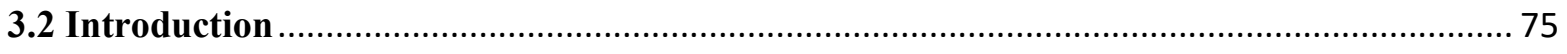

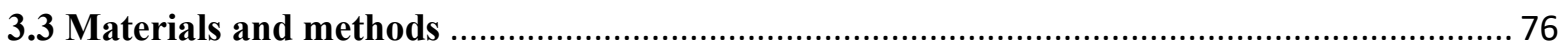

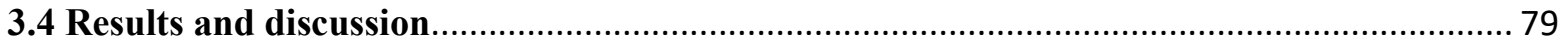

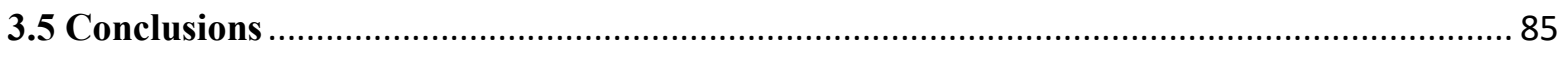

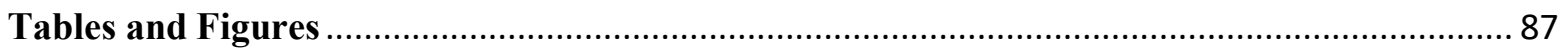

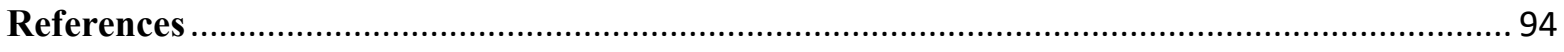

Chapter 4. Survival of Salmonella and the surrogate Enterococcus faecium in Cooking of Moisture Enhanced Reconstructed Comminuted Chicken Patties by Double Pan-broiling ........................... 97

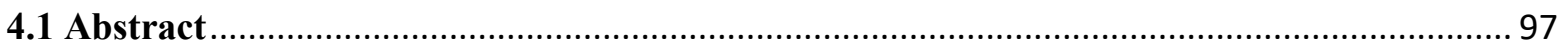

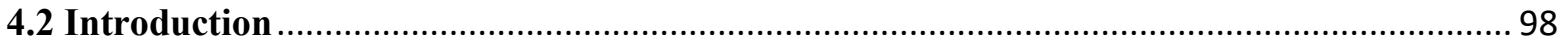

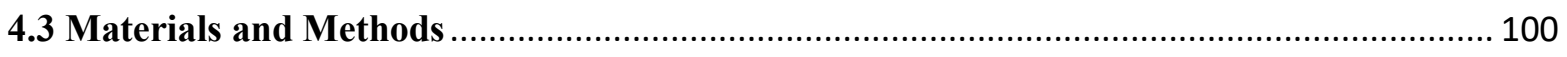

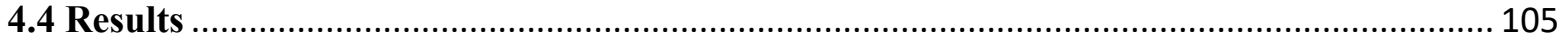

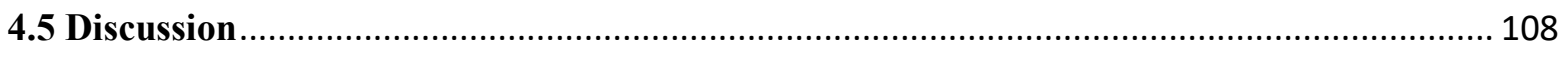

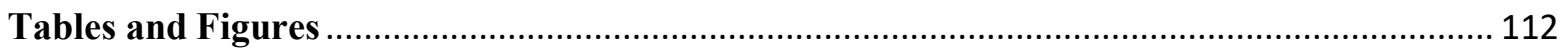

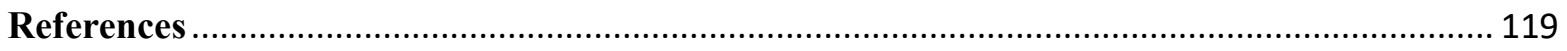

Chapter 5. Survey of Locally Small Produce Growers' Perception of Antibiotic Resistance Issues at

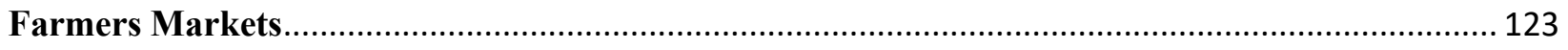

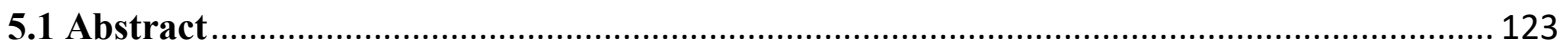

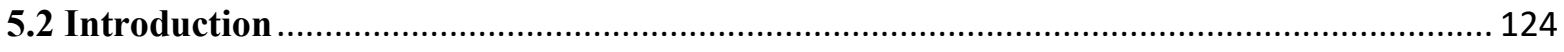

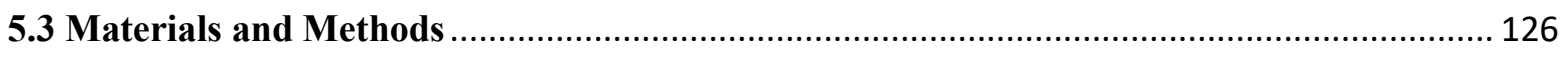

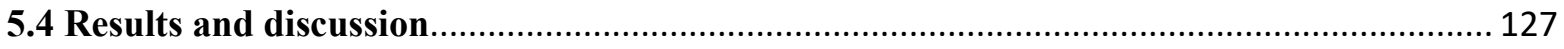


5.5 Conclusions

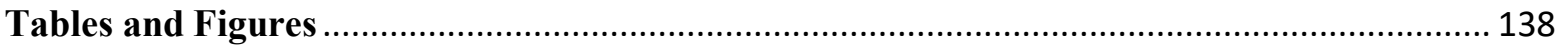

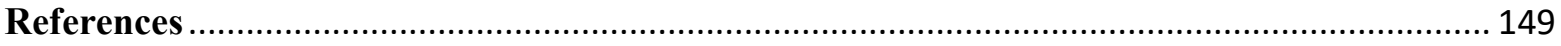




\section{Chapter 1}




\section{Chapter 1. Literature Review}

\subsection{Foodborne Bacteria}

There is close relationship between the consumption of food and human disease. Foodborne illness can be caused by consuming food contaminated with biological and chemical hazards include bacteria, parasites, viruses, chemicals, and other toxin agents. Foodborne bacteria refer to the biological agents that can lead to a foodborne illness. Foodborne bacteria generally cause foodborne illness by food-infection and food-intoxication. Food-infection is caused by ingestion of food containing live pathogen which grow and establishes itself into the human host. Foodintoxication is caused ingestion of food containing toxins formed by pathogens which resulted from the pathogen growth in food item. It takes more time from ingestion to the onset of symptoms by food-infection than food-intoxication due to the difference of the incubation period.

The occurrence of two or more cases of similar symptoms by ingestion of a common food product can be defined as a foodborne disease outbreak ${ }^{1}$. According to the U.S. Centers of Disease Control and Prevention (CDC), more than 250 foodborne diseases are identified annually with an estimation of 48 million illness, 128,000 hospitalization, and 3,000 death ${ }^{2}$. A recent surveillance of foodborne illness from CDC reported that there were 5760 outbreaks from 2009 to 2015 , resulting 100,939 illnesses, 5699 hospitalization, and 145 deaths in the U.S. ${ }^{3}$. Among the 2953 outbreaks with confirmed etiologies, norovirus was the most common causes of outbreaks (38\%), followed by Salmonella (30\%), Shiga toxin-producing Escherichia coli (STECs 6\%), Campylobacter (5\%), Clostridium perfringens (4\%), scombroid toxin (3\%), ciguatoxin (3\%), Staphylococcus aureus (1\%), Vibrio parahaemolyticus (1\%), and Listeria 
monocytogenes (1\%). Listeria, Salmonella, and STECs were the top three most common causes of hospitalizations and deaths among all outbreak related pathogens ${ }^{3}$.

Although there are raising concerns of food safety in the United States recently, the foodborne disease is still a serious public health issue. The characteristics of those most important foodborne bacteria associated with outbreaks are summarized in this review.

\subsubsection{Salmonella spp.}

Salmonella belongs to the family Enterobacteriaceae. It is widely distributed in nature with two species, S. enterica and S. bongori. More than 2600 serotypes are being divided into six subspecies in S. enterica species (S. e. enterica, S. e. salamae, S. e. arizonae, S. e. diarizonae, S. e. houtenae, and S. e. indica) ${ }^{4}$. The serovars are differentiated by Kauffman-white classification, which are defined by the lipopolysaccharide and flagellar $\mathrm{H}$ antigens of taxonomic groups. For epidemiological purpose, three groups are divided for Salmonellae: (a) The host-adapted serovars, (b) Un-adapted serovars, and (c) Serovars causing human diseases. ${ }^{5}$

Salmonella species are Gram-negative, non-endospore forming, rod shape, facultative anaerobes with peritrichous flagella indicating strong motility ability. The cell diameters of Salmonella species are between 0.7 and $1.5 \mu \mathrm{m}$ and lengths are between 2 and $5 \mu \mathrm{m} .{ }^{6}$ The main habitat of Salmonella spp. is the intestinal tract of humans and animals. They could also be found in other parts of nature such as insects, soil, and polluted water. The transition of Salmonella spp. can be

from animal to human and from human to human. Food-poisoning of Salmonella spp. is usually caused by the ingestion of food products containing great number of specific species of Salmonella. The syndromes include nausea, vomiting, abdominal pain, headache, and diarrhea. Sometimes the syndromes are accompanied with prostration, muscular weakness, moderate 
fever, and restlessness. It usually takes 12-14 hours from the time of ingestion of food to the onset of typical syndromes. Certain serovars could cause serious human diseases such as typhoid fever and paratyphoid fever ${ }^{6}$, which could lead to life threatening symptoms. The average mortality rate of Salmonella is $4.1 \%{ }^{7}$. Salmonella spp. are intracellular pathogens that can invade macrophages, dendritic, and epithelial cells. The pathogenicity islands (PAIs) of different Salmonella spp. encode virulence factors facilitating host infection. The two most pivotal PAIs are Salmonella pathogenicity island 1 (SPI-1) and 2 (SPI-2). Virulence genes involved in the intestinal process of infection are found in SPI-1, and SPI-2 or the remaining SPIs are responsible for intracellular survival, fimbrial expression, magnesium and iron uptake, multidrug antibiotic resistance, and the development of systemic infections ${ }^{8}$.

Like typical Gram-negative bacteria, Salmonella are able to grow on many culture media and produce visible colonies at $37^{\circ} \mathrm{C}$ after incubating 24 hours. The optimum $\mathrm{pH}$ is near neutral. Most of Salmonella spp. produce hydrogen sulfide, which can be detected by the media containing ferrous sulfates including Xylose-Lysine- Deoxycholate agar (XLD) and triple sugar iron slants ${ }^{6}$. The multiplex polymerase chain reaction ${ }^{9}$ and real-time polymerase chain reaction ${ }^{10}$ are the molecular techniques to detect Salmonella. Salmonella spp. cannot be killed by freezing, but they are vulnerable to high acidity or alkalinity, high salt concentration, heat, and UV light. The recommended internal temperature of non-intact meat products for protecting Salmonella infection is $75^{\circ} \mathrm{C}\left(167^{\circ} \mathrm{F}\right)^{6}$. Salmonella spp. are the leading pathogens causing foodborne illness in the USA ${ }^{11}$. U.S.-CDC estimated that Salmonella cause about 1.35 million infections, 26,500 hospitalizations, and 420 death annually in the U.S. ${ }^{12}$. More than $60 \%$ of Salmonella infection cases were undiagnosed because of sporadic infection or unreported ${ }^{6}$. Two large recorded outbreaks of Salmonellosis 
occurring with a large scale of infections were recorded in 1985 and 1994. In 1985, 2\% milk from a single dairy plant in Illinois contaminated with antibiotic-resistant Salmonella Typhimurium infected 200,000 person ${ }^{14}$. In 1994, 138,000 gallons of ice cream contaminated with Salmonella Enteritidis resulted 224,000 illness ${ }^{13}$. The largest product recall in US history is also caused by Salmonella spp. contamination. ${ }^{14}$ Contaminated peanuts and their byproducts led over 200 companies recalling their products. Recently, a multistate outbreak of Salmonella Enteritidis infections linked to peaches according to the most recent CDC outbreak report ${ }^{15}$. Developing effective control and prevention strategies of Salmonellosis is important. In the U.S., Food and Drug Administration (FDA), United States Department of Agriculture -Food Safety and Inspection Service (USDA-FSIS) are the agencies that create standards and inspections to ensure public safety. For Salmonella, USDA-FSIS has established a 5-year Salmonella Action Plan to reduce Salmonella infections ${ }^{6}$. Proper regulation of each step from farm to table is the approach to prevent Salmonellosis at industry scale. Establishing a good food safety education regarding safe preparation and handling of foods in homes and developing outreach/extension courses for food service personnel is the primary factor to reduce possible outbreaks.

\subsubsection{Listeria monocytogenes}

Listeria is a genus of the family Listeriaceae. This genus is close to the Brochothrix based on the 16S ribosomal RNA sequence data. Thus, these two genera are within Clostridium-LactobaillusBacillus branch ${ }^{16}$. There are 21 of Listeria species identified until $2020^{17}$. Listeria are Grampositive, non-spore-forming, rod-shaped facultative anaerobic bacteria, from which Listeria monocytogenes is the species that causing foodborne illness. L. monocytogenes is widely existing in environments including decaying vegetables, soils, animal feces, sewage, silage, and water, 
and can be growing in dairy products, fresh and frozen meat products, seafood, and fruits and vegetables. L. monocytogenes can survive in extreme conditions of temperatures ranged from 1 to $45^{\circ} \mathrm{C}$ and in high salt concentrations. L. monocytogenes has 13 serovars including $1 / 2 \mathrm{a}, 1 / 2 \mathrm{~b}$, 1/2c, 3a, 3b, 3c, 4a, 4ab, 4b, 4c, 4d, 4e, and 7. The three most prevalent serovars that associated with majority of foodborne infections, in decreasing orders, are $1 / 2 a, 1 / 2 b$, and $4 b^{18}$.

The nutritional requirements of L. monocytogenes include seven amino acids (leucine, isoleucine, valine, methionine, arginine, cysteine, and glutamine) and four vitamins (riboflavin, thiamine, biotin, and thioctic acid) ${ }^{19}$. It can grow very well on many common bacterial support media such as trypticase soy, brain heart infusion, and tryptose. The ideal growth $\mathrm{pH}$ is ranged 68 , and the optimum temperature is ranged $30-37^{\circ} \mathrm{C}\left(86-98.6^{\circ} \mathrm{F}\right)$. Some studies indicated that particular species/strains (L.monocytogenes LCDC 81-861 and Scott A ) rew in the pH range of 4.1-9.6 $6^{20,21}$. In general, the detection of Listeria can use selective medium/agar, 12L multiple channel biochemical test, and multiplex polymerase chain reaction or real-time polymerase chain reaction.

Consumption of foods contaminated with L. monocytogenes can cause a serious foodborne illness named listeriosis. Listeriosis can cause serious illness such as meningitis, gastroenteritis, and septicemia especially in pregnant women, newborn, the elderly, and immune compromised patients $^{22}$. Despite the annual number of listeriosis is relatively low, the mortality rate can be as high as $30 \%{ }^{23}$. The pathogenesis of Listeria is yet understood completely but recent research results bring interesting outcomes. Although Listeria is Gram-positive bacteria, it shares the same property as Gram-negative bacteria that have the lipopolysaccharide (LPS). This property permits Listeria to induces macrophage phagocytic and then bound by the polysaccharides of macrophage. For nonphagocytic cells, uptakes can be happend by binding host cellular receptors 
with internalin $\mathrm{A}$ and $\mathrm{B}^{24}$. Listeria can escape from phagolysosomal membranes into cytoplasm facilitated by listeriolysin O (LLO). The ActA protein can then push the organism toward the cytoplasmic membrane. The bacteria can transport into adjacent host cells repeatedly with the assistant of LLO and the other two bacterial phospholipases ${ }^{25}$. Moreover, the expression of virulence factors can be controlled by a transcriptional factor PrfA, which is thermoregulated and expressed at their optimal temperatures ${ }^{17}$.

World Health Organization (WHO) reported that listeriosis has an estimated worldwide incidence ranging from $0.1-1.1$ cases per 1 million population ${ }^{26}$. CDC estimated about 1,600 people suffering from listeriosis each year resulting 260 deaths ${ }^{27}$. The most recent annual surveillance from CDC reported 675 listeriosis cases in $2014^{28}$. In 2020, the latest outbreak had 11 cases in 3 states associated with deli meat products ${ }^{29}$. Many countries have established microbial sampling standards on the number of Listeria allowed in food products, especially on ready-to-eat products. In the U.S., the USDA-FSIS enforces a zero-tolerance policy $(<1$ cell/25 gram of L.monocytogenes in samples) for contamination of ready-to-eat foods with listeria, which means any of the ready-to-eat foods that contain listeria can be considered adulterated and be subject to recall from 2002 to 2006 , there were $32.4 \%$ of total recalls products issued by the USDA-FSIS were due to L. monocytogenes ${ }^{30}$. Although restricted sample plans were applied in most food industrial areas in the U.S., routine daily prevention is needed. Keeping food refrigerated below $4{ }^{\circ} \mathrm{C}\left(39^{\circ} \mathrm{F}\right)$ and avoid dangerous temperature zones of $40-140^{\circ} \mathrm{F}$, reheating overnight foods, and cooking all meats to a safe internal temperature are the examples. Since 2003, U.S.-FDA has established three alternatives to assist meat industry to well control $L$. monocytogenes, including 1) post-lethality treatment and antimicrobials; 2) post-lethality treatment or antimicrobials; 3) sanitization and microbial testing. 


\subsubsection{Campylobacter jejuni}

Campylobacter spp. are members of the Campylobacteriaceae family with 18 species, 6 subspecies and 2 biovars ${ }^{31}$. One of the primary species that causing foodborne illness is Campylobacter jejuni subsp. jejuni, referred as Campylobacter jejuni. It is closely related to the genus Arcobacter. The genome of campylobacter jejuni was the first foodborne pathogen that has been sequenced ${ }^{32}$. Campylobacter jejuni were first isolated from stool samples of a patient with diarrhea in Brussels, Belgium in $1972^{33}$.

Campylobacter jejuni is a Gram-negative, small, slender, spirally curved rods shape, microaerophilic bacteria, which could be changed into coccal form when exposing to oxygen ${ }^{34}$. C. jejuni is oxidase and catalase test positive bacteria. The growth conditions of $C$. jejuni are different from most other foodborne pathogens because they are microaerophilic, which requiring small amounts of oxygen $(3 \%-6 \%)$. The optimum growth temperature is $40^{\circ} \mathrm{C}\left(104^{\circ} \mathrm{F}\right)$, $\mathrm{pH}$ at $5.5-8.0$, and in the presence of up to $1.75 \%$ of sodium chloride. $10 \%$ of carbon dioxide is required for well growth ${ }^{32}$. C. jejuni is not an environmental bacterial but more associated with warm-blooded animals. It is commonly associated with poultry and is dominated in their feces. The prevalence of $C$. jejuni in fecal samples of poultry is ranged from around $30 \%$ to $100 \%{ }^{35}$. Campylobacteriosis is an infectious disease caused by Campylobacter. Patients exposed to this organism could develop symptoms within 2-5 days and illness could last 7 days following the onset. C. jejuni infection caused by ingestion of contaminated foods or waters, and the infective dose can be as low as 800 organisms, which causes abdominal pain, diarrhea, fever, and malaise ${ }^{36}$. Both the susceptibility of the host and the related virulence of the infecting strain are crucial for the pathogenesis of $C$. jejuni. The gastrointestinal mucus is penetrated by $C$. jejuni at the initial stage of infection. The virulence factors can be released on gastrointestinal mucus after 
adhering to the gut enterocytes. The hypoacylated LPS of $C$. jejuni induces moderate TLR4mediated inflammatory response in macrophages resulting in the failure of bacterial clearance in patients ${ }^{37}$.

It is interesting to see that the global incidence of campylobacteriosis in the past decade increased, especially in North America, Europe, and Australia, indicating that campylobacter infection is endemic in those regions ${ }^{38}$. According to the $\mathrm{CDC}$ report of campylobacter, this organism causes an estimated 1.5 million illnesses each year in the United States ${ }^{39}$. In addition, there were total 56 confirmed and 13 suspected outbreaks reported to the U.S. National Outbreak Reporting System, among which included 1,550 illnesses and 52 hospitalized cases ${ }^{40}$. The FoodBorne Diseases Active Surveillance Network pointed that Campylobacter was the leading cause of travel-associated gastroenteritis among nine foodborne pathogens between 2004 to 2009, based on the surveillance data from seven states in the United States, which is accounted for $41.7 \%$ of cases, followed by Salmonella $(36.7 \%)$ and Shigella $(13.0 \%)^{41}$. The most recent (in 2014) outbreak of C. jejuni is related to the consumption of raw milk in Utah caused a total of 99 cases of campylobacteriosis ${ }^{42}$. A study suggested that $50 \%-80 \%$ of campylobacteriosis of human cases is associated with chicken products ${ }^{43}$. The annual costs of campylobacteriosis is approximately 1.3 billion dollars in the United States ${ }^{44}$. Because of the great association between poultry industries, campylobacteriosis, and the high costs, the control of dissemination and contamination of Campylobacter in poultry industry is important for both food safety and agricultural economy. The intervention strategies include reducing environmental exposure, reducing Campylobacter frequency from colonized chickens, and increasing the immune capability of chickens in response to Campylobacter. At the consumer level, campylobacteriosis 
can be prevented by avoid eating raw, unpasteurized or undercooked foods, and cooking poultry meat products to safe internal temperatures.

\subsubsection{Enterococcus}

Enterococcus is a genus of lactic acid bacteria from Enterococcaceae family ${ }^{45}$. The organisms are Gram-positive cocci sharing many characteristics with the Streptococcus and Lactococcus. In 1984, Enterococcus was separated from Streptococcus as a unique genus based on the results of DNA-DNA and DNA-rRNA hybridization. The bacteria were transferred from "Streptococcus faecalis", "Streptococcus faecium", "Streptococcus avium" and "Streptococcus gallinarum" to “Enterococcus faecalis", “Enterococcus faecium”, "Enterococcus avium”, "Enterococcus gallinarum" consequently ${ }^{46}$. With more chemotaxonomic studies and phylogenetic evidence of 16S rDNA sequence information, 36 species of Enterococcus have been identified ${ }^{47}$. Enterococcus is Gram-positive, non-spore forming, facultative anaerobic organism. It can survive in a wider range of temperatures $\left(5-65^{\circ} \mathrm{C}\right)$ and $\mathrm{pHs}(4.5-10)$ than any other foodborne bacteria. They can also survive in a high sodium chloride concentration condition. The organism is a fastidious microorganism requiring special growth factors, including B vitamin and other amino acids ${ }^{48}$. Enterococci are ubiquitous microorganisms that can be found in different environments, including water, soil, sewage, and plants. They are also known as commensal microbiota in gastrointestinal tract of human and animal origin. Two species commonly found in the human intestines are Enterococcus faecalis $(90-95 \%)$ and Enterococcus faecium (5\%-10\%) ${ }^{45}$. Enterococcus also occurs in many different foods. In general, E. faecium, E. faecalis, E. durans, E. casseliflavus, and E. lactis are present in raw or pasteurized milk and cheese products.

Enterococci can also be isolated from raw meat, sea food, and fermented vegetables ${ }^{49-51}$. Some specific Enterococci species are used as starter of fermentation and probiotics due to their 
biological funcations. However, the organisms have opportunistic pathogenicity implicated in several nosocomial infections due to its virulence factors and developed antibiotic resistance, which leading enterococcal probiotics to be a careful assessment candidate of probiotics ${ }^{52}$. In recent years, the incidence of enterococcal infections has increased significantly. Enterococci is currently accounting for approximately 110,000 urinary tract infections, 25,000 cases of bacteremia, 40,000 wound infections, and 1,100 cases of endocarditis annually in the United States $^{53}$. Clinical infections caused by Enterococcus include endocarditis, bacteriaemia, urinary tract, central nervous system, intra-abdominal and pelvic infections. Virulence factors of Enterococcus include aggregation substances (agg, asa1), cytolysin (cyl), gelatinase (gelE), extracellular surface protein (esp), adhesion to collagen (ace, acm), and adhesion-like endocarditis antigens (efaAfs and efaAfm $)^{54}$. Virulence factors of Enterococcus causing opportunistic infections could be enhanced by the antibiotic resistance.

Specific Enterococcus species can be used as surrogate microorganisms (indicators), which may be employed to reflect the microbiological quality of foods in related to their shelf life or microbial food safety. They are generally used in the real industrial scale food processing facility to avoid introducing the pathogen. An idea surrogate microorganism should be easy and rapid detected, distinguished, nonpathogenic and have similar inactivation or growth kinetic to the target pathogen ${ }^{55}$. For example, E. faecium NRRL B-2354 is a commonly used species of Enterococcus that with a long history in food products and thermal process validation. This strain has no majority of virulence factors and is sensitive to medically relevant antibiotics. Studies indicated that E. faecium can be an appropriate indicator for Salmonella spp. in the thermal inactivation models ${ }^{56,57}$. The industry could possibility to apply E. faecium as a safer alternative surrogate microorganism in their antimicrobial or thermal challenge studies. 


\subsection{Antimicrobial}

In the food industry, many chemicals have been routinely assessed for their efficacy in inactivating pathogens and used to sanitize food contact surfaces. The sanitization process is a necessary and required step to reduce microbial populations below the requirements set by regulations. The pathogens with primary microbial safety concern are the enterohemorrhagic $E$. coli, Salmonella, and L. monocytogenes. To achieve the required level of sanitization, the chemicals must be applied at a certain concentration for a specified time period. One of the desirable objectives of food sanitizer is the capability to achieve $99.999 \%$ (a 5-log reduction) of reductions in 30 seconds for the target pathogen $^{58}$. Some pathogens required by zero tolerance policy must be destroyed or irreversibly inactivated by all specified organisms within a certain period of time. Certain chemicals could be both sanitizer and disinfectant. In general, antimicrobial treatment can be applied either by spraying, dipping solutions or as ingredients of the products. However, all treatments pose challenges. The effectiveness of sanitization or disinfection varies greatly with the type and $\mathrm{pH}$ of chemicals, contact time, and the background microflora present in the food products. Temperature of antimicrobial solutions for application is considered an important factor for the efficacy of chemicals. High water temperatures can lead to the off-gassing of antimicrobials such as chlorinated water. Moreover, a high organic load may bind and deactivate antimicrobials. Common commercial antimicrobials used in food processing plants in North America are peracetic acid (PAA), lactic acid (LA), lactic and citric acid blend (LCA), sodium hypochlorite ( $\mathrm{SH}$ ), and SaniDate (a mixture of PAA and $\mathrm{H}_{2} \mathrm{O}_{2}$ ). The details are discussed as follows.

\subsubsection{Peracetic acid (PAA)}


Peracetic acid (PAA) is an organic peroxide-based compound with the formula $\mathrm{CH}_{3} \mathrm{CO}_{3} \mathrm{H}$. It is acid colorless liquid with a strong, pungent odor, and has an oxidation potential. PAA is highly corrosive and unstable in the concentrated form. It is formed as an equilibrium mixture of acetic acid and hydrogen peroxide. For commercial application, all three chemicals are activated in an aqueous solution with supplement of stabilizers ${ }^{59}$. PAA is widely used not only in many food and beverage industries, but also in hospital, health care, and pharmaceutical facilities as an antimicrobial agent, surfactant, and sanitizer. It can be applied in the sprayer, dip tank, and chiller. In the United State, the application of PAA is followed by standards from FDA and USDA-FSIS. For fresh produce without further rinse requirement, FDA approved PAA to be used up to 80 parts per million (ppm) in wash waters ${ }^{60}$. According to the latest version of FSIS Directive 7120.1, PAA solutions are approved for use in concentrations ranging from 50 to 2,000 ppm in meat, poultry, and egg products ${ }^{61}$. PAA is relatively stable with low reactivity and formed harmless by-products in water solutions, it has been one of the most commonly used antimicrobials in food processing.

SaniDate is relatively new developed commercial antimicrobial mainly composed with PAA and $\mathrm{H}_{2} \mathrm{O}_{2}$. Since PAA can achieve an equilibrium status by formulating with different concentrations of hydrogen peroxide or acetic acid. Therefore, the ratio of PAA and $\mathrm{H}_{2} \mathrm{O}_{2}$ can be adjusted in processing waters for different purposes. Different SaniDate versions are used for various purposes $^{62}$. For example, if meat products or carcasses need to remain the skin color, the high levels of acid and lower levels of hydrogen peroxide of SaniDate formula will be used to avoid discoloration of skins.

\subsubsection{Lactic acid (LA) and lactic and citric acid blend (LCA)}


Lactic acid (LA) is an organic, hydroxy acid with the formula $\mathrm{CH}_{3} \mathrm{CH}(\mathrm{OH}) \mathrm{COOH}$. It is a colorless solution in the dissolved state and miscible with water ${ }^{63}$. Lactic acid can be produced through biochemical synthesis and from natural sources. For centuries, lactic acid, as antibacterial substances, was used in preserving many foods including vegetables, sausages, and milk products. Lactic acid fermentation converting simple carbohydrates (glucose, sucrose, or galactose) to lactic acid under anaerobic conditions to manufacture fermented food products including yogurt, pickles, and sauerkraut. Lactic acid is the regular synthetic metabolite products from the biochemical process. The conjugate base of lactic acid is called lactate. During normal metabolism and exercise, the L-lactate can be consistently produced from pyruvate via the lactate dehydrogenase. The antimicrobial mechanisms of lactic acid are creating acid and oxidative stresses for bacterial cells. For acid stress, lactic acid undissociated molecules flow through the cell membranes and ionize inside. The acidic intracellular environment causes the inactivation of enzymatic activities and deformation of proteins and DNA structure, thereby damages the extracellular membrane. The sudden severe acid stress leads to oxidative stress. The NADH oxidation is then suppressed, which affecting the electron transport system resulting the death of the microorganism ${ }^{64}$. Theoretically, lactic acid is more effective against Gram-negative bacteria than Gram-positive bacteria, especially for E. coli and Salmonella. However, studies indicated that lactic acid is a predominant antimicrobial agent not only for Gram-negative bacteria but also effective for Gram-positive bacteria ${ }^{65}, 66$. One study even provided the conclusion that antibacterial activity of lactic acid is stronger against the tested Gram-positive bacteria than the Gram-negative bacteria ${ }^{64}$. Different concentrations and contact times could lead the results to vary from each other therefore verified and validated guidance needs to be followed for application. According to the latest version of FSIS Directive 7120.1, lactic acid 
solutions are approved for use in the range of 1 to $5 \%$ as an antimicrobial agent for poultry, beef, and pork, including intact or non-intact meat ${ }^{61}$.

Citric acid is a weak organic acid that exists in a variety of fruits and vegetables that has the formula $\mathrm{C}_{6} \mathrm{H}_{8} \mathrm{O}_{7}$. In the metabolism process, it is a key metabolic intermediate and is the starting point of the tricarboxylic acid (TCA) cycle. Citric acid is widely used as an acidifier, flavoring addictive, chelating agent with annual production of more than two million tons ${ }^{67}$. In food industry, it is usually used as a flavoring and preservative agent because it is an edible acid. Also, it is an excellent chelating agent for improving the saponification of soaps and laundry detergents by chelating the metals in hard water ${ }^{68}$. The combination of lactic acid and citric acid makes the combination agent have both chelating and bactericidal abilities. Moreover, citric acid improving the acidity in blend solution. Thus, the lactic and citric acid blend (LCA) is popular as an antimicrobial agent in many plants in the United States. A study indicated that LCA be more effective than LA for inactivating E. coli $\mathrm{O} 157: \mathrm{H} 7$ and $S$. Typhimurium ${ }^{69}$.

\subsubsection{Sodium Hypochlorite (SH)}

Sodium hypochlorite ( $\mathrm{SH}$ ) is a chemical agent commercially known as bleach. The formula of $\mathrm{SH}$ is $\mathrm{NaOCl}$ or $\mathrm{NaClO}$ in liquid or salt. It is distinctive odor, pale greenish-yellow solution as liquid and can be crystallized as a pentahydrate $\mathrm{NaOCl} \cdot 5 \mathrm{H}_{2} \mathrm{O}$ for a slat formula. $\mathrm{SH}$ is a corrosive, unstable chemical and decomposes explosively by heat or friction, and its decomposition can be accelerated by $\mathrm{CO}_{2}$ at the atmospheric pressure ${ }^{70}$. Sodium hypochlorite dissolved in water forms hypochlorous acid $(\mathrm{HOCl})$ as a weak acid but strong oxidizing agent used as disinfectant or bleaching agent in hospitals, food establishments, and the water industries, referred as free available chlorine. 
SH has strong antimicrobial activity against a wide range of organisms including bacteria, fungi, and viruses. The antimicrobial mechanism of $\mathrm{SH}$ is attributed to the penetration of $\mathrm{HOCl}$ into the microbial cell due to its electrical neutrality and its modest molecular size. $\mathrm{HOCl}$ attack the microbial cells from both outside and inside of the cell, thereby accelerating the inactivation rate and enhancing its antimicrobial activity. The successful penetration consequently interfers with the cytoplasmic enzymatic function, cellular metabolism, and phospholipid degradation of microorganisms ${ }^{71}$. A concentrated sodium hypochlorite solution has high $\mathrm{pH}$ due to the presence of $\mathrm{NaOH}$. SH can act as an organic fat surfactant, in which reducing the surface tension of the solution by degrading fatty acids and transforming them to become fatty acid salts and glycerol. Thus, SH has strong sporicidal activity because the high concentration of -OH can dissolve the spore's coat that mainly composed by proteins ${ }^{72}$. The effectiveness of antimicrobial activity and excellent organic solvent makes SH used widely in endodontics as plant field irrigating solution. Diluted mixture of water and SH is a common antimicrobial used in the food industry as well as a sanitizer for the food processing environment. It can be used to treat pasteurizer cooling water, washing fruits and vegetables, and sanitizing food contact surfaces. Federal regulations indicated that the use of sanitizing solutions containing sodium hypochlorite on food processing equipment and food contact articles with two provisions: (a) Solution used on food processing facilities must be allowed to drain completely before being contacting with food products; (b) Solutions used for sanitizing equipment shall not exceed $200 \mathrm{ppm}$ of free available chlorine. For the application of chlorine bleach on raw fruits and vegetables, the concentration of sanitizer must not exceed $2000 \mathrm{ppm}$ and the produce must be rinsed with potable water following the chlorine treatment ${ }^{73}$. For meat product, early study provided a significant microbial reduction of SH on beef plate meat ${ }^{74}$.While relative low sanitizer efficacy of SH against $E$. coli $\mathrm{O} 157: \mathrm{H} 7$ biofilm on 
beef surface was found and indicated that SH may not an effective agent for biofilm inactivation on meat product ${ }^{75}$.

\subsubsection{Antimicrobial treatments for egg and poultry industry}

The U.S. poultry industry is the world's largest producer and second largest exporter of poultry meat and a major egg supplier. Consumption of poultry meat and egg products occupys a large food market worldwide ${ }^{76}$. Maintaining microbial food safety in the processing of poultry products is critical in the U.S. poultry industry.

In the industrial scale of egg processing, the eggshell and content contamination by foodborne pathogens can occur in the reproductive tract during the egg formation process ${ }^{77}$. Bacteria could further contaminate the content of the egg by penetrating into the interior of the shell through the shell pores or damaged areas ${ }^{78}$. The warm and humidity environment of egg ranch is an ideal environment for bacteria growth and transmission. The United States Environmental Protection Agency (EPA) has published guidance for use of food-grade shell-egg sanitizers due to the potential risk of contamination of egg contents by foodborne pathogens ${ }^{79}$. Many chemical agents have been developed for sanitizing eggs. To disinfect bacteria, using antimicrobials to wash eggs had been studied as early as 1961. Chemical compounds including calcium hypochlorite, sodium hypochlorite, formaldehyde, potassium permanganate, pyridine, sodium phosphate tribasic, sodium ophenylphenate, and zinc sulphate with different concentrations are tested and indicating a bactericidal effect ${ }^{80}$. Another study in 1965 also indicated that using different types of chemical agents to wash eggshells can remove over $80 \%$ of contaminants ${ }^{81}$. However, several studies listed some of the available compounds fail to disinfection of eggs and further facilitated bacteria penetrating into egg content ${ }^{82,83}$. Moreover, a research tested three commercial sanitizers (sodium carbonate, sodium hypochlorite, and potassium hydroxide) found that none of the 
chemicals applied at the recommended concentrations from the manufacturer could completely eliminate Salmonella Enteritidis $\left(10^{4}-10^{6} \mathrm{CFU} / \mathrm{ml}\right)$ from eggshells ${ }^{84}$. The failure of antimicrobials is probably mediated by the removal of the cuticle layer of the egg. The cuticle layer of the egg can act as a cover to impede bacterial penetration by closing the pores within the shell. Some antimicrobial could cause the side-effect by damaging the cuticle layer of the eggshell. A study suggested that $0.5 \%$ trisodium phosphate and $50 \mathrm{ppm}$ cetylpyridinium chloride could damage the cuticle layer and cause microbial penetration ${ }^{85}$. The scanning electron microscopy was used to determine if the antimicrobial can damage the cuticle layer in one study, which found that alkaline sodium carbonate altered the eggshell surface and resulting bacterial recontamination $^{86}$. An ideal egg-washing solution should inactivate microorganisms without damaging the cuticle of eggshells.

Poultry products have been identified as significant reservoirs of Salmonella and Campylobacter from the environment ${ }^{87}$. The USDA-FSIS has proposed that the frequency of Salmonella on poultry carcasses should be below $10.4 \%$. During the industry scale of poultry processing, live birds are slaughtered, de-feathered, eviscerated, cleaned, and finally chilled. Both large industrial scale of broiler houses and small local chicken coops face the challenges of risks of crosscontamination at many stages in the process ${ }^{88}$. Chlorine has been used as an antimicrobial in the chilling tank and allowed up to $50 \mathrm{ppm}$ according to USDA-FSIS guidlines ${ }^{89}$. However, the exists of organic compounds and high $\mathrm{pH}$ levels can reduce the efficacy of chlorine ${ }^{90}$. In addition, a study verified that suggested concentrations of chlorine cannot disinfect Salmonella on broiler skins ${ }^{91}$. Many more antimicrobials were studied for their application on poultry products, including organic acids, hydrogen peroxide, trisodium phosphate, chlorine dioxide, acidified sodium chlorite, and cetylpyridium chloride ${ }^{92-95}$. Among them, chlorine dioxide is 
usually used as an antimicrobial gas for poultry chiller. Comparing to the application in chilling tanks, some antimicrobial agents are more effective when used as rinses, dips, or in a sprayer. Acidified sodium chlorite is one of the examples used by spray application on chicken carcasses. Moreover, the contact time, water temperature, and concentration of antimicrobial are different for each processing step. Thus, the choice of antimicrobial for poultry products is not only determined by high disinfected efficacy but also requires cost-effectiveness. Some organic acid applications on poultry products may be leading to negative flavor and color changes ${ }^{96}$. To avoid the negative change of poultry product's quality, peracetic acid is the chemical synthesized compound that has low levels of organic acids but maintains the efficient antimicrobial activity $^{97}$. For poultry chiller application, PAA can also be an effective antimicrobial that decreasing the incidence of Salmonella and Campylobacter, in addition to extend the shelf-life of poultry products ${ }^{98}$.

\subsection{Electrostatic sprayer}

Electrostatics-based technology has emerged in the latter half of the $20^{\text {th }}$ century and be applied across industrial, commercial, and business sectors. It has quickly lead developments in powder \& liquid coating, xerographic copying, ink jetting, and agricultural pollination. The development of electrostatics-based technology has been generating many benefits in widespread area. In general, it is coulombic attracted by negatively charged particles onto a positively charged objectives. The atomization of the liquid penetrant is ideal for achieving extremely thin and uniform penetrant coverage, even on complex and unsmooth geometry surfaces due to the same charged polarity resulting from the homogeneous alignment of the electrostatic field lines and the penetrant particles. Specifically, the technique is using electrostatic forces for controlling 
particulate dynamics. The Lorentz equation quantifies the force $\mathrm{F}(\mathrm{N})$ by charge $\mathrm{q}(\mathrm{C})$ and velocity $\mathrm{v}(\mathrm{m} / \mathrm{s})$ under the electric field $\mathrm{E}(\mathrm{V} / \mathrm{m})$ and the magnetic field $\mathrm{B}\left(\mathrm{Wb} / \mathrm{m}^{2}\right)$ creating the formula is: $\mathrm{F}(\mathrm{N})=\mathrm{qE}+\mathrm{qvB}^{99}$. Because the particles are relatively small, the charge-to-mass ratios are adequate to provide electrostatic forces, thereby charged particles are feasible for many agricultural and biological usage. ${ }^{100}$ The nozzle structure and work process of the electrostatic sprayer are showed in Figure 1.

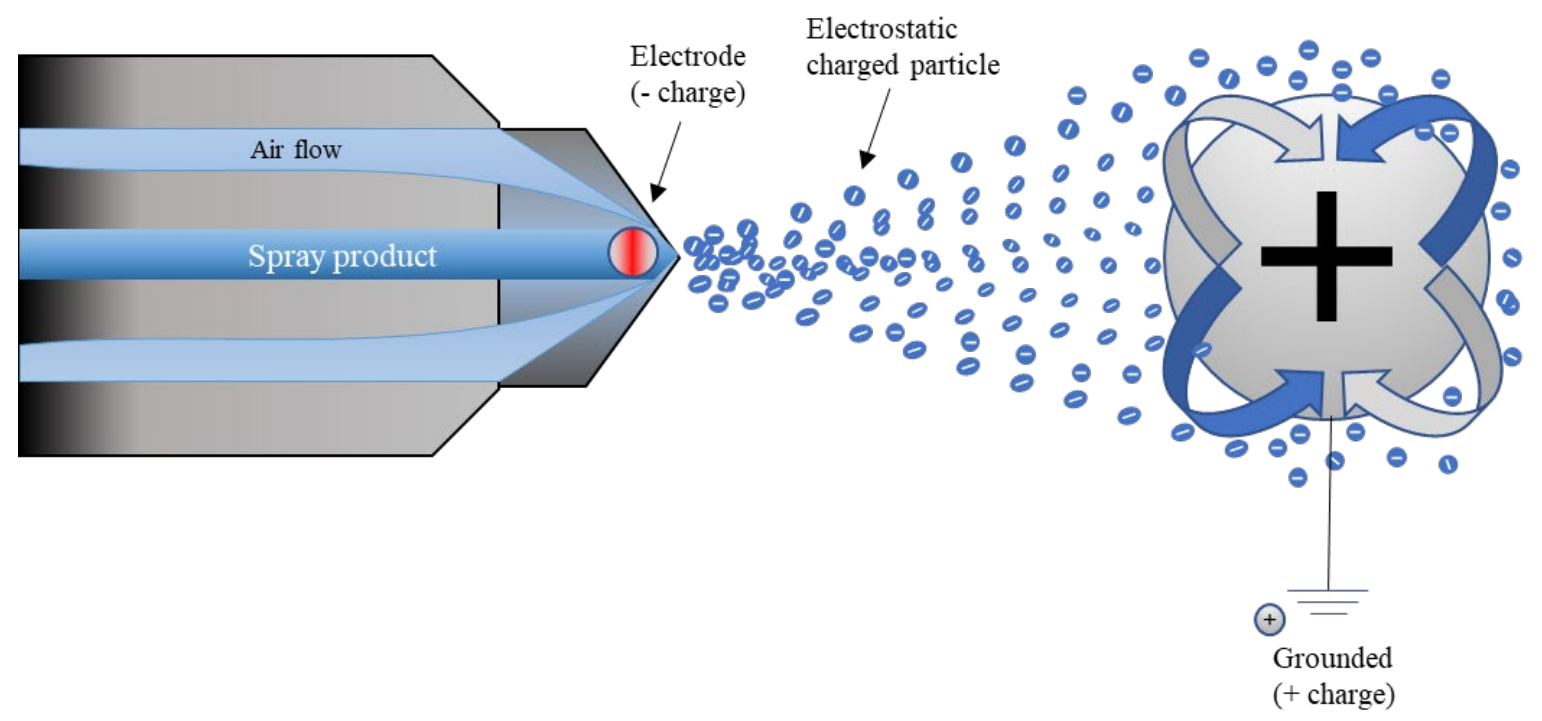

Figure 1. Configuration of the electrostatic spraying nozzle and the ionic workflow.

Law $^{101}$ developed the original electrostatic spray-charging system using air atomization which achieved a 7 folds increase in spray deposition compared to the conventional sprayer. The very first application of electrostatic technology is electrostatic spraying of pesticides to protect field crops, orchards, vineyards. Chemical and biological pest control always face a challenge because of the inefficiency of depositing pesticides onto the target. Pests, fungal, and spoilage microorganisms can be hiding underneath the leaves and cause off-target losses. The electrostatic spraying with pesticide improves not only the droplet-deposition efficiency but also the spatial distribution of deposited droplets throughout the surface of the target. A 1.4-2.4 fold cumulative 
deposition on living plant leaves was reported after using electrostatic sprayer ${ }^{102}$. A study further verified that electrostatic sprayer can improve pesticide efficacy in greenhouses by 3.7 times more of foliar deposition than a conventional sprayer ${ }^{103}$. Electrostatic pollination becomes another application of electrostatic technology. Natural pollen transportation depends on the insect population, contact time between insect and flowers, and weather conditions. The application of electrostatic pollen spray was studied by the same group that using electrostatic sprayer as pesticides, which indicated electrostatic spray increased 5.6 folds target orientations compare to that of the conventional sprayer ${ }^{104}$. Electrostatic spraying also enhanced surfacecoating covering areas in many postharvest processes, as well as surface-coating of food additives including flavorings, sweeteners, and vitamin compound. Snacks such as potato chips are coated by electrostatic sprayer resulting uniform morphology, evenly seasoning, and great transfer efficiency. Moreover, it can reduce the dusts during the process and further decrease the potential risks of cross-contamination by pathogens ${ }^{105}$. Electrostatic spraying of wax and waterloss barriers onto fruits and vegetables provided an additional 2.1-3.4 folds deposition, which well controls the spoilage microorganisms ${ }^{106}$. The application of antimicrobial in an electrostatic sprayer has been studied in recent years. Two different types of electrostatic sprayers with acidified electrolyzed water was effective to reduce Salmonella, Staphylococcus, and L. monocytogenes cell populations on eggs ${ }^{107}$. A study used an electrostatic sprayer with malic and lactic acid resulting 3.6 or greater $\log$ reductions of E. coli O157:H7 and Salmonella Typhimurium on spinaches ${ }^{108}$. It is clearly showed that electrostatic spraying technology is a highly economical penetrant application based on the aforementioned studies. The economic feasibility of electrostatic spraying needs to be evaluated because the cost of an electrostatic sprayer is much higher than a conventional garden sprayer. A cost-benefit analysis can provide 
direct and early identification of major economic factors affecting the adoption of electrostatic sprayers. More studies are needed to evaluate the efficacy of antimicrobials when applied electrostatic spraying for inactivating foodborne pathogens on food products.

\subsection{Thermal Inactivation of foodborne bacteria}

\subsubsection{Introduction of heating processing}

The use of cooking process to preserve food has a long history because of the destructive effect on microorganisms by the high temerature., which defined by the temperature above ambient. The preservation of wine by the heating process has been known in China back to early in AD $1117^{109}$. In the $18^{\text {th }}$ century, Italian scientist Lazzaro Spallanzani found thermal processing can extend meat broth shelf life and free from microorganisms ${ }^{109}$. French chemist Louis Pasteur then invented pasteurization to preventing wine and beer from souring and this approach was applied in milk industries starting from the late $19^{\text {th }}$ century ${ }^{110}$. Currently, food preservation by thermal processing can be categorized by pasteurization and sterilization.

Pasteurization is a thermal process by use of mild heat to destruct of all disease-producing organisms or reduce spoilage organisms in a certain food product. Milk pasteurization is achieved by one of following treatments: $63^{\circ} \mathrm{C}\left(145^{\circ} \mathrm{F}\right)$ for 30 minutes, $72^{\circ} \mathrm{C}\left(161^{\circ} \mathrm{F}\right)$ for 15 seconds, $89^{\circ} \mathrm{C}\left(191^{\circ} \mathrm{F}\right)$ for 1 second, $90^{\circ} \mathrm{C}\left(194^{\circ} \mathrm{F}\right)$ for 0.5 seconds, $94^{\circ} \mathrm{C}\left(201^{\circ} \mathrm{F}\right)$ for 0.1 seconds, $100^{\circ} \mathrm{C}\left(212^{\circ} \mathrm{F}\right)$ for 0.01 second. Beer pasteurization is usually using $60^{\circ} \mathrm{C}\left(140^{\circ} \mathrm{F}\right)$ for 8-15 minutes $^{111}$, which are equivalent and are sufficient to eliminate all yeast, mold, Gramnegative bacterial, and most Gram-positive bacteria. The shelf life of -pasteurized products are longer than raw products. A study of thermal inactivation of common bacteria in milk indicated that the bacteria strains (Staphylococcus aureus, Yersinia enterocolitica, Escherichia coli, 
Cronobacter sakazakii, Listeria monocytogenes, Salmonella Typhimurium) in milk can achieve an average of $6.8 \log$ reduction by pasteurization ${ }^{112}$. Novel pasteurization can heat droplets in a heated chamber with low temperature but short time, which significantly extended the shelf life without decreasing the values of nutrients and flavor ${ }^{113}$.

Sterilization refers to any process that eliminates all viable organisms including mold, yeast, and bacteria ${ }^{114}$. Heat treatment is one of the most common sterilization approaches to cease the activity of microorganisms by stop activities of related enzymes and improve the quality and maintains shelf-life time of non-perishable foods. UHT (Ultra-High Temperature) sterilization is one specific type of heat treatment are be used with the temperature over $100^{\circ}$. Moist and dry heat sterilizations are the two major categories of UHT sterilization. Dry heat is a gradual process taking for a long period of time. Microorganisms are disinfected by longtime exposure to a lethal temperature. Forced ventilation of hot air can increase the efficacy of disinfection due to the high rate of heat transferring into the treated subjects. The working temperature of dry heat sterilization ranges from 160 to $180^{\circ} \mathrm{C}$ and it is particularly used for disinfection of heat-stable materials such as devices used for surgery. Dry heat treatment for food products needs shorter exposure times at high temperatures in order to reduce heat-induced damage to the products ${ }^{114}$. Moist heat sterilization is more often used in thermal processing and a faster process than dry heat sterilization. It is achieved by denaturing the macromolecules, membrane, and primarily proteins of microorganisms. An autoclave is a typical moist heat sterilization that is wildly used, also known as a steam sterilizer. The sterility of the autoclave can be achieved by using steam heated to $121-134{ }^{\circ} \mathrm{C}\left(250-273{ }^{\circ} \mathrm{F}\right)$ under high pressure (> 15 PSI) and removed air chamber environment. The sterilization time and temperature are vary depending on the bioburden of a sterilized objective. A general cycle is $121^{\circ} \mathrm{C}\left(250^{\circ} \mathrm{F}\right)$ at $100 \mathrm{kPa}(15 \mathrm{psi})$ for $3-15$ minutes, 
which ensuring $6 \log$ reduction of most common microorganisms ${ }^{114}$. Canned foods are "commercially sterile", which means no viable organisms can be detected by common cultural methods. However, microorganisms could present in canned food products due to the heat resistance.

\subsubsection{Heat resistance of microorganisms}

Heat resistance of microbial cells is related to environmental conditions and characteristics of microorganisms.

Environmental factors affecting the heat resistance of microorganisms can be contributed to many parameters and described as follows. The presence of water is one parameter that affecting the heat resistance of microbial cells and with the decrease of humidity, moisture, or water activity $\left(\mathrm{a}_{\mathrm{w}}\right)$, the heat resistance increase. Water can facilitate heat denaturation of protein due to the formation of free -SH groups therefore increase the water-holding capacity of proteins and allowing thermal factors to break the peptide bonds ${ }^{115} \cdot \mathrm{pH}$ is another factor for heat resistance of microorganisms. Microorganisms are more resistant to heat when the $\mathrm{pH}$ at optimum growth condition than under an acid environment. The advantage taken of this fact is pasteurization, where beer and juice pasteurization temperature is relatively lower than milk pasteurization at the same time range ${ }^{109}$. Some salts have a protective effect on the microorganism, whereas other salts increase heat sensitivity. It has been shown that particular $\mathrm{Ca}^{2+}$ based salts can enhance heat resistance ${ }^{116}$. The presence of sugars can increase heat resistance. A study indicated that sugars increased the heat resistance of Salmonella with effect ordering decrease as sucrose $>$ glucose $>$ sorbitol $>$ fructose $>$ glycerol $^{117}$. Growth temperature affects heat resistance or sensitivity of microorganisms. It is believed that microorganisms become more heat resistant after grew at high temperature under genetic selection pressure. Many microorganisms gathering forming 
biofilms also increases heat resistance due to the production of protective substances excreted by cells. Strong biofilm formation combined with diverse resistances induced by heat resistance may allow for increased persistence, co-selection, and possible transfer of these resistance factors ${ }^{118}$. The growth stages of microorganisms determined the heat resistance. Microorganisms tend to be most resistance to heat in the stationary phase and less resistant in exponential phase. At the lag phase, heat resistance of microorganisms is also greater than exponential phase. Salmonella Senftenberg showed several times more resistant to heat in stationary phase than exponential phase ${ }^{119}$. Obviously, stationary phase has stressful environmental conditions with accumulation of mechanism waste. Yet the mechanism is complex and not well understood. The characteristics of microorganisms is another important factor that affecting heat resistance. In general, thermophile is more resistant than mesophile, followed by psychrophile; bacteria are more resistant than yeast and mold; Gram-positive organisms are more resistant than Gramnegative organisms; spore-forming organisms are more resistant than non-spore-former ones. A thermophilic organism can grow at a minimum of $45^{\circ} \mathrm{C}$ and a maximum of $70^{\circ} \mathrm{C}$ or above. The high heat resistance can be caused by the flagella, enzymes, and ribosomes of the thermophile. The flagella of the thermophile have more effective hydrogen bonding occurs may serve as a reason why it is more heat resistant than mesophile. As for enzymes, a more hydrophobic amino acid presence in thermophile and metal ions binding could contribute to the heat resistance. The high G-C content of rRNA makes a more stable structure leads heat resistance ribosome of a thermophile. Moreover, the increase in fat content can also cause heat resistance ${ }^{120}$. Spores of various Bacillus and Clostridium species are among the most resistant organisms. Bacterial endospores are extremely heat resistant and become a great concern in the thermal preservation of foods. The major factors of spore thermal resistance are protoplast dehydration and 
diminution. The water content of the protoplast can be lowered by thermal adaption resulting in a more resistant spore. Also, the shift of mineral content of spore increase heat resistance ${ }^{121}$. Other factors are known to generate additive effect, including thick proteinaceous coat, impermeable inner spore membrane, and the high level of dipicolinic acid in the spore core that protect core macromolecules from the heat ${ }^{122}$. An overlooked issue need to be concerned is relatively mild sub-lethal temperatures may activate spores to germinate rather than destroy them when studying heat resistance ${ }^{123}$.

\subsubsection{Mathematical thermal inactivation model}

Because thermal inactivation process widely used in food industries, the analysis of thermal inactivation kinetics of microorganisms is critical for food safety. The first-order kinetics of thermal inactivation of microorganisms can be described by either time or temperature, which generally includes thermal death time (TDT), decimal reduction time (D value), z value, F value. TDT is the time necessary to inactive a given number of organisms at a fixed temperature. The D value is the time to reduce $90 \%$ of microbial cells at a specific in a specific food product, which is referred to as 1 logarithm reduction of the microbial population. The $\mathrm{z}$ value is the number of degrees the temperature required to change to achieve a decrease of the $\mathrm{D}$ value by a factor of 10 , which is the mathematically equals the reciprocal of the slope of the TDT curve. D value shows the thermal sensitivity of a microorganism to a specific temperature, whereas the $\mathrm{z}$ value provides information on the relative resistance of microorganisms under various temperatures. The $\mathrm{D}$ and $\mathrm{z}$-value can be calculated from the two general linear models:

$\log \left(\mathrm{N}_{\mathrm{t}}\right)=\log \left(\mathrm{N}_{0}\right)-\mathrm{t} / \mathrm{D}$

or

$\mathrm{D}=\mathrm{t} /\left(\log \left(\mathrm{N}_{0}\right)-\log \left(\mathrm{N}_{\mathrm{t}}\right)\right)$ 
in which: $\mathrm{N}_{0}=$ the initial number of microorganisms, $\mathrm{N}_{\mathrm{t}}=$ the number of microorganisms at time $\mathrm{t}, \mathrm{D}=$ the decimal reduction time, $-(1 / \mathrm{D})=$ the slope $(\mathrm{k})$ of the curve.

To determine the $\mathrm{z}$ value, $\mathrm{D}$ values are plotted on a log scale for the references. The relationship between $\mathrm{z}$ and $\mathrm{D}$ value can be described as

$\log \left(\mathrm{D}_{1} / \mathrm{D}_{2}\right)=-1 / \mathrm{z}\left(\mathrm{T}_{1}-\mathrm{T}_{2}\right)$

or

$\mathrm{z}=\left(\mathrm{T}_{2}-\mathrm{T}_{1}\right) /\left(\log \mathrm{D}_{1}-\log \mathrm{D}_{2}\right)$

in which $\mathrm{D}_{1}$ and $\mathrm{D}_{2}$ refer two different decimal reduction times correspond to two different referenced temperatures, which are $T_{1}$ and $T_{2} .-1 / z$ is the slope $(k)$ of the curve. The temperature of the above equations can be expressed as ${ }^{\circ} \mathrm{C}$ or ${ }^{\circ} \mathrm{F}$ and the inactivation time usually can be expressed in seconds, minutes, and hours ${ }^{124}$. For low acid foods, especially canned foods, disinfection of spores or vegetative cells is the most important issue. F value is used to describe the equivalent time at $121.1^{\circ} \mathrm{C}\left(250^{\circ} \mathrm{F}\right)$ to destroy spores or vegetative cells for a targeted organism. 12-D concepts are introduced in canned food processing, which refers to the minimum heat process requiring for reducing the probability of survival of the most resistant Clostridium botulinum spore by $10^{12}$. Most of the commercial 12 -D tests are use $121.1^{\circ} \mathrm{C}\left(250^{\circ} \mathrm{F}\right)$ as the standard temperature. Thus, the F value can be calculated by the equation from the general survival curve with the assumption of eliminating all spore cells.

Simple models are preferred choices for the evaluation of thermal activity for inactivating bacterial cells. The simple linear model has been successfully applied in the food industry for decades. However, the assumption of the traditional thermal inactivation model is based on isothermal conditions without consideration of the geometric shape of the treated products. The real thermal inactivation processes face hurdles in many different situations and deviations from 
the simple linear model have been observed in many researches ${ }^{125,126}$, in which more predictive and deterministic models are needed. Many of the non-linear models can serve as thermal inactivation models with relatively low deviation.

Weibull model has been introduced to replace linear thermal inactivation kinetics based on the concept of Weibull frequency distribution. The equation of the Weibull model for thermal inactivation can be expressed as:

$\log \left(\mathrm{N}_{\mathrm{t}}\right)=\log \left(\mathrm{N}_{0}\right)-\mathrm{Kt}^{\alpha}$

in which $\mathrm{N}_{0}=$ the initial number of microorganisms, $\mathrm{Nt}=$ the number of microorganisms at time $\mathrm{t}, \mathrm{t}=$ heating time, $\mathrm{K}=$ the coefficient affects the rate of bacterial inactivation, $\alpha=$ shape parameter under isothermal condition. The curve formation is determined by shape parameter $\alpha$. When $\alpha>1$, the curve expressed by the equation bends downward, which representing the shoulder effect of bacteria kill. When $\alpha<1$, the curve expressed by the equation bends upward, which representing the tail effect. When $\alpha=1$, the equation is reduced to linear kinetic ${ }^{127}$. Therefore, the Weibull model is more accurate to describe thermal dynamics than the non-linear survival curve.

The modified Gompertz model has been used to describe isothermal microbial growth ${ }^{128}$ and be developed to describe isothermal inactivation kinetics ${ }^{129}$ as well. The equation of the modified Gompertz model for thermal inactivation can be expressed as:

$\left.\log \left(\mathrm{N}_{\mathrm{t}}\right)=\log \left(\mathrm{N}_{0}\right)[1-\exp [-\exp (-\mu(\mathrm{t}-\mathrm{M}))]\}\right]$

in which $\mathrm{N}_{0}=$ the initial number of microorganisms, $\mathrm{Nt}=$ the number of microorganisms at time $\mathrm{t}, \mathrm{t}=$ heating time, $\mu=$ the relative inactivation rate, $\mathrm{M}=$ time constant. The shoulder effect can be determined by the interception of the extrapolated tangent line with the time axis or with an initial value, whereas the tail effect, can be estimated by the asymptote of the function study ${ }^{130}$. 
The critical site's model has been used for microorganisms contain critical sites. A critical site can be a crucial enzyme, ribosomes, or damage of the membrane. The cell of the microorganisms can only survive with the presence of a minimum of intact critical sites. This model is analogous to the log-linear model and can be expressed as:

$\mathrm{N}_{\text {crit }} / \mathrm{Ncrit}_{0}=\exp \left(-\mathrm{K}_{\text {crit }}\right)$

in which $\mathrm{N}_{\text {crit }}=$ the number of critical sites per cell after any heating time, $\mathrm{N}_{\text {crito }}=$ number of critical sites per cell at time $0, \mathrm{~K}_{\text {crit }}=$ the inactivation rate constant of a critical site. $\mathrm{N}_{\text {crit }} / \mathrm{Ncrit}_{0}$ can be explanted as the probability of survival of a critical site. The probability of the whole cell survive under critical factor of $\mathrm{P}$ can be expressed as a binomial relation:

$\left.\left.\mathrm{P}=\operatorname{Bin}\left[\left(1-\mathrm{N}_{\text {crit }} / \mathrm{Ncrit}\right)\right) ;(\mathrm{n}-\mathrm{m}) ; \mathrm{m}\right)\right]$

in which $\mathrm{n}$ is the total number of critical sites, $\mathrm{m}$ is the maximum number of critical sites can be inactivated without cell death. The application of this model can be developed by enough data on in situ thermostability of cellular contents becomes available. Further studies are underway to establish whether the model of the critical site can be derived from a mechanistic base. Although the models of thermal inactivation have been established long time ago, A suitable model should always be evaluated when facing different food products with various heating conditions.

\subsubsection{Thermal inactivation of bacteria in poultry meat products}

The common pathogens of poultry products are Salmonella spp., Campylobacter jejuni, and Listeria monocytogenes. In 2002, a company recalled around 27.4 million pounds of ready-to-eat turkey and chicken products and led to 7 death due to contamination with foodborne pathogens ${ }^{131}$. Salmonella spp. is the leading pathogenic concern by the poultry industry. 
According to a CDC report in $2020^{132}, 17$ multistate outbreaks of Salmonella illnesses linked to contact with poultry in backyard flocks.

Thermal treatments are critical in control of foodborne pathogens in ready-to-eat (RTE) meat and poultry products ${ }^{133}$. Currently, the United States Department of Agriculture Food Safety and Inspection Service (USDA-FSIS) requires a $\geq 7-\log$ reduction in cooked poultry products ${ }^{134}$. An appendix titled as "Compliance Guidelines for Meeting Lethality Performance Standards for Certain Meat and Poultry Products" is applied in meat and poultry industries to establish thermal treatment for achieving required pathogen reduction levels ${ }^{135}$. However, the appendix is only based on a research ${ }^{136}$ tested Salmonella in beef products and cannot represent the wide range of thermal processing procedures currently applied by meat and poultry processors especially small and very small local processors. The thermal tolerance of different pathogens at a given temperature can be varied widely and determined by many factors including water activity, $\mathrm{pH}$, fat content, and meat composition of ingredients. Due to the limited research supporting the appendix, it is crucial to conduct more researches to provide appropriate guidance of thermal treatment to meat and poultry products. Researches about thermal inactivation of bacteria in poultry can be developed either on nutrient media or on meat products ${ }^{137,138}$. A meta-analysis referred that the thermal kinetics of thermal inactivation on the raw chicken has a significant difference to laboratory media ${ }^{139}$. Thus, specific poultry parts from different environments are necessary for comprehensively understanding their thermal kinetic.

The thermal inactivation of bacteria in various chicken breasts have been studied. Murphy ${ }^{138}$ evaluated thermal inactivation of six Salmonella spp. and Listeria innocua in the ground chicken breast in water bath heating at $67.5^{\circ} \mathrm{C}$ and $70^{\circ} \mathrm{C}$ and found the thermal kinetics highly depends on the sample sizes and shapes. Murphy ${ }^{140}$ further standardized ground chicken breast size and 
temperature of thermal inactivation from $55^{\circ} \mathrm{C}-70^{\circ} \mathrm{C}$. The average $\mathrm{D}$ values and $\mathrm{z}$ value for Salmonella (D values:9.68 to $0.076 \mathrm{~min}$ at $55^{\circ} \mathrm{C}$ to $70^{\circ} \mathrm{C} / \mathrm{z}$ value: $6.25^{\circ} \mathrm{C}$ ) and Listeria (D values: 12.32 to $0.045 \mathrm{~min}$ at $55^{\circ} \mathrm{C}$ to $70^{\circ} / \mathrm{z}$ value: $6.29^{\circ} \mathrm{C}$ ) were calculated. Similar study ${ }^{141}$ used fully cooked chicken breasts provided closing average D value and z value for Salmonella (D values: 24.07 to $0.097 \mathrm{~min}$ at $55^{\circ} \mathrm{C}$ to $70^{\circ} \mathrm{C} / \mathrm{z}$ value: $6.26^{\circ} \mathrm{C}$ ) and Listeria (D values: 56.17 to $0.126 \mathrm{~min}$ at $55^{\circ} \mathrm{C}$ to $70^{\circ} / \mathrm{z}$ value: $5.67^{\circ} \mathrm{C}$ ). However, a study that worked with marinated chicken breast ${ }^{142}$ indicated different thermal kinetics by both Salmonella and L. monocytogenes. The D value changed up to 47.65 minutes and 54.87 minutes, respectively. The thermal inactivation of bacteria in ground chicken thigh and $\operatorname{skin}^{143}$ provided different thermal kinetics compare to chicken breast studies. The differences in thermal kinetics in different poultry parts indicated that the components of poultry meat contribute largely to the inactivation of pathogens. Poultry carcass ${ }^{144}$ had also been studied by thermal inactivation of Escherichia coli and Salmonella Typhimurium but without thermal kinetics calculation.

It is difficult to establish a universal supporting guidance for thermal inactivation due to the great number of variables contributing to the heat resistance of a pathogen in poultry meat products. Besides the federal regulations, more specific guidelines can improve food safety in the meat and poultry industry. Concepts of developing risk management guidelines have been provided in recent years. An example is Codex Alimentarius who introduced the concepts of Food Safety Objective (FSO), Performance Objective (PO), and Performance Criterion (PC) ${ }^{145}$. This FSO concept can be applied in the poultry meat thermal inactivation process ${ }^{146}$. Furthermore, researches on thermal inactivation of different bacteria strains in poultry under dynamic conditions is needed for developing risk assessment of various poultry meat products. 


\subsection{Antibiotic resistance}

\subsubsection{Introduction}

The discovery of antibiotics was once considered the breakthrough of modern medicine. However, antibiotics tend to lose their efficacy in recent 20 years because of the occurrence of antibiotic resistance (AR) among bacterial pathogens under selective pressure ${ }^{147}$. In general, AR is the protection mechanisms of microbes to protect them from the attaching of antibiotics. Resistant microorganisms are difficult to treat and requiring higher doses or alternative medications. Bacterial has strong general-spectrum drug-resistant or totally drug-resistant is defined as "superbugs" ${ }^{148}$. Three types of resistance are defined. First is epidemiological resistance, which means a reduction of the susceptibility of bacteria to antibiotics is detected to a threshold that is an upper limit of normal dose of the concerned species. The second resistant type is pharmacological resistance based on the minimal inhibitory concentration (MIC) of the antibiotic. If the applied antibiotic concentration is above MIC, it indicates bacteria pharmacological resistance. The third type is clinical resistance, which means a treatment failure to treatment the infection caused by the concerned bacterium. The AR can often be confirmed by using function-based and sequence-based molecular techniques such as polymerase chain reaction (PCR), hybridization, and microarray assay ${ }^{149,150}$.

Several mechanisms contribute to AR of bacteria including enzymatic degradation of antibiotics, antibiotic target modification, and pathways shifting. AR bacteria could synthesis enzymes that causing the degradation of antibiotics. The $\beta$-lactamase enzymes hydrolyzing the $\beta$-lactam ring of $\beta$-lactam cephalosporins is an example of enzymatic degradation, which are main concern of Gram-negative bacteria ${ }^{151}$. Antibiotic targeted modification can lead antibiotics to lose binding capacity thereby lose their effectiveness due to the resistant bacteria modified the binding 
protein. Methicillin-resistant Staphylococcus aureus is an example of modifying antibiotic protein binding affinity ${ }^{152}$. Bacteria could also change the permeability of the cell envelope by specific enzymes, which implies a reduction of entry or increase in the efflux of antibiotics. AR is acquired when a susceptible strain has become resistant under selective pressures including gene mutation or horizontal gene transfer (HGT). In the molecular aspect, all the mechanisms of AR are mediated by antibiotic resistome.

Resistome represents all the AR genes (ARGs) and their precursors in both pathogenic and nonpathogenic bacteria ${ }^{153}$. Because AR can be divided into intrinsic and acquired resistance, the antibiotic resistome can be classified as intrinsic and mobile resistome, respectively. As the name showed, intrinsic antibiotic resistome stands for the genetic information originally existing in whole genome whereas the mobile antibiotic resistome stands for the AR gene which can be disseminated through HGT. The mobile antibiotic resistome generally has been considered to have a higher risk for the transfer of AR. Intrinsic antibiotic resistome has a relatively low-risk rank, but sometimes there is a possibility that an intrinsic antibiotic resistance gene can be captured by mobile genetic elements (MGEs) and becomes a mobile AR gene in a certain evolution stage. Unlike intrinsic AR genes that mostly are stationary, the mobile AR genes are highly transferable inside or outside of cell wall and membrane system. Mediation of MGEs is regarded as the major contributor to bacterial genome innovation and evolution. These MGEs include plasmids, transposons, integrons, integrative elements, genomic islands, and phages. As we mentioned the HGT plays an important role in the transfer of antibiotic resistome, factors that influencing HGT impacting the AR genes exchanging among bacteria cells. The basic mechanisms of HGT transportation are mainly transformation, transduction, and conjugative transfer. Transformation is the natural uptake and integration of naked DNA from environments. 
This process depends on the physiological state of competence of the recipient bacterium. Transduction is generally mediated by phage infection by bringing the DNA of a previous host to the new one. A conjugative transfer is the transferring of DNA via vehicles such as a plasmid, conjugative transposon, and bacterial phage.

\subsubsection{AR in Natural Environment}

Antibiotic resistome includes not only resistance genes of pathogenic and non-pathogenic bacteria, but also containing the genes with the potential to function as resistance genes. The antibiotic resistome appeared before the clinical use of antibiotics. Resistance genes probably are embedded into the bacterial genome for a long time since the antibiotic biosynthetic pathways emerged several hundred years ago. Therefore, the natural environment is the first reservoir for the antibiotic resistome. A study isolated 480 spore-forming bacteria from soil samples in diverse locations (urban, agricultural, and forest) and constructed a library of 480 strains that were subsequently screened against 21 antibiotics. The results of this study showed that each isolate was averagely resistant to eight antibiotics, even resistant to the chemical synthetic antibiotics such as sulfa drugs ${ }^{154}$. Antibiotics can be served as a carbon source for the growth of soil bacteria. Furthermore, the bacteria subsisting on antibiotics are surprisingly phylogenetically diverse many of which are closely related to human pathogens ${ }^{155}$. Besides terrestrial environments, aquatic environments are also a huge reservoir for the antibiotic resistome. The antibiotic resistome has been detected in many water environments, such as sewage, hospital,

and animal production wastewaters, groundwater, drinking water, and surface water ${ }^{156}$. Marine environments host antibiotic resistome conferring resistance to ampicillin, tetracycline, nitrofurantoin, and sulfadimethoxine; nearly seventy percent of those antibiotic genes were unknown ${ }^{157}$. Air environment has been also considered as the reservoir of antibiotic resistome. 
Because confinement of thousands of animals requiring controls to reduce heat and regulate humidity, poultry and swine houses are ventilated with fans that result in a considerable movement of materials into the external environment. A study in swine CAFOs found that use of ventilation systems detected resistant bacteria in the air ${ }^{158}$., which is clearly indicating that environmental bacteria are served as a direct reservoir of antibiotic resistome.

Agriculture is using natural environments to produce foods for our benefit. Because the natural environments are the first reservoir of antibiotic resistome, the agricultural production is considered as one of the antibiotic resistome reservoirs. To prevent disease and improve feed efficiency, livestock animal and plant microbiomes have acquired antibiotic resistome over long time exposure to antibiotics and its environments. It is easy to imagine host-associated environments especially the gut microbiota is a complex antibiotic resistome reservoir because of the high-frequency exposure to antibiotics. Undoubtedly, the animals and their related environments constitute a huge reservoir of antibiotic resistomes.

\subsubsection{AR in Food}

Foods are obtained from natural environments and could be contaminated with AR microorganism, which play as a natural vehicle of antibiotic resistome. The cross-contamination of AR microorganisms could happen from farm to table including harvesting, processing, handling, packing, and storage. Animal products could contain antibiotic resistome as a result of fecal contamination and post-slaughtering process. Plant products could be contaminated with antibiotic resistome from fertilizer, soil, and irrigation water. Specific food production could be contaminated with antibiotic resistome by intentional application of microorganisms or contaminated with microbial pathogens. 
Livestock animals serve as the main meat resources of many meatproducts. Many AR studies for livestock animals have been provided evidence that antibiotic resistome has been widely existed in many countries. A study assessed the type and concentrations of the antibiotic resistome at three stages of manure processing to land disposal in three large-scale commercial swine farms in China. The study detected 149 unique AR genes and found the top 63 AR genes of which were enriched 192-fold up to 28000-fold compared with respective antibiotic-free manure or soil controls. The study also pointed out that antibiotic resistome was highly enriched in farm samples ${ }^{159}$. In another recent study, the catalog of antibiotic resistome in the swine gut was established and indicated the antibiotic resistome in their guts encoding resistance to bacitracin, cephalosporin, macrolide, streptogramin B, and tetracycline which are prevalent in swine production chains from different countries ${ }^{160}$. It is obvious that the use of antibiotics affecting the swine gut antibiotic resistome. In a study of the dairy and beef production, the resistome of North American dairy and beef production effluents were evaluated ${ }^{161}$. The analyzed samples from soil, manure, and wastewater samples in feedlot, ranch and dairy operations were collected, and the antimicrobial drug were identified from every experimental stage. In poultry farm, ARSalmonella strains have been most frequently detected ${ }^{162,163}$. In plant farm, antibiotic resistome can be originated from the plant metabolites, which result in the generation of multidrug efflux systems. A self-transmissible multiple resistance plasmids in Escherichia coli isolated from mixed salad, arugula, and cilantro was reported ${ }^{164}$. Similarly, AR E. coli was found in lettuce collected from farmer's market in Canada ${ }^{165}$. Fermented food products needed to be used by a starter culture of microorganisms (usually lactic acid bacteria), which could cause antibiotic resistome conjugation in food products. A study tested the transferability of AR from lactic acid bacteria (Enterococcus faecalis, Lactococcus lactis) to potential pathogenic strains in fermented 
whole milk indicating that lactic acid bacteria can lead to the exchange of antibiotic resistome ${ }^{64}$. Food distribution is the most important pathway for antibiotic resistome. Undoubtedly, the consumer will be the end antibiotic resistome reservoir by the ingestion of food products containing antibiotic resistome that may from bacteria, bacteriophages, and DNA fragments. An interesting example found that a complete food chain dissemination of antibiotic resistome, which discovered MCR-1 collision resistance gene originally only found in animals and retail meats, but also found in food samples and the human gut microbiome ${ }^{166}$. Therefore, the AR issue in food should not only monitor and reduce the presence of bacteria in food products but also try to understand the mechanism and dissemination pathways of the antibiotic resistome. The antibiotic resistome in the natural environment, livestock animals, and human being is more complex than expected. As the increasing over-usage of antibiotics, antibiotics and antibiotic resistome are now considered as a type of pollutant. The lateral transportation of genetic information causes AR genes are transported by humans and animals which play as an intermediate of circulation. The diversity of antibiotic resistome in natural environments and from farm animals suggests that we have to be focus on the management of antibiotic resistome spreading. A central concept is finding a balance of antibiotic resistome circle. The contribution of agriculture to the reservoirs is significant, and the consequences for public health are farreaching.

\section{References}

1. U.S. Food and Drug Administration (FDA). Outbreaks of Foodborne Illness. Accessed Jan. 1st, 2021. https://www.fda.gov/food/recalls-outbreaks-emergencies/outbreaks-foodborneillness

2. Centers for Disease Control and Prevention (CDC). Foodborne Germs and Illnesses. Accessed Jan. 1st, 2021. https://www.cdc.gov/foodsafety/foodborne-germs.html 
3. Dewey-Mattia D, Manikonda K, Hall AJ, Wise ME, Crowe SJ. Surveillance for Foodborne Disease Outbreaks - United States, 2009-2015. Morbidity and mortality weekly report Surveillance summaries (Washington, DC : 2002). Jul 27 2018;67(10):1-11. doi:10.15585/mmwr.ss6710a1

4. Gal-Mor O, Boyle EC, Grassl GA. Same species, different diseases: how and why typhoidal and non-typhoidal Salmonella enterica serovars differ. Frontiers in microbiology. 2014;5:391-391. doi:10.3389/fmicb.2014.00391

5. Jay JM, Loessner MJ, Golden DA. Modern Food Microbiology. Food Science Text Series. New York: Springer; 2005:619.

6. wikipedia. Salmonella. Accessed Jan. 1st, 2021, https://en.wikipedia.org/wiki/Salmonella\#cite note-4

7. Jay JM, Loessner MJ, Golden DA. Modern Food Microbiology. Food Science Text Series. New York: Springer; 2005:625.

8. Sirıken B. [Salmonella pathogenicity islands]. Mikrobiyoloji bulteni. Jan 2013;47(1):1818. Salmonella Patojenite Adaları. doi:10.5578/mb.4138

9. Alvarez J, Sota M, Vivanco AB, et al. Development of a multiplex PCR technique for detection and epidemiological typing of salmonella in human clinical samples. J Clin Microbiol. 2004;42(4):1734-1738. doi:10.1128/jcm.42.4.1734-1738.2004

10. Hoorfar J, Ahrens P, Rådström P. Automated 5' nuclease PCR assay for identification of Salmonella enterica. J Clin Microbiol. 2000;38(9):3429-3435. doi:10.1128/JCM.38.9.34293435.2000

11. Scallan E, Hoekstra RM, Angulo FJ, et al. Foodborne illness acquired in the United States--major pathogens. Emerg Infect Dis. 2011;17(1):7-15. doi:10.3201/eid1701.p11101

12. Centers for Disease Control and Prevention (CDC). Salmonella. https://www.cdc.gov/salmonella/index.html

13. Hennessy TW, Hedberg CW, Slutsker L, et al. A national outbreak of Salmonella enteritidis infections from ice cream. The Investigation Team. $N$ Engl J Med. May 16 1996;334(20):1281-6. doi:10.1056/nejm199605163342001

14. Cavallaro E, Date K, Medus C, et al. Salmonella typhimurium infections associated with peanut products. $N$ Engl J Med. Aug 18 2011;365(7):601-10. doi:10.1056/NEJMoa1011208

15. Centers for Disease Control and Prevention (CDC). Outbreak of Salmonella Enteritidis Infections Linked to Peaches. Centers for Disease Control and Prevention. Accessed Jan 5th, 2020, https://www.cdc.gov/salmonella/enteritidis-08-20/index.html

16. Ludwig W, Schleifer K-H, Stackebrandt E. 16S rRNA analysis of Listeria monocytogenes and Brochothrix thermosphacta. FEMS Microbiology Letters. 1984;25(2-3):199-204. doi:10.1111/j.1574-6968.1984.tb01456.x

17. wikipedia. Listeria. Accessed Jan 5th, 2021, https://en.wikipedia.org/wiki/Listeria\#cite note-3

18. Jay JM, Loessner MJ, Golden DA. Modern Food Microbiology. Food Science Text Series. New York: Springer; 2005:559.

19. Jones GS, D'Orazio SEF. Listeria monocytogenes: cultivation and laboratory maintenance. Curr Protoc Microbiol. 2013;31:9B.2.1-9B.2.7.

doi:10.1002/9780471729259.mc09b02s31

20. BUCHANAN RL, KLAWITTER LA. Effects of Temperature and Oxygen on the Growth of Listeria monocytogenes at pH 4.5. Journal of Food Science. 1990;55(6):1754-1756.

doi:https://doi.org/10.1111/j.1365-2621.1990.tb03620.x 
21. Conner DE, Brackett RE, Beuchat LR. Effect of temperature, sodium chloride, and $\mathrm{pH}$ on growth of Listeria monocytogenes in cabbage juice. Applied and Environmental Microbiology. 1986;52(1):59.

22. Buchanan RL, Gorris LGM, Hayman MM, Jackson TC, Whiting RC. A review of Listeria monocytogenes: An update on outbreaks, virulence, dose-response, ecology, and risk assessments. Food Control. 2017/05/01/ 2017;75:1-13. doi:https://doi.org/10.1016/i.foodcont.2016.12.016

23. Jemmi T, Stephan R. Listeria monocytogenes: food-borne pathogen and hygiene indicator. Revue scientifique et technique (International Office of Epizootics). Aug 2006;25(2):571-80.

24. Lingnau A, Domann E, Hudel M, et al. Expression of the Listeria monocytogenes EGD inlA and inlB genes, whose products mediate bacterial entry into tissue culture cell lines, by PrfA-dependent and -independent mechanisms. Infection and immunity. Oct 1995;63(10):3896903. doi:10.1128/iai.63.10.3896-3903.1995

25. Jay JM, Loessner MJ, Golden DA. Modern Food Microbiology. Food Science Text Series. New York: Springer; 2005:604.

26. (WHO) WHO. Listeriosis. World Health Organization (WHO). Accessed Jan 10th, 2021, https://www.who.int/news-room/fact-sheets/detail/listeriosis

27. Centers for Disease Control and Prevention (CDC). Listeria. Accessed Jan 10th, 2021. https://www.cdc.gov/salmonella/index.html

28. Centers for Disease Control and Prevention (CDC). National Listeria surveillance annual summary, 2014. 2014. https://www.cdc.gov/nationalsurveillance/pdfs/listeria-annual-summary2014-508.pdf

29. Centers for Disease Control and Prevention (CDC). Outbreak of Listeria Infections Linked to Deli Meats. Accessed Jan 10th, 2021, https://www.cdc.gov/listeria/outbreaks/delimeat10-20/index.html

30. Drevets DA, Bronze MS. Listeria monocytogenes : epidemiology, human disease, and mechanisms of brain invasion. FEMS Immunology \& Medical Microbiology. 2008;53(2):151165. doi:10.1111/j.1574-695X.2008.00404.X

31. Humphrey T, O'Brien S, Madsen M. Campylobacters as zoonotic pathogens: a food production perspective. International journal of food microbiology. 2007;117(3):237-257.

32. Jay JM, Loessner MJ, Golden DA. Modern Food Microbiology. Food Science Text Series. New York: Springer; 2005:669.

33. Altekruse SF, Stern NJ, Fields PI, Swerdlow DL. Campylobacter jejuni--an emerging foodborne pathogen. Emerg Infect Dis. Jan-Feb 1999;5(1):28-35. doi:10.3201/eid0501.990104 34. Crushell E, Harty S, Sharif F, Bourke B. Enteric campylobacter: purging its secrets? Pediatric research. Jan 2004;55(1):3-12. doi:10.1203/01.Pdr.0000099794.06260.71

35. Epps SVR, Harvey RB, Hume ME, Phillips TD, Anderson RC, Nisbet DJ. Foodborne Campylobacter: infections, metabolism, pathogenesis and reservoirs. Int J Environ Res Public Health. 2013;10(12):6292-6304. doi:10.3390/ijerph10126292

36. wikipedia. Campylobacter jejuni. Accessed Jan. 15th, 2021, https://en.wikipedia.org/wiki/Campylobacter_jejuni

37. Korneev KV, Kondakova AN, Sviriaeva EN, et al. Hypoacylated LPS from Foodborne Pathogen Campylobacter jejuni Induces Moderate TLR4-Mediated Inflammatory Response in Murine Macrophages. Frontiers in cellular and infection microbiology. 2018;8:58. doi:10.3389/fcimb.2018.00058 
38. Kaakoush NO, Castaño-Rodríguez N, Mitchell HM, Man SM. Global Epidemiology of Campylobacter Infection. Clin Microbiol Rev. 2015;28(3):687-720. doi:10.1128/CMR.00006-15 39. Centers for Disease Control and Prevention (CDC). Campylobacter (Campylobacteriosis). https://www.cdc.gov/campylobacter/index.html

40. Hall AJ, Wikswo ME, Manikonda K, Roberts VA, Yoder JS, Gould LH. Acute gastroenteritis surveillance through the National Outbreak Reporting System, United States. Emerg Infect Dis. 2013;19(8):1305-1309. doi:10.3201/eid1908.130482

41. Kendall ME, Crim S, Fullerton K, et al. Travel-associated enteric infections diagnosed after return to the United States, Foodborne Diseases Active Surveillance Network (FoodNet), 2004-2009. Clinical infectious diseases : an official publication of the Infectious Diseases Society of America. Jun 2012;54 Suppl 5:S480-7. doi:10.1093/cid/cis052

42. Davis K, Dunn A, Burnett C, et al. Campylobacter jejuni Infections Associated with Raw Milk Consumption - Utah, 2014. MMWR Morbidity and mortality weekly report. 04/01 2016;65:301-305. doi:10.15585/mmwr.mm6512a1

43. Hazards EPoB. Scientific Opinion on Campylobacter in broiler meat production: control options and performance objectives and/or targets at different stages of the food chain. EFSA Journal. 2011;9(4):2105. doi:https://doi.org/10.2903/j.efsa.2011.2105

44. Batz MB, Hoffmann S, Morris JG, Jr. Ranking the disease burden of 14 pathogens in food sources in the United States using attribution data from outbreak investigations and expert elicitation. J Food Prot. Jul 2012;75(7):1278-91. doi:10.4315/0362-028x.Jfp-11-418

45. wikipedia. Enterococcus. Accessed Jan. 21st, 2021, https://en.wikipedia.org/wiki/Enterococcus

46. Schleifer KH, Kilpper-Bälz R. Transfer of Streptococcus faecalis and Streptococcus faecium to the Genus Enterococcus nom. rev. as Enterococcus faecalis comb. nov. and Enterococcus faecium comb. nov. International Journal of Systematic and Evolutionary Microbiology. 1984;34(1):31-34. doi:https://doi.org/10.1099/00207713-34-1-31

47. Byappanahalli MN, Nevers MB, Korajkic A, Staley ZR, Harwood VJ. Enterococci in the Environment. Microbiology and Molecular Biology Reviews. 2012;76(4):685-706.

doi:10.1128/mmbr.00023-12

48. Jay JM, Loessner MJ, Golden DA. Modern Food Microbiology. Food Science Text Series. New York: Springer; 2005:483.

49. Omar NB, Castro A, Lucas R, et al. Functional and Safety Aspects of Enterococci Isolated from Different Spanish Foods. Systematic and Applied Microbiology. 2004/01/01/ 2004;27(1):118-130. doi:https://doi.org/10.1078/0723-2020-00248

50. Nair PS, Surendran PK. BIOCHEMICAL CHARACTERIZATION OF LACTIC ACID BACTERIA ISOLATED FROM FISH AND PRAWN. 2005:

51. Barbosa J, Ferreira V, Teixeira P. Antibiotic susceptibility of enterococci isolated from traditional fermented meat products. Food microbiology. Aug 2009;26(5):527-32. doi:10.1016/j.fm.2009.03.005

52. Ben Braïek O, Smaoui S. Enterococci: Between Emerging Pathogens and Potential Probiotics. BioMed Research International. 2019/05/23 2019;2019:5938210. doi:10.1155/2019/5938210

53. Huycke MM, Sahm DF, Gilmore MS. Multiple-drug resistant enterococci: the nature of the problem and an agenda for the future. Emerg Infect Dis. Apr-Jun 1998;4(2):239-49.

doi:10.3201/eid0402.980211 
54. Barbosa J, Gibbs PA, Teixeira P. Virulence factors among enterococci isolated from traditional fermented meat products produced in the North of Portugal. Food Control. 2010/05/01/ 2010;21(5):651-656. doi:https://doi.org/10.1016/j.foodcont.2009.10.002 55. Jay JM, Loessner MJ, Golden DA. Modern Food Microbiology. Food Science Text Series. New York: Springer; 2005:475.

56. Bianchini A, Stratton J, Weier S, et al. Use of Enterococcus faecium as a surrogate for Salmonella enterica during extrusion of a balanced carbohydrate-protein meal. J Food Prot. Jan 2014;77(1):75-82. doi:10.4315/0362-028x.Jfp-13-220

57. Piyasena P, McKellar RC, Bartlett FM. Thermal inactivation of Pediococcus sp. in simulated apple cider during high-temperature short-time pasteurization. Int J Food Microbiol. Jan 26 2003;82(1):25-31. doi:10.1016/s0168-1605(02)00264-7

58. Sanitizers and Disinfectants: The Chemicals of Prevention. Food Safety Magazine. Accessed Jan 22ed, 2021. https://www.food-safety.com/articles/6707-sanitizers-anddisinfectants-the-chemicals-of-prevention

59. Shen X, Sheng L, Gao H, Hanrahan I, Suslow Trevor V, Zhu M-J. Enhanced Efficacy of Peroxyacetic Acid Against Listeria monocytogenes on Fresh Apples at Elevated Temperature. Original Research. Frontiers in Microbiology. 2019-June-18 2019;10(1196)doi:10.3389/fmicb.2019.01196

60. U.S. Food and Drug Administration (FDA). Code of Federal Regulations Title 21. Accessed Jan 27th, 2021.

https://www.accessdata.fda.gov/SCRIPTs/cdrh/cfdocs/cfcfr/CFRSearch.cfm?fr=173.315\&Search $\underline{\text { Term }=\text { chemicals }}$

61. USDA Food Safety and Inspection Service (USDA-FSIS). Related Documents for FSIS Directive 7120.1 - Safe and Suitable Ingredients used in the Production of Meat, Poultry, and Egg Products. Accessed Jan 27th, 2021.

https://www.fsis.usda.gov/wps/portal/fsis/topics/regulations/directives/7000-series/safe-suitableingredients-related-document

62. Peroxyacetic acid - BioSafe Systems. Accessed Jan 29, 2021, https://biosafesystems.com/peroxyacetic-acid/

63. wikipedia. Lactic acid. Accessed Jan 29th, 2021, https://en.wikipedia.org/wiki/Lactic acid

64. Stanojević-Nikolić S, Dimić G, Mojović L, Pejin J, Djukić-Vuković A, Kocić-Tanackov S. Antimicrobial Activity of Lactic Acid Against Pathogen and Spoilage Microorganisms. Journal of Food Processing and Preservation. 2016;40(5):990-998. doi:https://doi.org/10.1111/jfpp.12679

65. Daskalov H. Original Contribution EFFECT OF DIFFERENT ORGANIC ACID TREATMENTS WITH SIMILAR pH TO CONTROL LISTERIA MONOCYTOGENES ON COOKED FRANKFURTERS. 2012:

66. Over KF, Hettiarachchy N, Johnson MG, Davis B. Effect of organic acids and plant extracts on Escherichia coli O157:H7, Listeria monocytogenes, and Salmonella Typhimurium in broth culture model and chicken meat systems. J Food Sci. Nov-Dec 2009;74(9):M515-21. doi:10.1111/j.1750-3841.2009.01375.x

67. wikipedia. Citric acid. Accessed Jan 29th, 2021, https://en.wikipedia.org/wiki/Citric acid 68. Verhoff FH. Citric Acid. Ullmann's Encyclopedia of Industrial Chemistry. 
69. Bae Y-M, Lee S-Y. Combined effects of organic acids and salt depending on type of acids and pathogens in laboratory media and acidified pickle. Journal of Applied Microbiology. 2015;119(2):455-464. doi:https://doi.org/10.1111/jam.12845

70. wikipedia. Sodium hypochlorite. Accessed Feb 1st, 2021, https://en.wikipedia.org/wiki/Sodium hypochlorite

71. Estrela C, Estrela CR, Barbin EL, Spanó JC, Marchesan MA, Pécora JD. Mechanism of action of sodium hypochlorite. Brazilian dental journal. 2002;13(2):113-7. doi:10.1590/s010364402002000200007

72. Fukuzaki S. Mechanisms of actions of sodium hypochlorite in cleaning and disinfection processes. Biocontrol science. Dec 2006;11(4):147-57. doi:10.4265/bio.11.147

73. McGlynn W. Guidelines for the Use of Chlorine Bleach as a Sanitizer in Food Processing Operations. Accessed Feb. 1st, 2021, https://extension.okstate.edu/fact-sheets/guidelines-for-theuse-of-chlorine-bleach-as-a-sanitizer-in-food-processing-operations.html

74. Marshall RT, Anderson ME, Naumann HD, Stringer WC. Experiments in Sanitizing Beef With Sodium Hypochlorite (1,) (2). J Food Prot. Apr 1977;40(4):246-249. doi:10.4315/0362$028 \mathrm{x}-40.4 .246$

75. C. Simpson Beauchamp, D. Dourou, Geornaras, et al. Sanitizer Efficacy against Escherichia coli O157:H7 Biofilms on Inadequately Cleaned Meat-contact Surface Materials. Food protection trends. 2010;32:173-182.

76. Grossen G, Ha KA. Poultry \& Eggs. Feb. 1st, 2021. https://www.ers.usda.gov/topics/animal-products/poultry-eggs/

77. Humphrey TJ. Contamination of egg shell and contents with Salmonella enteritidis: a review. International journal of food microbiology. 1994/01// 1994;21(1-2):31-40. doi:10.1016/0168-1605(94)90197-x

78. Padron M. Salmonella typhimurium penetration through the eggshell of hatching eggs. Avian diseases. Apr-Jun 1990;34(2):463-5.

79. (EPA) USEPA. Guidance for Use of Food-Grade Shell-Egg Sanitizers. Feb. 2nd, 2021. https://www.epa.gov/pesticide-labels/guidance-use-food-grade-shell-egg-sanitizers

80. Bierer BW, Barnett BD, Valentine HD. Experimentally Killing Salmonella typhimurium on Egg Shells by Washing. Poultry Science. 1961/07/01/ 1961;40(4):1009-1014. doi:https://doi.org/10.3382/ps.0401009

81. Rizk SS, Ayres JC, Kraft AA. Disinfection of Eggs Artificially Inoculated with Salmonellae: 1. Application of Several Disinfectants1. Poultry Science. 1966/07/01/ 1966;45(4):764-769. doi:https://doi.org/10.3382/ps.0450764

82. Holley RA, Proulx M. Use of egg washwater $\mathrm{pH}$ to prevent survival of Salmonella at moderate temperatures. Poult Sci. May 1986;65(5):922-8. doi:10.3382/ps.0650922

83. Moats WA. Egg Washing -A Review. J Food Prot. Nov 1978;41(11):919-924. doi:10.4315/0362-028x-41.11.919

84. Soljour G, Assanta MA, Messier S, Boulianne M. Efficacy of egg cleaning compounds on eggshells contaminated with Salmonella enterica serovar Enteritidis. J Food Prot. Apr 2004;67(4):706-12. doi:10.4315/0362-028x-67.4.706

85. Kim JW, Slavik MF. Changes in Eggshell Surface Microstructure after Washing with Cetylpyridinium Chloride or Trisodium Phosphate. J Food Prot. Aug 1996;59(8):859-863. doi:10.4315/0362-028x-59.8.859 
86. Wang H, Slavik MF. Bacterial penetration into eggs washed with various chemicals and stored at different temperatures and times. J Food Prot. Mar 1998;61(3):276-9.

doi:10.4315/0362-028x-61.3.276

87. Kagambèga A, Thibodeau A, Trinetta V, et al. Salmonella spp. and Campylobacter spp. in poultry feces and carcasses in Ouagadougou, Burkina Faso. Food Science \& Nutrition. 2018;6(6):1601-1606. doi:https://doi.org/10.1002/fsn3.725

88. Sanosil. Disinfecting chicken coops with a poultry disinfectant - the basics. Accessed Feb. 2nd, 2021, https://www.sanosil.com/en/application-

fields/landwirtschaft/tierzucht/huhnerfarmen/

89. Tsai L-S, Schade JE, Molyneux BT. Chlorination of Poultry Chiller Water: Chlorine Demand and Disinfection Efficiencyl. Poultry Science. 1992/01/01/ 1992;71(1):188-196. doi:https://doi.org/10.3382/ps.0710188

90. LILLARD HS. LEVELS OF CHLORINE AND CHLORINE DIOXIDE OF EQUIVALENT BACTERICIDAL EFFECT IN POULTRY PROCESSING WATER. Journal of Food Science. 1979;44(6):1594-1597. doi:https://doi.org/10.1111/j.1365-2621.1979.tb09097.x

91. Tamblyn KC, Conner DE. Bactericidal activity of organic acids in combination with transdermal compounds againstSalmonella typhimuriumattached to broiler skin. Food microbiology. 1997/10/01/ 1997;14(5):477-484. doi:https://doi.org/10.1006/fmic.1997.0112 92. Bilgili SF, Conner DE, Pinion JL, Tamblyn KC. Broiler skin color as affected by organic acids: influence of concentration and method of application. Poultry Science. 1998/05/01/ 1998;77(5):752-757. doi:https://doi.org/10.1093/ps/77.5.752

93. Sefna V, Irshad A, Sankar KJA, Lakshmi AT, Vasudevan VN. The Use of Chlorine Dioxide Solution as an Effective Decontaminant for Broiler Chicken Carcass. International Journal of Livestock Research. 2019;9(8):19. doi:http://dx.doi.org/10.5455/ijlr.20190604090949 94. LILLARD HS, THOMSON JE. Efficacy of Hydrogen Peroxide as a Bactericide in Poultry Chiller Water. Journal of Food Science. 1983;48(1):125-126. doi:https://doi.org/10.1111/j.1365-2621.1983.tb14804.x

95. Yang Z, Li Y, Slavik M. Use of antimicrobial spray applied with an inside-outside birdwasher to reduce bacterial contamination on prechilled chicken carcasses. J Food Prot. Jul 1998;61(7):829-32. doi:10.4315/0362-028x-61.7.829

96. Moore A, Nannapaneni R, Kiess A, Sharma CS. Evaluation of USDA approved antimicrobials on the reduction of Salmonella and Campylobacter in ground chicken frames and their effect on meat quality. Poultry Science. 2017/07/01/ 2017;96(7):2385-2392.

doi:https://doi.org/10.3382/ps/pew497

97. Fatemi P, Frank JF. Inactivation of Listeria monocytogenes/Pseudomonas biofilms by peracid sanitizers. J Food Prot. Jul 1999;62(7):761-5. doi:10.4315/0362-028x-62.7.761

98. Bauermeister LJ, Bowers JWJ, Townsend JC, McKee SR. The Microbial and Quality Properties of Poultry Carcasses Treated with Peracetic Acid as an Antimicrobial Treatment. Poultry Science. 2008/11/01/ 2008;87(11):2390-2398. doi:https://doi.org/10.3382/ps.2008-00087 99. wikipedia. Lorentz force. Accessed Feb 4th, 2021, https://en.wikipedia.org/wiki/Lorentz_force

100. Edward Law S. Agricultural electrostatic spray application: a review of significant research and development during the 20th century. Journal of Electrostatics. 2001/05/01/ 2001;51-52:25-42. doi:https://doi.org/10.1016/S0304-3886(01)00040-7 
101. Law SE. Embedded- Electrode Electrostatic-Induction Spray-Charging Nozzle: Theoretical and Engineering Design. Transactions of the ASAE. 1978;21(6):1096-1104. doi:https://doi.org/10.13031/2013.35448

102. Edward Law S. Spatial Distribution of Electrostatically Deposited Sprays on Living Plants. Journal of Economic Entomology. 1982;75(3):542-544. doi:10.1093/jee/75.3.542

103. Kabashima JN, Giles DK, Parrella MP. Electrostatic sprayers improve pesticide efficacy in greenhouses. California Agriculture. 1995;49(4):31-35. doi:10.3733/ca.v049n04p31 104. Law SE, Banerjee S, Wetzstein HY, Eisikowitch D. Electrostatic application of pollen sprays: effects of charging field intensity and aerodynamic shear upon deposition and germinability. 1996:1940-1948 vol.4.

105. Ratanatriwong P, Barringer SA, Delwiche J. Sensory Preference, Coating Evenness, Dustiness, and Transfer Efficiency of Electrostatically Coated Potato Chips. Journal of Food Science. 2003;68(4):1542-1547. doi:https://doi.org/10.1111/j.1365-2621.2003.tb09681.x 106. Law SE, Cooper SC. Air-assisted electrostatic sprays for postharvest control of fruit and vegetable spoilage microorganisms. IEEE Transactions on Industry Applications.

2001;37(6):1597-1602. doi:10.1109/28.968166

107. Russell SM. Effect of Sanitizers Applied by Electrostatic Spraying on Pathogenic and Indicator Bacteria Attached to the Surface of Eggs. Journal of Applied Poultry Research. 2003/07/01/ 2003;12(2):183-189. doi:https://doi.org/10.1093/japr/12.2.183

108. Almasoud A, Hettiarachchy N, Rayaprolu S, Horax R, Eswaranandam S. Electrostatic spraying of organic acids on biofilms formed by E. coli O157:H7 and Salmonella Typhimurium on fresh produce. Food research international (Ottawa, Ont). Dec 2015;78:27-33.

doi:10.1016/j.foodres.2015.11.012

109. wikipedia. Pasteurization. Accessed Feb 7th, 2021, https://en.wikipedia.org/wiki/Pasteurization

110. wikipedia. Louis Pasteur. Accessed Feb 7th, 2021, https://en.wikipedia.org/wiki/Louis Pasteur

111. Jay JM, Loessner MJ, Golden DA. Modern Food Microbiology. Food Science Text Series. New York: Springer; 2005:415.

112. Pearce LE, Smythe BW, Crawford RA, Oakley E, Hathaway SC, Shepherd JM. Pasteurization of milk: The heat inactivation kinetics of milk-borne dairy pathogens under commercial-type conditions of turbulent flow. Journal of Dairy Science. 2012/01/01/ 2012;95(1):20-35. doi:https://doi.org/10.3168/jds.2011-4556

113. Myer PR, Parker KR, Kanach AT, Zhu T, Morgan MT, Applegate BM. The effect of a novel low temperature-short time (LTST) process to extend the shelf-life of fluid milk.

SpringerPlus. 2016;5(1):660. doi:10.1186/s40064-016-2250-1

114. wikipedia. Sterilization. Accessed Feb 7th, 2021, https://en.wikipedia.org/wiki/Sterilization_(microbiology)

115. Jay JM, Loessner MJ, Golden DA. Modern Food Microbiology. Food Science Text Series. New York: Springer; 2005:416.

116. Cazemier AE, Wagenaars SF, ter Steeg PF. Effect of sporulation and recovery medium on the heat resistance and amount of injury of spores from spoilage bacilli. J Appl Microbiol. May 2001;90(5):761-70. doi:10.1046/j.1365-2672.2001.01302.x

117. Corry JEL. The Effect of Sugars and Polyols on the Heat Resistance of Salmonellae. Journal of Applied Bacteriology. 1974;37(1):31-43. doi:https://doi.org/10.1111/j.13652672.1974.tb00412.x 
118. Marti R, Schmid M, Kulli S, et al. Biofilm Formation Potential of Heat-Resistant Escherichia coli Dairy Isolates and the Complete Genome of Multidrug-Resistant, Heat-Resistant Strain FAM21845. Appl Environ Microbiol. Aug 1 2017;83(15)doi:10.1128/aem.00628-17 119. $\mathrm{Ng} \mathrm{H}$, Bayne HG, Garibaldi JA. Heat resistance of Salmonella: the uniqueness of Salmonella senftenberg 775W. Appl Microbiol. 1969;17(1):78-82.

120. Jay JM, Loessner MJ, Golden DA. Modern Food Microbiology. Food Science Text Series. New York: Springer; 2005:432.

121. Beaman TC, Greenamyre JT, Corner TR, Pankratz HS, Gerhardt P. Bacterial spore heat resistance correlated with water content, wet density, and protoplast/sporoplast volume ratio. Journal of bacteriology. 1982;150(2):870-877. doi:10.1128/JB.150.2.870-877.1982

122. Setlow P. Spore Resistance Properties. Microbiology spectrum. Oct 2014;2(5)doi:10.1128/microbiolspec.TBS-0003-2012

123. Smelt JP, Brul S. Thermal inactivation of microorganisms. Critical reviews in food science and nutrition. 2014;54(10):1371-85. doi:10.1080/10408398.2011.637645

124. D value, $Z$ value and F value. Accessed Feb 9th, 2021, https://pharmastate.blog/d-valuez-value-and-f-value/

125. Withell ER. The significance of the variation in shape of time-survivor curves. The Journal of hygiene. Apr 1942;42(2):124-83. doi:10.1017/s0022172400035361

126. Moats WA. Kinetics of thermal death of bacteria. Journal of bacteriology. Jan 1971;105(1):165-71. doi:10.1128/jb.105.1.165-171.1971

127. van Boekel MAJS. On the use of the Weibull model to describe thermal inactivation of microbial vegetative cells. International Journal of Food Microbiology. 2002/03/25/ 2002;74(1):139-159. doi:https://doi.org/10.1016/S0168-1605(01)00742-5

128. Zwietering MH, Jongenburger I, Rombouts FM, van 't Riet K. Modeling of the bacterial growth curve. Applied and environmental microbiology. 1990;56(6):1875-1881.

doi:10.1128/AEM.56.6.1875-1881.1990

129. Huang L. Thermal inactivation of Listeria monocytogenes in ground beef under isothermal and dynamic temperature conditions. Journal of Food Engineering. 2009;90(3):380387.

130. Gill CO, McGinnis JC, Barbut S, Young D, Lee N, Rahn K. Microbiological conditions of moisture-enhanced chicken breasts prepared at a poultry packing plant. J Food Prot. Dec 2004;67(12):2675-81. doi:10.4315/0362-028x-67.12.2675

131. Team HE. Worst Foodborne Illness Outbreaks in Recent U.S. History. Accessed Feb 10th, 2021, https://www.healthline.com/health/worst-foodborne-illness-outbreaks

132. Centers for Disease Control and Prevention (CDC). Outbreaks of Salmonella Infections Linked to Backyard Poultry. Accessed Feb 10th, 2021. https://www.cdc.gov/salmonella/backyardpoultry-05-20/index.html

133. USDA Food Safety and Inspection Service (USDA-FSIS). Model for Risk Assessment for the Impact of Lethality Standards on Salmonellosis from Ready-to-Eat Meat and Poultry Products. Accessed Feb 10th, 2021.

https://www.fsis.usda.gov/wps/portal/footer/!ut/p/a0/04_Sj9CPykssy0xPLMnMz0vMAfGjzOJN AyxdDU28DbwsvIxdDDzDnA3NLIONjdzCjPQLsh0VAZaJ MY!/?1dmy\&current=true\&urile= wcm $\% 3$ Apath $\% 3 \mathrm{~A} \% 2$ Ffsis-content $\% 2$ Finternet $\% 2$ Fmain $\% 2$ Ftopics $\% 2$ Fscience $\% 2$ Friskassessments $\% 2$ Fsalmonellosis-risk-assessment-model $\% 2$ Fsalmonellosis-ra-model

134. Performance standards for the production of certain meat and poultry products. The Daily Journal of the United States Government. Accessed Feb 24th, 2021. 
https://www.federalregister.gov/documents/2001/02/27/01-4420/performance-standards-for-theproduction-of-processed-meat-and-poultry-products

135. USDA Food Safety and Inspection Service (USDA-FSIS). FSIS Salmonella Compliance Guidelines for Small and Very Small Meat and Poultry Establishments that Produce Ready-toEat (RTE) Products and Revised Appendix A. Accessed Feb 10th, 2021. https://www.fsis.usda.gov/wps/portal/fsis/topics/regulatory-compliance/guidelines/2017-0008 136. GOODFELLOW SJ, BROWN WL. Fate of Salmonella Inoculated into Beef for Cooking. Journal of Food Protection. 1978;41(8):598-605. doi:10.4315/0362-028x-41.8.598

137. Duffy G, Sheridan JJ. The effect of temperature, $\mathrm{pH}$ and medium in a surface adhesion immunofluorescent technique for detection of Listeria monocytogenes. J Appl Microbiol. Jul 1997;83(1):95-101. doi:10.1111/j.1361-5072.1997.00195.x

138. Murphy RY, Marks BP, Johnson ER, Johnson MG. Inactivation of Salmonella and Listeria in ground chicken breast meat during thermal processing. J Food Prot. Sep 1999;62(9):980-5. doi:10.4315/0362-028x-62.9.980

139. Smadi H, Sargeant JM, Shannon HS, Raina P. Growth and inactivation of Salmonella at low refrigerated storage temperatures and thermal inactivation on raw chicken meat and laboratory media: Mixed effect meta-analysis. Journal of Epidemiology and Global Health. 2012/12/01/ 2012;2(4):165-179. doi:https://doi.org/10.1016/j.jegh.2012.12.001

140. Murphy RY, Marks BP, Johnson ER, Johnson MG. Thermal Inactivation Kinetics of Salmonella and Listeria in Ground Chicken Breast Meat and Liquid Medium. Journal of Food Science. 2000;65(4):706-710. doi:https://doi.org/10.1111/j.1365-2621.2000.tb16076.x 141. Murphy RY, Duncan LK, Berrang ME, Marcy JA, Wolfe RE. Thermal inactivation Dand Z-values of Salmonella and Listeria innocua in fully cooked and vacuum packaged chicken breast meat during postcook heat treatment. Poult Sci. Oct 2002;81(10):1578-83. doi:10.1093/ps/81.10.1578

142. Karyotis D, Skandamis PN, Juneja VK. Thermal inactivation of Listeria monocytogenes and Salmonella spp. in sous-vide processed marinated chicken breast. Food research international (Ottawa, Ont). Oct 2017;100(Pt 1):894-898. doi:10.1016/j.foodres.2017.07.078 143. Murphy RY, Osaili T, Duncan LK, Marcy JA. Thermal Inactivation of Salmonella and Listeria Monocytogenes in Ground Chicken Thigh/Leg Meat and Skin. Poultry Science. 2004/07/01/ 2004;83(7):1218-1225. doi:https://doi.org/10.1093/ps/83.7.1218

144. Biswas S, Nazmi A, Pitesky M, Gallardo R, Pandey P. Thermal Inactivation of Escherichia coli and Salmonella Typhimurium in Poultry Carcass and Litter at Thermophilic Temperatures. Journal of Applied Poultry Research. 2019/06/01/ 2019;28(2):307-317. doi:https://doi.org/10.3382/japr/pfy072

145. Program USC. U.S. CODEX PROGRAM STRATEGIC PLAN 2019-2023. Accessed Feb 10th, 2021. https://www.usda.gov/sites/default/files/documents/us-codex-program-strategicplan.pdf

146. Membré JM, Bassett J, Gorris LG. Applying the food safety objective and related standards to thermal inactivation of Salmonella in poultry meat. $J$ Food Prot. Sep 2007;70(9):2036-44. doi:10.4315/0362-028x-70.9.2036

147. Rossolini GM, Arena F, Pecile P, Pollini S. Update on the antibiotic resistance crisis. Current opinion in pharmacology. Oct 2014;18:56-60. doi:10.1016/j.coph.2014.09.006

148. wikipedia. Antimicrobial resistance. Accessed Feb 12th, 2021, https://en.wikipedia.org/wiki/Antimicrobial_resistance 
149. Perreten V, Vorlet-Fawer L, Slickers P, Ehricht R, Kuhnert P, Frey J. Microarray-based detection of 90 antibiotic resistance genes of gram-positive bacteria. J Clin Microbiol. May 2005;43(5):2291-302. doi:10.1128/jcm.43.5.2291-2302.2005

150. Strommenger B, Kettlitz C, Werner G, Witte W. Multiplex PCR assay for simultaneous detection of nine clinically relevant antibiotic resistance genes in Staphylococcus aureus. J Clin Microbiol. Sep 2003;41(9):4089-94. doi:10.1128/jcm.41.9.4089-4094.2003

151. Livermore DM, Woodford N. The $\beta$-lactamase threat in Enterobacteriaceae, Pseudomonas and Acinetobacter. Trends in microbiology. 2006/09/01/ 2006;14(9):413-420. doi:https://doi.org/10.1016/j.tim.2006.07.008

152. Pinho MG, Filipe SR, de Lencastre H, Tomasz A. Complementation of the essential peptidoglycan transpeptidase function of penicillin-binding protein 2 (PBP2) by the drug resistance protein PBP2A in Staphylococcus aureus. Journal of bacteriology. Nov 2001;183(22):6525-31. doi:10.1128/jb.183.22.6525-6531.2001

153. Wright GD. The antibiotic resistome: the nexus of chemical and genetic diversity. Nature Reviews Microbiology. 2007/03/01 2007;5(3):175-186. doi:10.1038/nrmicro1614

154. D'Costa VM, McGrann KM, Hughes DW, Wright GD. Sampling the antibiotic resistome. Science (New York, NY). Jan 20 2006;311(5759):374-7. doi:10.1126/science.1120800

155. Dantas G, Sommer MO, Oluwasegun RD, Church GM. Bacteria subsisting on antibiotics. Science (New York, NY). Apr 4 2008;320(5872):100-3. doi:10.1126/science.1155157

156. Zhang XX, Zhang T, Fang HH. Antibiotic resistance genes in water environment. Applied microbiology and biotechnology. Mar 2009;82(3):397-414. doi:10.1007/s00253-008-1829-z

157. Hatosy SM, Martiny AC. The Ocean as a Global Reservoir of Antibiotic Resistance Genes. Applied and Environmental Microbiology. 2015;81(21):7593-7599.

doi:10.1128/aem.00736-15

158. Gibbs SG, Green CF, Tarwater PM, Mota LC, Mena KD, Scarpino PV. Isolation of antibiotic-resistant bacteria from the air plume downwind of a swine confined or concentrated animal feeding operation. Environmental health perspectives. Jul 2006;114(7):1032-7. doi:10.1289/ehp.8910

159. Zhu Y-G, Johnson TA, Su J-Q, et al. Diverse and abundant antibiotic resistance genes in Chinese swine farms. Proceedings of the National Academy of Sciences. 2013;110(9):3435. doi:10.1073/pnas.1222743110

160. Xiao L, Estellé J, Kiilerich P, et al. A reference gene catalogue of the pig gut microbiome. Nature Microbiology. 2016/09/19 2016;1(12):16161. doi:10.1038/nmicrobiol.2016.161

161. Noyes NR, Yang X, Linke LM, et al. Characterization of the resistome in manure, soil and wastewater from dairy and beef production systems. Scientific reports. Apr 20 2016;6:24645. doi:10.1038/srep24645

162. Sánchez-Salazar E, Gudiño ME, Sevillano G, et al. Antibiotic resistance of Salmonella strains from layer poultry farms in central Ecuador. Journal of Applied Microbiology. 2020;128(5):1347-1354. doi:https://doi.org/10.1111/jam.14562

163. Boamah VE, Agyare C, Odoi H, Adu F, Gbedema SY, Dalsgaard A. Prevalence and antibiotic resistance of coagulase-negative Staphylococci isolated from poultry farms in three regions of Ghana. Infect Drug Resist. 2017;10:175-183. doi:10.2147/IDR.S136349

164. Blau K, Bettermann A, Jechalke S, et al. The Transferable Resistome of Produce. mBio. 2018;9(6):e01300-18. doi:10.1128/mBio.01300-18 
165. Wood JL, Chen JC, Friesen E, Delaquis P, Allen KJ. Microbiological Survey of Locally Grown Lettuce Sold at Farmers' Markets in Vancouver, British Columbia. Journal of Food Protection. 2015;78(1):203-208. doi:10.4315/0362-028X.JFP-14-199

166. Mulvey MR, Mataseje LF, Robertson J, et al. Dissemination of the mcr-1 colistin resistance gene. The Lancet Infectious diseases. Mar 2016;16(3):289-90. doi:10.1016/s14733099(16)00067-0 


\section{Chapter 2}




\section{Chapter 2. Comparison of the Efficacy of Electrostatic versus Conventional Sprayer with Commercial Antimicrobials To Inactivate Salmonella, Listeria monocytogenes, and Campylobacter jejuni for Eggs and Economic Feasibility Analysis}

\subsection{Abstract}

\section{Objective}

To compare the efficacy of antimicrobials be sprayed by electrostatic versus conventional sprayer for inactivation of Salmonella, Listeria monocytogenes, and Campylobacter jejuni on eggs and to determine the economic feasibility of these treatments.

\section{Methods}

Eggs were dip inoculated with overnight cultures (18 h) of Salmonella Typhimurium, Salmonella Tennessee, a two-strain mixture of L. monocytogenes, and a three-strain mixture of $C$. jejuni (microaerophilic condition). Inoculated eggs were then not sprayed or subjected to electrostatic and conventional spraying with peroxyacetic acid (PAA; 0.1\%), lactic acid (5.0\%), lactic and citric acid blend (2.5\%), sodium hypochlorite (SH; $50 \mathrm{ppm})$, and SaniDate-5.0 (SD [a mixture of PAA and $\mathrm{H} 2 \mathrm{O} 2$ ]; $0.25 \%$ ) for $30 \mathrm{~s}$ (15 s each side). Surviving bacteria on eggshells were recovered on xylose lysine Tergitol 4 agar (Salmonella), modified Oxford agar ( $L$. monocytogenes), or Brucella agar (C. jejuni).

\section{Results}

Compared with conventional spraying, electrostatic spraying of PAA, SD, and SH achieved significant additional reductions $(\mathrm{P}<0.05)$ of Salmonella, L. monocytogenes, and C. jejuni of 0.96 to $3.18,1.19$ to 3.05 , and 0.96 to $1.62 \log$ CFU per egg, respectively. A simple cost comparison suggests that regardless of the antimicrobial agent used, the cost of using an electrostatic sprayer is 20 to $40 \%$ lower than that of a conventional sprayer for a small poultry 
farm that produces 1,500 eggs per day. Among the five antimicrobials, the total sanitizing cost was lowest for SH, followed by PAA and SD.

\section{Conclusions}

The results indicated that electrostatic spraying of commercial antimicrobials can be considered an effective and economical approach to enhancing the microbial safety of eggs, especially for small poultry processors.

\subsection{Introduction}

According to the American Egg Board ${ }^{1}, 7.67$ billion table eggs were produced in the United States in October 2017, and as of 1 February 2018, 320 million layers were producing table eggs. With an annual consumption of approximately 275 eggs per person in $2017^{1}$, eggs are considered a major part of the American diet. The universal acceptance of eggs as an economic and nutritious protein source makes their microbial safety a critical issue from the public health perspective ${ }^{2}$. A primary microbial safety concern in the egg industry is Salmonella contamination, which was associated with 11.6 to $29.0 \%$ of foodborne illness outbreaks in the United States between 1998 and 2008 . On 16 April 2018, 35 people in nine states were affected in a Salmonella infection outbreak that led to a recall of nearly 207 million eggs from megaproducer Rose Acre Farms ${ }^{4}$. According to the U.S. Food and Drug Administration, the egg contamination was most likely associated with a rodent issue and improper cleaning and sanitizing practices ${ }^{4}$. Because listeriosis cases are sporadic and often isolated, Listeria is not often considered epidemiologically important during poultry rearing. However, live birds can be an important vehicle of transmission for Listeria spp., and Listeria monocytogenes has been isolated from poultry farms ${ }^{5}$. Campylobacter jejuni has been detected in unwashed eggs entering an egg processing facility ${ }^{6}$. Although no outbreaks of $C$. jejuni infection associated with eggs has 
been reported in the United States, C. jejuni is still considered a major foodborne pathogen on eggs, according to the Egg Safety Center ${ }^{7}$. To minimize the potential of contamination from eggshells, the U.S. Department of Agriculture requires that all commercial eggs be washed and sanitized before reaching consumers. The sanitizing process typically includes four steps: wetting, washing, rinsing, and drying ${ }^{8}$. Eggs are wetted using a light spray of warm water to moisten and remove debris, washed in an alkaline detergent solution $\left(\mathrm{pH} 10\right.$ to $\left.11,32^{\circ} \mathrm{C}\right)$ with rotating brushes, rinsed with sanitizer (100 to $200 \mathrm{ppm}$ of chlorinated water), and dried in jet dryers ${ }^{8}$. Commercial antimicrobials, including sodium hypochlorite (SH), lactic acid (LA), peroxyacetic acid (PAA), and hydrogen peroxide $\left(\mathrm{H}_{2} \mathrm{O}_{2}\right)$, have been evaluated at various concentrations and temperatures in the washing process for reducing foodborne pathogens on eggshells ${ }^{8-10}$. Currently, egg companies use fogging systems with sanitizers (i.e., glutaraldehyde or formaldehyde gas) to disinfect foodborne pathogens in the hatchery environment. However, almost all commercial antimicrobial chemicals applied in the fogging system rely on a large amount of water to deliver and distribute the antimicrobial agent. These systems limit the ability of egg hatchery processors to effectively apply antimicrobials because of high operating costs, negative effects on egg quality, and exposure of employees to high concentrations of hazardous chemicals ${ }^{11}$. Therefore, there is a growing interest in developing and applying new intervention technologies that overcome these drawbacks while maintaining adequate pathogen reduction ${ }^{12}$. Electrostatic spraying technology has emerged in the past 15 to 20 years. It works by coulombic attraction of negatively charged fluid droplets onto a positively charged surface, thus generating an evenly coated surface with improved fluid retention and minimal exposure time ${ }^{13}$. In a previous study, electrostatic spraying of organic acids and grape seed extracts on spinach resulted in a 3- to 4-log reduction of Salmonella Typhimurium ${ }^{14}$. Russel $1{ }^{15}$ found that 
electrostatic spraying of acidified electrolyzed water was effective for controlling Salmonella, Staphylococcus, and L. monocytogenes on eggs. More studies are needed to evaluate the efficacy of antimicrobials when applied electrostatically for inactivating foodborne pathogens on food products. The economic feasibility of electrostatic spraying also must be taken into account because the cost of an electrostatic sprayer is much higher than that of conventional garden sprayers. A cost-benefit analysis can provide direct and early identification of major economic factors that affect the adoption of electrostatic sprayers by poultry processors.

The objectives of this study were (i) to compare the efficacy of commercial antimicrobials distributed by electrostatic versus conventional sprayers for inactivating Salmonella, $L$. monocytogenes, and C. jejuni on eggshells and (ii) to evaluate the economic feasibility for egg producers of using electrostatic sprayers versus conventional sprayers.

\subsection{Materials and Methods}

\subsubsection{Bacterial inoculum preparation}

Salmonella Typhimurium ATCC 14028, Salmonella Tennessee ATCC 10722, L. monocytogenes L2624 and L2625 (cantaloupe outbreak, serotype 1/2b; Joshua Gurtler, U.S. Department of Agriculture [USDA], Agricultural Research Service [ARS], Wyndmoor, PA), and C. jejuni RM5032, RM1188, and RM1464 (Nereus Gunther, USDA, ARS, Wyndmoor, PA) were used in this study. Each individual Salmonella and L. monocytogenes strain was maintained on xylose lysine Tergitol 4 agar (XLT4; Hardy Diagnostics, Santa Maria, CA) and modified Oxford agar (MOX; Hardy Diagnostics), respectively, at $48^{\circ} \mathrm{C}$. To prepare the inoculum, single colonies of each Salmonella and L. monocytogenes strain were inoculated individually into $10 \mathrm{~mL}$ of tryptic soy broth (Hardy Diagnostics) and incubated at $35^{\circ} \mathrm{C}$ for $24 \mathrm{~h}$. Before the experiment, the two 
Salmonella and two L. monocytogenes cultures were combined, harvested by centrifugation $(5,000 \times g, 15$ min; Symphony 4417, VWR International, Radnor, PA), washed twice with $0.1 \%$ buffered peptone water (BPW) to remove the residual media, centrifuged, and resuspended in $0.1 \% \mathrm{BPW}$. The bacterial population of the final inoculum suspension was $\sim 8.0 \log \mathrm{CFU} / \mathrm{mL}$ for Salmonella and L. monocytogenes based on the spread plating results of the inoculum on XLT4 (Salmonella) and MOX (L. monocytogenes).

For C. jejuni, each individual strain was maintained on Brucella agar (Hardy Diagnostics) at $48^{\circ} \mathrm{C}$ under microaerophilic conditions with a gas generator $\left(5.0 \% \mathrm{O}_{2}, 10 \% \mathrm{CO}_{2}\right.$, and $85 \% \mathrm{~N}_{2}$; Hardy Diagnostics) in a 2.5-L microaerophilic jar (Hardy Diagnostics). The Campy latex agglutination test kit (Hardy Diagnostics) was used to verify the colonies with agglutinated clumping on the Brucella agar. Two colonies of each C. jejuni strain were picked, inoculated into $10 \mathrm{~mL}$ of Bolton's broth (Hardy Diagnostics), and incubated for $48 \mathrm{~h}$ at $42^{\circ} \mathrm{C}$ under in the microaerophilic jar. The three strains were then combined, centrifuged at 5,000 $3 \mathrm{~g}$ for $15 \mathrm{~min}$, washed twice in $0.1 \% \mathrm{BPW}$, centrifuged again, and resuspended in $0.1 \% \mathrm{BPW}$. The final inoculum level of the three-strain combination was $7.5 \log \mathrm{CFU} / \mathrm{mL}$ according to the spread plating results on Brucella agar.

\subsubsection{Egg collection and inoculation}

Fresh eggs (12 per pack) were purchased from a local Kroger supermarket (Morgantown, WV). Three eggs from each replicate of the experiment were selected to detect the natural presence of

Salmonella and Campylobacter spp. based on the methods described by Li et al. ${ }^{16}$. No pathogens were detected in these eggs. A worst-case scenario immersion method was applied by dipping six eggs into $500 \mathrm{~mL}$ of $0.1 \% \mathrm{BPW}$ containing the mixed culture of Salmonella and $L$.

monocytogenes and the three-strain mixture of $C$. jejuni. Each batch of eggs was immersed for 
$30 \mathrm{~min}$ and then drained on foil paper under the hood for $30 \mathrm{~min}$ at room temperature $\left(22.5^{\circ} \mathrm{C}\right)$ to allow the attachment of pathogens before applying spray treatments. The final target inoculation level of the microorganism on eggs was $\sim 4.5$ to $5.5 \log$ CFU per egg.

\subsubsection{Electrostatic and conventional spraying of antimicrobials on eggs}

Six inoculated eggs were put into an egg pack and left untreated (control; eggs dipped in a solution of bacterial culture but not sprayed). Other batches of six inoculated eggs were sprayed with one of the five antimicrobials with either a conventional garden sprayer (1-gal [3.8-L] plastic tank sprayer, Chapin, Batavia, NY) or a portable electrostatic sprayer (BP2, Electrostatic Spraying Systems, Watkinsville, GA) for $30 \mathrm{~s}$ (15 s each side) and drained for 15 min under a biosafety hood. The flow rates were $0.97 \mathrm{~mL} / \mathrm{s}$ for the electrostatic sprayer and $7.23 \mathrm{~mL} / \mathrm{s}$ for the conventional sprayer. The distance of the sprayer nozzle to eggshells was kept at $25 \mathrm{~cm}$ with a $45^{\circ}$ angle.

The five test antimicrobials were prepared in $200 \mathrm{~mL}$ of distilled water: PAA $(0.1 \%, \mathrm{pH} 3.0$, $15.7^{\circ} \mathrm{C}$; Birko, Henderson, $\left.\mathrm{CO}\right), \mathrm{LA}\left(5 \%, \mathrm{pH} 2.0,15.3^{\circ} \mathrm{C}\right.$; Birko), LA and citric acid blend (LCA; $2.5 \%, \mathrm{pH} 2.7,15.2^{\circ} \mathrm{C}$; Chicxide, Birko), $\mathrm{SH}\left(50 \mathrm{ppm}, \mathrm{pH} 9.1,14.4^{\circ} \mathrm{C}\right.$; Birko), and SaniDate-5.0 (SD [a mixture of 5.3\% PAA and 23\% $\mathrm{H}_{2} \mathrm{O}_{2}$ ]; 0.25\%, pH 7.25, $15.2^{\circ} \mathrm{C}$; Arbico Organics, Tucson, AZ). The concentrations of all antimicrobials except SD were the highest allowed by the USDA Food Safety and Inspection Service directive $7120.7^{17}$ and were tested in our previous study ${ }^{18}$. The concentration of each test antimicrobial agent was calculated according to the supplier's fact sheet.

\subsubsection{Microbiological analysis}

The eggs were cracked by hand with gloves, and the contents were removed. The eggshells and membranes were then placed into $50 \mathrm{~mL}$ of Bolton's broth supplemented with $0.1 \%$ sodium 
thiosulfate (Fisher Scientific, Springfield, NJ) and gently rubbed by hand for $5 \mathrm{~min}$ in a sterile Whirl-Pak bag (Nasco, Fort Atkinson, WI). The rinse solution of eggs was spread plated onto three different agar media. XLT4 was used for Salmonella, and MOX was used for $L$.

monocytogenes, and both types of plates were incubated at $35^{\circ} \mathrm{C}$ for $48 \mathrm{~h}$. Brucella agar was used for C. jejuni, and plates were incubated in microaerophilic jars for $48 \mathrm{~h}$. All colonies on agar plates were manually counted, and colony counts were transformed to log CFU per milliliter of rinse solution.

\subsubsection{Data analysis}

Studies were repeated twice with 6 eggs per treatment per repeat, resulting in a total of 12 eggs per treatment. Experiments were conducted with a $2 \times 5$ factorial design with electrostatic versus conventional sprayers (two factors) and five antimicrobials for Salmonella, L. monocytogenes, and C. jejuni. The mixed model procedure of SAS (version 9.2, SAS Institute, Cary, NC) was used to analyze the survival and reduction of each individual pathogen with the two spraying methods and five antimicrobial treatments and their interactions. The reductions in bacterial levels were calculated as $\log \left(\mathrm{N}_{0} / \mathrm{N}\right)$, where $\mathrm{N}_{0}$ is the mean plate count of the control treatment and $\mathrm{N}$ is the plate count of each individual sprayed sample ${ }^{19}$. The means were compared with a significance level of $\alpha=0.05$, as determined by the Tukey honestly significant difference test.

\subsubsection{Economic feasibility analysis}

To assess the economic feasibility of the electrostatic versus the conventional sprayers, we calculate the operating cost of both sprayers, according to the following assumptions: (i) each electrostatic sprayer costs $\$ 3,000$, and each conventional sprayer costs $\$ 60$; (ii) the rechargeable battery of an electrostatic sprayer can last for 2,500 cycles; (iii) the electrostatic sprayer has a life span of six years; (iv) the conventional sprayer can last for 2,000 refills; (v) the maintenance cost 
of the electrostatic sprayer is $\$ 100$ per year; (vi) the flow rates of the electrostatic and conventional sprayer are 0.97 and $7.23 \mathrm{ml} / \mathrm{s}$, respectively; (vii) each dozen of eggs will be sprayed for $30 \mathrm{~s}$ ( $15 \mathrm{~s}$ for each side); (viii) labor cost is $\$ 8 /$ hour; (ix) water cost, including sewage, is $\$ 10$ per 1000 gallons.

Assumptions are also needed for the price of the antimicrobials. Table 1 lists the price for each type of antimicrobial used in the calculation and the amount of each required to generate the concentration level for $200 \mathrm{ml}$ water as described in the spraying test, as well as the total cost per gallon of mixed chemical solution. The per-gallon cost of the antimicrobial solution ranges from $\$ 0.03$ for SH to $\$ 1.14$ for LA. Based on the flow rates, each gallon of the antimicrobial solution can be applied on 125 and 16 sets of eggs using an electrostatic and conventional sprayer, respectively. To simplify the analysis, we assume the costs of implementing the other three steps in the U.S. commercial egg sanitizing process, i.e., wetting, rinsing, and drying, are the same for electrostatic and conventional sprayers. These costs were not considered in the present analysis. We then compute the annual operating cost for a small poultry farm that produces 1,500 eggs per day using the conventional and electrostatic sprayer, respectively.

\subsection{Results and Discussion}

\subsubsection{Comparison of electrostatic versus conventional sprayer}

The antimicrobial efficacy of using an electrostatic sprayer to deliver various antimicrobial agents (acids and surfactants) has been reported for leafy greens, cantaloupes, raw meat, and eggshells ${ }^{14,15,20-22}$. Although electrostatic sprayers have been assumed to be more efficient than conventional sprayers, few studies have been conducted to compare the effectiveness of electrostatic versus conventional sprayers for delivering antimicrobials to control foodborne 
pathogens on poultry products. In the present study, the initial populations of Salmonella, $L$. monocytogenes, and C. jejuni recovered from eggs were 5.52 to $5.64,5.81$ to 6.40 , and 4.24 to $4.81 \log$ CFU per egg, respectively (Tables 2 through 4). According to the mixed model procedure, for Salmonella and L. monocytogenes the antimicrobial efficacy was based on the spraying method $(\mathrm{P}<0.05)$, the type of antimicrobial agent $(\mathrm{P}<0.05)$, and their interactions $(\mathrm{P}<$ 0.05). For C. jejuni, the significance of the spraying method was borderline $(\mathrm{P}=0.05)$, and the type of antimicrobial agent and the interaction of the agent with the spraying method were not significant $(\mathrm{P}>0.05)$. Overall, the least squares means across the five tested antimicrobials suggest that electrostatic spraying is more effective $(\mathrm{P}<0.05)$ than conventional spraying for reducing Salmonella (2.24 versus $0.88 \log$ CFU per egg), L. monocytogenes (2.53 versus 1.11 $\log$ CFU per egg), and C. jejuni (1.61 versus $0.66 \log$ CFU per egg) on eggs. Russel122 reported that electrostatic spraying of the antimicrobial chemicals BioSentry 904 and BioxH eliminated Salmonella Enteritidis on 60 to $100 \%$ of eggs, Staphylococcus aureus on 87 to $100 \%$ of eggs, $L$. monocytogenes on $100 \%$ of eggs, and Escherichia coli on $93 \%$ of eggs. Compared with conventional sprayers, whose use often results in poor retention of larger droplets, surface runoff, and uneven distribution of tested antimicrobial solutions, the electrostatic spraying technique ensures a more uniform spread and greater retention of small antimicrobial droplets and ensures that eggshell surfaces are fully covered with the antimicrobial agents ${ }^{14}$.

\subsubsection{Efficacy of antimicrobial treatments}

Antimicrobials sprayed conventionally onto eggs significantly reduced the Salmonella population (survival of 4.37 to $5.00 \log$ CFU per egg) compared with the untreated control (5.52 $\log \mathrm{CFU}$ per egg), with the reduction ranging from 0.52 (SH) to 1.15 (PAA) $\log \mathrm{CFU}$ per egg (Table 2). Compared with the conventional sprayer, PAA, SD, and SH sprayed electrostatically 
achieved a significant additional reduction $(\mathrm{P}<0.05)$ of Salmonella by $3.18,1.58$, and $0.96 \log$ CFU per egg, respectively. However, no significant difference $(\mathrm{P}>0.05)$ was found for reductions in LA and LCA samples. The efficacy of commercial antimicrobials for inactivating Salmonella on eggshells has been well documented in previous studies. Padron ${ }^{23}$ found that double dipping in $6 \% \mathrm{H}_{2} \mathrm{O}_{2}$ reduced the number of eggs positive for Salmonella Typhimurium by $55 \%$. Musgrove et al. ${ }^{10}$ found that compared with water-treated broiler hatching eggs, spraying with $1.5 \% \mathrm{H}_{2} \mathrm{O}_{2}$ reduced the prevalence of Salmonella recovered from these eggs from 100 to 10\%. AlAjeeli et al. ${ }^{9}$ reported that spraying chlorine (100 ppm), PAA (135 ppm), and $\mathrm{H}_{2} \mathrm{O}_{2}$ combined with UV light with a prototype egg treatment device reduced Salmonella Enteritidis to below the detection limit (200 CFU per egg). Hudson et al. (14) found that washing dropletinoculated Salmonella on eggs in 200 ppm of chlorine with a surfactant (T-128) reduced Salmonella Enteritidis and Salmonella Typhimurium by approximately $5.0 \log$ CFU/mL. Similar to the results for Salmonella, conventional spraying with antimicrobials significantly reduced $L$. monocytogenes $(\mathrm{P}<0.05)$ on eggs, with surviving populations of 4.50 to $5.11 \log \mathrm{CFU}$ per egg compared with $5.81 \log$ CFU per egg for the unsprayed control (Table 3). No significant difference $(\mathrm{P}>0.05)$ was found among the reductions ( 0.70 to 1.31 log CFU per egg) resulting from treatment with the various antimicrobials. Electrostatic spraying significantly increased ( $\mathrm{P}$ $<0.05$ ) the reduction levels from 1.25 to $4.30,0.70$ to 1.89 , and 1.20 to $3.17 \log$ CFU per egg for PAA, SH, and SD, respectively (Table 3). LA and LCA eggs sprayed with the electrostatic system had only slightly greater microbial reduction ( $\mathrm{P}>0.05)$, by 0.34 to $0.54 \log \mathrm{CFU}$ per egg, than did the same groups of eggs treated with conventional spraying (Table 3). The surviving populations of L. monocytogenes were 2.10 to $4.95 \log \mathrm{CFU}$ per egg after electrostatic spraying (Table 3). Because of the low infective dose ( $\sim .3$ to $100 \mathrm{CFU} / \mathrm{g}$ in food) of L. monocytogenes 
for pregnant women and immunocompromised individuals ${ }^{24}$, the level of this pathogen that survived on the treated eggs in this study is still a microbial safety concern. Multiple-hurdle approaches from hatchery to packaging and transportation should be developed to decrease the survival of L. monocytogenes on commercial eggs.

The efficacy of antimicrobials for controlling Campylobacter on eggs has not been validated in previous studies because of the very low prevalence of Campylobacter on eggs ${ }^{25-27}$. In the present study, significantly lower survival (3.36 to 3.77 log CFU per egg) was found on eggs treated with antimicrobials using conventional sprayers compared with the untreated control (4.24 log CFU per egg; Table 4). All five tested antimicrobials reduced the $C$. jejuni counts by 0.47 to $0.88 \log$ CFU per egg, with no difference between the antimicrobials (Table 4). Compared with the conventional sprayer, electrostatic spraying of PAA, SH, and SD increased the reduction $(\mathrm{P}<0.05)$ by $0.96,1.18$, and $1.62 \log \mathrm{CFU}$ per egg, respectively (Table 4). Again, no difference $(\mathrm{P}>0.05)$ was found for reduction in LA and LCA eggs for the two types of sprayers. Based on the results from the experiment, electrostatic spraying of antimicrobials was less effective against Campylobacter than it was against Salmonella or L. monocytogenes (Tables 2 through 4). Newell and Fearnley ${ }^{28}$ also reported that the management practices used in the commercial broiler processing line to control Salmonella often have little impact on Campylobacter because of the differences in the physiology and ecology between facultative pathogens (e.g., Salmonella and L. monocytogenes) and microaerophilic pathogens (e.g., Campylobacter). The microlayer of liquid solution that uniformly covered the egg surfaces after electrostatic spraying may create a microaerophilic environment that favors the survival of Campylobacter over that of Salmonella or L. monocytogenes. 
Overall, electrostatic spraying of antimicrobials significantly increased the reduction of Salmonella and L. monocytogenes; the antimicrobial efficacy was ranked as PAA $>\mathrm{SD}>\mathrm{SH}=$ $\mathrm{LA}=\mathrm{LCA}$. However, no difference was found for the reduction of $C$. jejuni among the five tested antimicrobials using the electrostatic sprayers. $\mathrm{SD}\left(23 \% \mathrm{H}_{2} \mathrm{O}_{2}\right.$ and $5.3 \%$ PAA $)$ has been recommended by the West Virginia Small Farm Center to treat poultry meat from small-scale poultry producers in West Virginia ${ }^{16}$. Brinez et al. ${ }^{29}$ reported that a mixture of PAA and $\mathrm{H}_{2} \mathrm{O}_{2}$ (0.1\%) decreased Staphylococcus, Listeria, and E. coli by $>5 \log$ CFU after 10 min of contact in the presence of organic matter. Results of the present study indicate a similar or greater reduction of Salmonella, L. monocytogenes, and C. jejuni by SD as compared with SH. Therefore, SD could be used by small-scale poultry processors as an alternative to SH to improve the microbial safety of eggs.

In this study, for all three pathogens, electrostatic spraying of PAA, SH, and SD resulted in greater reductions compared with conventional spraying. However, no significant difference was found for LA and LCA egg samples. The contrast in results might be explained by the differences in antimicrobial modes of action. PAA, SH, and SD oxidize bacterial cells, resulting in protein denaturation and cell wall disruption ${ }^{30,31}$. Thus, the more antimicrobial agent on the egg surface, the stronger the oxidation effect. The antimicrobial action of organic acids occurs with their undissociated forms, which easily enter into cells and lower the bacterial intracellular $\mathrm{pH}^{32}$. The ability of the organic acids LA and LCA to pass into the bacterial cell is mainly determined by the molecular weight and $\mathrm{pH}$ levels ${ }^{14}$. Therefore, better egg surface coverage from electrostatic spraying might not be enough to significantly increase LA and LCA penetration into bacterial cells.

\subsubsection{Cost comparison of electrostatic versus conventional sprayer}


Although electrostatic sprayers are more effective for decontaminating Salmonella and $L$. monocytogenes on eggs than are conventional sprayers, a major hurdle that may limit the adoption of electrostatic spraying is their high initial cost. Compared with conventional garden sprayers, which are inexpensive and easy to replace, electrostatic sprayers require a nontrivial initial investment and regular maintenance. However, electrostatic sprayers do have the advantage of using lower amounts of chemicals and water, generating less waste and resulting in lower chemical exposure for workers. Fewer worker hours are needed to operate electrostatic sprayers because they are more efficient and their bottles do not need to be refilled as often as those of conventional sprayers.

Table 5 provides the annual cost comparison for the two types of sprayers, assuming a small poultry farm that produces an average of 1,500 eggs per day following the assumptions discussed in the "Materials and Methods" section. The fixed costs were calculated based on the need for two conventional sprayers per year for sanitizing the eggs because of wear, although the combined cost of these two sprayers is still lower than the annualized cost of an electrostatic sprayer. No battery replacement is needed for the electrostatic sprayer because the total number of recharges needed are within the 2,500-cycle assumption for the 6-year window considered in the analysis. Because of the efficiency of electrostatic sprayers, their annual variable or operating costs are considerably lower than those of conventional sprayers. In particular, the cost of antimicrobials is $.85 \%$ lower for an electrostatic sprayer. Combined, the total cost of spraying antimicrobials on eggs, regardless of the type of antimicrobial used, was calculated as 20 to $40 \%$ lower when using an electrostatic sprayer. Among the five antimicrobials used to treat eggs, the total sanitizing cost was lowest with SH, followed by PAA and SD. The total annual operating cost was highest with LA. 


\subsection{Conclusions}

In this study, we compared the efficacy of antimicrobials sprayed by electrostatic versus conventional sprayers for inactivation of Salmonella, L. monocytogenes, and C. jejuni on eggs. We also evaluated the economic feasibility of the two spraying methods. Results from this study indicate that spraying eggs with an electrostatic sprayer and commercial antimicrobials, in particular PAA, SH, and SD, is an effective approach for controlling foodborne pathogens on egg surfaces, and this method of application is economically feasible. Future studies should be conducted in a pilot scale egg processing setting to mimic large industrial egg processing conditions. 
Tables and Figures 
Table 1. Cost of peroxyacetic acid (PAA), lactic acid (LA), LA and citric acid blend (LCA), sodium hypochlorite (SH), and SaniDate-5.0 (SD) and the cost of mixed solutions ${ }^{\alpha}$

\begin{tabular}{llllll}
\hline \multicolumn{1}{c}{ Comparator } & PAA & LA & LCA & SH & SD \\
\hline Price for 5 gal (18.9 L) $(\$)$ & 141.8 & 104.5 & 108.4 & 25.0 & 311.0 \\
& 0 & 0 & 0 & 0 & 0 \\
Required amt for 200 ml water $(\mathrm{mL})$ & 1.34 & 11.40 & 5.00 & 3.20 & 0.50 \\
Cost of mixed solution with 200 ml water & 0.01 & 0.06 & 0.03 & 0.00 & 0.18 \\
$(\$ / \mathrm{ml})$ & & & & & \\
Cost of mixed solution per gallon (3.8 L) $(\$)$ & 0.20 & 1.14 & 0.54 & 0.09 & 3.47 \\
\hline
\end{tabular}

${ }^{\alpha}$ Cost data obtained from Birko; cost for $5.7 \%$ chlorine was $\$ 5 /$ gal. Treatment conditions were $\quad$ PAA: $0.1 \%$, pH 3.0, $15.7^{\circ} \mathrm{C}$; LA: $5 \%$, pH 2.0, $15.3^{\circ} \mathrm{C}$; LCA: $2.5 \%$, pH $2.7,15.2^{\circ} \mathrm{C}$;

$\mathrm{SH}: 50 \mathrm{ppm}, \mathrm{pH} 9.1,14.4^{\circ} \mathrm{C}$; $\mathrm{SD}$ (a mixture of PAA and $\mathrm{H}_{2} \mathrm{O}_{2}$ ): $0.25 \%, \mathrm{pH} 7.25,15.2^{\circ} \mathrm{C}$. 
Table 2. Survival and reduction of Salmonella Typhimurium and Salmonella Tennessee on eggshells left untreated or treated by conventional and electrostatic spray of peroxyacetic acid (PAA), lactic acid (LA), LA and citric acid blend (LCA), sodium hypochlorite (SH), and SaniDate-5.0 (SD) for $30 \mathrm{~s}$ with draining for $15 \mathrm{~min}^{a}$

\begin{tabular}{llclcc}
\hline & \multicolumn{2}{c}{ Survival (log CFU/egg) } & & \multicolumn{2}{c}{ Reduction (log CFU/egg) } \\
\cline { 1 - 2 } \cline { 5 - 6 } Treatment $^{b}$ & Conventional & Electrostatic & & Conventional & Electrostatic \\
\cline { 1 - 2 } \cline { 5 - 6 } Control & $5.52 \pm 0.66 \mathrm{~A}$ & $5.64 \pm 0.95 \mathrm{~A}$ & & $\mathrm{NA}^{c}$ & $\mathrm{NA}$ \\
$\mathrm{PAA}$ & $4.37 \pm 0.83 \mathrm{C}$ & $1.31 \pm 1.45 \mathrm{D}$ & & $1.15 \pm 0.83 \mathrm{~A} \mathrm{a}$ & $4.33 \pm 1.45 \mathrm{~A} \mathrm{~b}$ \\
$\mathrm{LA}$ & $4.47 \pm 0.59 \mathrm{C}$ & $4.22 \pm 0.50 \mathrm{~B}$ & & $1.05 \pm 0.59 \mathrm{~A} \mathrm{a}$ & $1.42 \pm 0.50 \mathrm{~B} \mathrm{a}$ \\
$\mathrm{LCA}$ & $4.56 \pm 0.54 \mathrm{C}$ & $3.95 \pm 0.48 \mathrm{~B}$ & & $0.96 \pm 0.54 \mathrm{~A} \mathrm{a}$ & $1.69 \pm 0.48 \mathrm{~B} \mathrm{a}$ \\
$\mathrm{SH}$ & $5.00 \pm 0.80 \mathrm{~B}$ & $4.16 \pm 0.36 \mathrm{~B}$ & & $0.52 \pm 0.80 \mathrm{~B} \mathrm{a}$ & $1.48 \pm 0.36 \mathrm{~B} \mathrm{~b}$ \\
SD & $4.81 \pm 0.98 \mathrm{BC}$ & $3.35 \pm 0.76 \mathrm{C}$ & & $0.71 \pm 0.98 \mathrm{AB}$ a & $2.29 \pm 0.76 \mathrm{C} \mathrm{b}$ \\
\hline
\end{tabular}

${ }^{a}$ Within each column, mean values with different uppercase letters are significantly different $(\mathrm{P}<0.05)$. Within each row, mean values with different lowercase letters are significantly different $(\mathrm{P}<0.05)$.

${ }^{b}$ Treatment conditions were PAA: $0.1 \%$, pH 3.0, $15.7^{\circ} \mathrm{C}$; LA: $5 \%, \mathrm{pH} 2.0,15.38 \mathrm{C}$; LCA:

$2.5 \%, \mathrm{pH} 2.7,15.2^{\circ} \mathrm{C}$; $\mathrm{SH}: 50 \mathrm{ppm}, \mathrm{pH} 9.1,14.4^{\circ} \mathrm{C}$; $\mathrm{SD}$ (a mixture of PAA and $\mathrm{H}_{2} \mathrm{O}_{2}$ ):

$0.25 \%, \mathrm{pH} 7.25,15.2^{\circ} \mathrm{C}$.

${ }^{c} \mathrm{NA}$, reduction data not available. 
Table 3. Survival and reduction of Listeria monocytogenes on eggshells left untreated or treated by conventional and electrostatic spray of peroxyacetic acid (PAA), lactic acid (LA), LA and citric acid blend (LCA), sodium hypochlorite (SH), and SaniDate-5.0 (SD) for $30 \mathrm{~s}$ with draining for $15 \mathrm{~min}^{a}$

\begin{tabular}{|c|c|c|c|c|}
\hline \multicolumn{3}{|c|}{ Survival (log CFU/egg) } & \multicolumn{2}{|c|}{ Reduction (log CFU/egg) } \\
\hline Treatment $^{b}$ & Conventional & Electrostatic & Conventional & Electrostatic \\
\hline Control & $5.81 \pm 0.58 \mathrm{~A}$ & $6.40 \pm 0.61 \mathrm{~A}$ & $\mathrm{NA}^{c}$ & NA \\
\hline PAA & $4.56 \pm 1.12 \mathrm{C}$ & $2.10 \pm 1.49 \mathrm{D}$ & $1.25 \pm 1.12 \mathrm{~A} \mathrm{a}$ & $4.30 \pm 1.49 \mathrm{~A} \mathrm{~b}$ \\
\hline LA & $4.50 \pm 0.50 \mathrm{C}$ & $4.55 \pm 0.28 \mathrm{~B}$ & $1.31 \pm 0.50 \mathrm{~A} \mathrm{a}$ & $1.85 \pm 0.28 \mathrm{~B} \mathrm{a}$ \\
\hline LCA & $4.70 \pm 0.53 \mathrm{C}$ & $4.95 \pm 0.55 \mathrm{~B}$ & $1.11 \pm 0.53 \mathrm{AB}$ a & $1.45 \pm 0.55 \mathrm{~B} \mathrm{a}$ \\
\hline $\mathrm{SH}$ & $5.11 \pm 0.79 \mathrm{~B}$ & $4.51 \pm 0.45 \mathrm{~B}$ & $0.70 \pm 0.79 \mathrm{~B} \mathrm{a}$ & $1.89 \pm 0.45 \mathrm{~B} \mathrm{~b}$ \\
\hline SD & $4.61 \pm 0.89 \mathrm{C}$ & $3.23 \pm 1.32 \mathrm{C}$ & $1.20 \pm 0.89 \mathrm{~A} \mathrm{a}$ & $3.17 \pm 1.32 \mathrm{C} \mathrm{b}$ \\
\hline
\end{tabular}

${ }^{a}$ Within each column, mean values with different uppercase letters are significantly different $(\mathrm{P}<0.05)$. Within each row, mean values with different lowercase letters are significantly different $(\mathrm{P}<0.05)$.

${ }^{b}$ Treatment conditions were PAA: $0.1 \%$, pH 3.0, $15.7^{\circ} \mathrm{C}$; LA: $5 \%, \mathrm{pH} 2.0,15.38 \mathrm{C}$; LCA: $2.5 \%, \mathrm{pH} 2.7,15.2^{\circ} \mathrm{C}$; $\mathrm{SH}: 50 \mathrm{ppm}, \mathrm{pH} 9.1,14.4^{\circ} \mathrm{C}$; $\mathrm{SD}$ (a mixture of PAA and $\mathrm{H}_{2} \mathrm{O}_{2}$ ): $0.25 \%, \mathrm{pH} 7.25,15.2^{\circ} \mathrm{C}$.

${ }^{c} \mathrm{NA}$, reduction data not available. 
Table 4. Survival and reduction of Campylobacter jejuni on eggshells left untreated or treated by conventional and electrostatic spray of peroxyacetic acid (PAA), lactic acid (LA), LA and citric acid blend (LCA), sodium hypochlorite (SH), and SaniDate-5.0 (SD) for $30 \mathrm{~s}$ with draining for $15 \mathrm{~min}^{a}$

\begin{tabular}{|c|c|c|c|c|}
\hline & \multicolumn{2}{|c|}{ Survival (log CFU/egg) } & \multicolumn{2}{|c|}{ Reduction (log CFU/egg) } \\
\hline Treatment $^{b}$ & Conventional & Electrostatic & Conventional & Electrostatic \\
\hline Control & $4.24 \pm 0.61 \mathrm{~A}$ & $4.81 \pm 0.33 \mathrm{~A}$ & $\mathrm{NA}^{c}$ & NA \\
\hline PAA & $3.36 \pm 0.60 \mathrm{~B}$ & $2.97 \pm 0.47 \mathrm{C}$ & $0.88 \pm 0.60 \mathrm{~A} \mathrm{a}$ & $1.84 \pm 0.47 \mathrm{~A} \mathrm{~b}$ \\
\hline LA & $3.77 \pm 0.82 \mathrm{~B}$ & $4.00 \pm 1.62 \mathrm{~B}$ & $0.47 \pm 0.82 \mathrm{~A} \mathrm{a}$ & $0.81 \pm 1.62 \mathrm{~A} \mathrm{a}$ \\
\hline LCA & $3.57 \pm 1.45 \mathrm{~B}$ & $3.51 \pm 0.56 \mathrm{~B}$ & $0.67 \pm 1.45 \mathrm{~A} \mathrm{a}$ & $1.30 \pm 0.56 \mathrm{~A} \mathrm{a}$ \\
\hline $\mathrm{SH}$ & $3.50 \pm 0.58 \mathrm{~B}$ & $2.89 \pm 0.52 \mathrm{C}$ & $0.74 \pm 0.58 \mathrm{~A} \mathrm{a}$ & $1.92 \pm 0.52 \mathrm{Ab}$ \\
\hline SD & $3.69 \pm 1.48 \mathrm{~B}$ & $2.64 \pm 1.76 \mathrm{C}$ & $0.55 \pm 1.48 \mathrm{~A} \mathrm{a}$ & $2.17 \pm 1.76 \mathrm{~A} \mathrm{~b}$ \\
\hline
\end{tabular}

${ }^{a}$ Within each column, mean values with different uppercase letters are significantly different $(\mathrm{P}<0.05)$. Within each row, mean values with different lowercase letters are significantly different $(\mathrm{P}<0.05)$.

${ }^{b}$ Treatment conditions were PAA: $0.1 \%$, pH 3.0, $15.7^{\circ} \mathrm{C}$; LA: $5 \%$, pH 2.0, $15.38 \mathrm{C}$; LCA:

$2.5 \%, \mathrm{pH} 2.7,15.2^{\circ} \mathrm{C}$; $\mathrm{SH}: 50 \mathrm{ppm}, \mathrm{pH} 9.1,14.4^{\circ} \mathrm{C}$; $\mathrm{SD}$ (a mixture of PAA and $\mathrm{H}_{2} \mathrm{O}_{2}$ ): $0.25 \%, \mathrm{pH} 7.25,15.2^{\circ} \mathrm{C}$.

${ }^{c} \mathrm{NA}$, reduction data not available. 
Table 5. Annual cost comparison of conventional versus electrostatic sprayer using peroxyacetic acid (PAA), lactic acid (LA), lactic and citric acid blend (LCA), sodium hypochlorite $(\mathrm{SH})$, SaniDate ${ }^{\circledR}-5.0\left(\mathrm{SD}\right.$, a mixture of PAA and $\left.\mathrm{H}_{2} \mathrm{O}_{2}\right)$ for a poultry farm producing 1,500 eggs per day

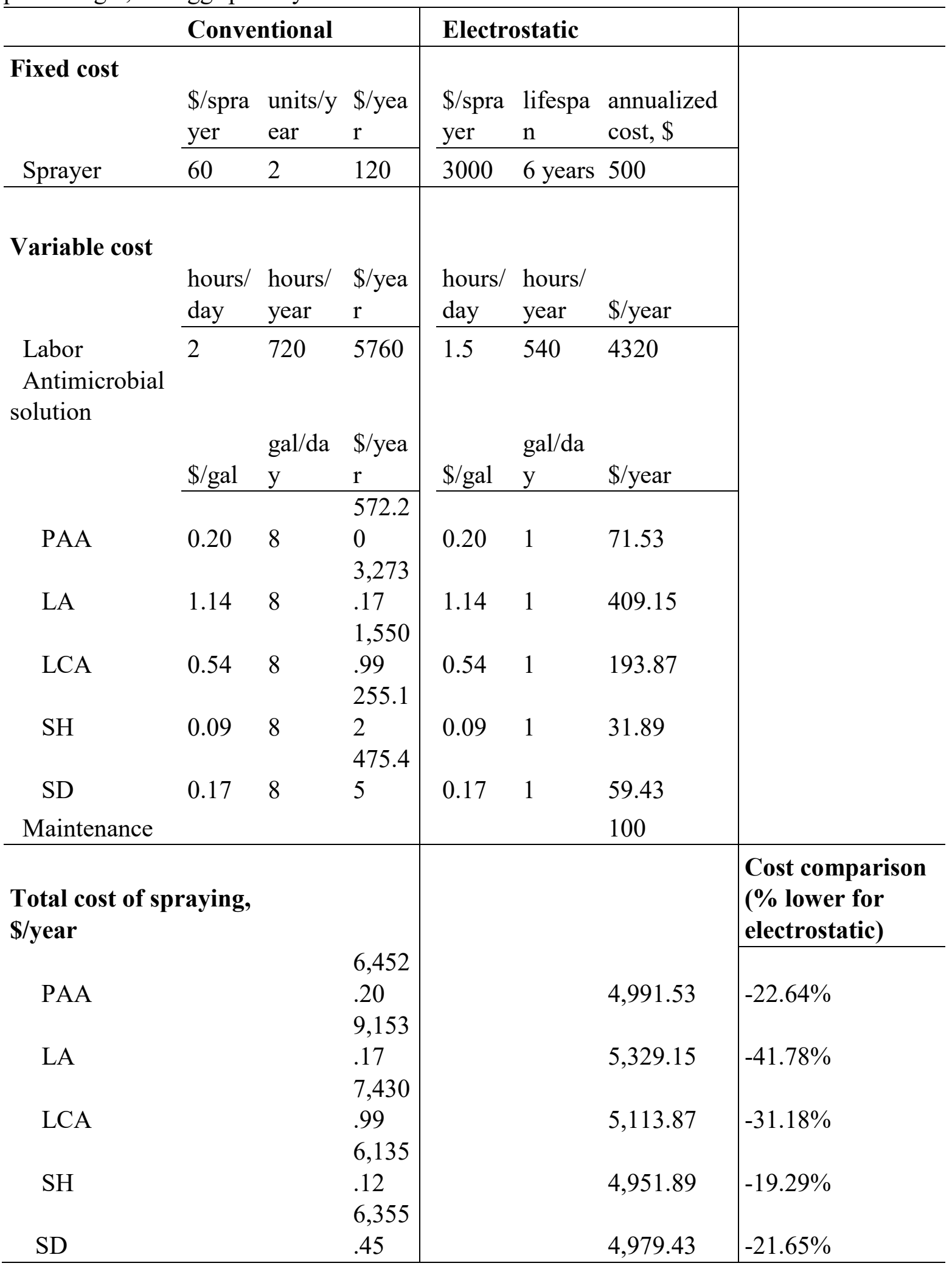




\section{References}

1. About the U.S. egg industry. American Egg Board. Accessed May 16th, 2018. https://www.aeb.org/farmers-and-marketers/industry-overview

2. Howard ZR, O'Bryan CA, Crandall PG, Ricke SC. Salmonella Enteritidis in shell eggs: Current issues and prospects for control. Food Research International. 2012/03/01/ 2012;45(2):755-764. doi:https://doi.org/10.1016/j.foodres.2011.04.030

3. Painter JA, Hoekstra RM, Ayers T, et al. Attribution of foodborne illnesses, hospitalizations, and deaths to food commodities by using outbreak data, United States, 19982008. Emerg Infect Dis. Mar 2013;19(3):407-15. doi:10.3201/eid1903.111866

4. Multistate outbreak of Salmonella Braenderup infections linked to Rose Acre Farms shell eggs. Centers for Disease Control and Prevention (CDC). Accessed May 16th, 2018. https://www.cdc.gov/salmonella/Braenderup-04-18/index.html.

5. Rothrock MJ, Jr., Davis ML, Locatelli A, et al. Listeria Occurrence in Poultry Flocks: Detection and Potential Implications. Frontiers in veterinary science. 2017;4:125. doi:10.3389/fvets.2017.00125

6. Jones DR, Anderson KE, Guard JY. Prevalence of coliforms, Salmonella, Listeria, and Campylobacter associated with eggs and the environment of conventional cage and free-range egg production. Poult Sci. May 2012;91(5):1195-202. doi:10.3382/ps.2011-01795

7. Pathogens. Egg Safety Center. Accessed May 16th, 2018. https://eggsafety.org/pathogens/

8. Hudson LK, Harrison MA, Berrang ME, Jones DR. Alternative Antimicrobial Commercial Egg Washing Procedures. J Food Prot. Jul 2016;79(7):1216-20. doi:10.4315/0362-028x.Jfp-15-423

9. Al-Ajeeli MN, Taylor TM, Alvarado CZ, Coufal CD. Comparison of eggshell surface sanitization technologies and impacts on consumer acceptability. Poult Sci. May 2016;95(5):1191-7. doi:10.3382/ps/pew014

10. Musgrove MT, Cox NA, Berrang ME, Buhr RJ, Richardson LJ, Mauldin JM. Effect of inoculation and application methods on the performance of chemicals used to disinfect Salmonella-contaminated broiler hatching eggs. Journal of Applied Poultry Research. 2010/12/01/ 2010;19(4):387-392. doi:https://doi.org/10.3382/japr.2009-00105

11. Russell SM. Controlling Salmonella in poultry production and processing. CRC Press; 2012:310.

12. Stella JM, Luchansky JB, Miller K, et al. Use of an Electrostatic Spraying System or the Sprayed Lethality in Container Method To Deliver Antimicrobial Agents onto the Surface of Beef Subprimals To Control Shiga Toxin-Producing Escherichia coli. J Food Prot. Aug 2017;80(8):1393-1400. doi:10.4315/0362-028x.Jfp-16-406

13. Edward Law S. Agricultural electrostatic spray application: a review of significant research and development during the 20th century. Journal of Electrostatics. 2001/05/01/ 2001;51-52:25-42. doi:https://doi.org/10.1016/S0304-3886(01)00040-7

14. Ganesh V, Hettiarachchy NS, Ravichandran M, et al. Electrostatic sprays of food-grade acids and plant extracts are more effective than conventional sprays in decontaminating Salmonella Typhimurium on spinach. J Food Sci. Nov-Dec 2010;75(9):M574-9. doi:10.1111/j.1750-3841.2010.01859.x

15. Russell SM. The effect of electrolyzed oxidative water applied using electrostatic spraying on pathogenic and indicator bacteria on the surface of eggs. Poult Sci. Jan 2003;82(1):158-62. doi:10.1093/ps/82.1.158

16. Li K, Lemonakis L, Glover B, Moritz J, Shen C. Impact of Built-up-Litter and Commercial Antimicrobials on Salmonella and Campylobacter Contamination of Broiler 
Carcasses Processed at a Pilot Mobile Poultry-Processing Unit. Frontiers in veterinary science. 2017;4:88. doi:10.3389/fvets.2017.00088

17. Safe and Suitable Ingredients Used in the Production of Meat, Poultry, and Egg

Products. FSIS Directive 7120.1, Revision 39. United States Department of Agriculture-Food Safety and Inspection Service (USDA-FSIS).

https://www.fsis.usda.gov/wps/wcm/connect/bab10e09-aefa-483b-8be8-

809a1f051d4c/7120.1.pdf?MOD=AJPERES

18. Lemonakis L, Li K, Adler JM, Shen C. Microbiological quality assessment and validation of antimicrobials against unstressed or cold-stress adapted Salmonella and surrogate Enterococcus faecium on broiler carcasses and wings. Poult Sci. Sep 1 2017;96(11):4038-4045. doi:10.3382/ps/pex 195

19. Adler JM, Cain-Helfrich ED, Shen C. Reductions in Natural Microbial Flora, Nonpathogenic Escherichia coli , and Pathogenic Salmonella on Jalapeno Peppers Processed in a Commercial Antimicrobial Cabinet: A Pilot Plant Trial. J Food Prot. Nov 2016;79(11):1854-1859. doi:10.4315/0362-028x.Jfp-16-222

20. Almasoud A, Hettiarachchy N, Rayaprolu S, Horax R, Eswaranandam S. Electrostatic spraying of organic acids on biofilms formed by E. coli O157:H7 and Salmonella

Typhimurium on fresh produce. Food research international (Ottawa, Ont). Dec 2015;78:2733. doi:10.1016/j.foodres.2015.11.012

21. Massey LM, Hettiarachchy NS, Martin EM, Ricke SC. Electrostatic Spray of FoodGrade Organic Acids and Plant Extract to Reduce Escherichia coli O157:H7 on Fresh-Cut Cantaloupe Cubes. Journal of Food Safety. 2013;33(1):71-78.

doi:https://doi.org/10.1111/jfs.12024

22. Russell SM. Effect of Sanitizers Applied by Electrostatic Spraying on Pathogenic and Indicator Bacteria Attached to the Surface of Eggs. Journal of Applied Poultry Research. 2003/07/01/2003;12(2):183-189. doi:https://doi.org/10.1093/japr/12.2.183

23. Padron M. Egg dipping in hydrogen peroxide solution to eliminate Salmonella typhimurium from eggshell membranes. Avian diseases. Jul-Sep 1995;39(3):627-30.

24. Montville TJ, Matthews KR, Kniel KE. Food Microbiology: An Introduction. American Society of Microbiology Press; 2012.

25. Dipineto L, Gargiulo A, Russo TP, et al. Campylobacter jejuni, Campylobacter coli, and cytolethal distending toxin genes in laying hens. Avian diseases. Mar 2011;55(1):103-5. doi:10.1637/9525-091510-ResNote.1

26. Doyle MP. Association of Campylobacter jejuni with laying hens and eggs. Appl Environ Microbiol. Mar 1984;47(3):533-6. doi:10.1128/aem.47.3.533-536.1984

27. Sulonen J, Kärenlampi R, Holma U, Hänninen ML. Campylobacter in Finnish Organic Laying Hens in Autumn 2003 and Spring 2004. Poultry Science. 2007/06/01/ 2007;86(6):1223-1228. doi:https://doi.org/10.1093/ps/86.6.1223

28. Newell DG, Fearnley C. Sources of Campylobacter colonization in broiler chickens. Applied and environmental microbiology. 2003;69(8):4343-4351. doi:10.1128/aem.69.8.43434351.2003

29. Briñez WJ, Roig-Sagués AX, Hernández Herrero MM, López-Pedemonte T, Guamis B. Bactericidal efficacy of peracetic acid in combination with hydrogen peroxide against pathogenic and non pathogenic strains of Staphylococcus spp., Listeria spp. and Escherichia coli. Food Control. 2006/07/01/ 2006;17(7):516-521.

doi:https://doi.org/10.1016/j.foodcont.2005.02.014

30. Block SS. Disinfection, sterilization, and preservation. Lippincott Williams \& Wilkins; 2011.

31. Middleton AM, Chadwick MV, Gaya H. Disinfection of bronchoscopes, contaminated in vitro with Mycobacterium tuberculosis, Mycobacterium avium-intracellulare and 
Mycobacterium chelonae in sputum, using stabilized, buffered peracetic acid solution ('NuCidex'). The Journal of hospital infection. Oct 1997;37(2):137-43. doi:10.1016/s01956701(97)90183-3

32. ADAMS MR, HALL CJ. Growth inhibition of food-borne pathogens by lactic and acetic acids and their mixtures. International Journal of Food Science \& Technology. 1988;23(3):287-292. doi:https://doi.org/10.1111/j.1365-2621.1988.tb00581.x 


\section{Chapter 3}




\section{Chapter 3. Inactivation of Campylobacter jejuni in Moisture Enhanced Non-Intact Chicken Patties by Double Pan-broiling as Affected by Cooking Set-Up Temperature and Pump Rate}

\subsection{Abstract}

\section{Objective}

This study aimed to evaluate the thermal inactivation of Campylobacter jejuni in moisture enhanced reconstructed non-intact chicken patties with various pump rates and double panbroiled at different temperatures.

\section{Methods}

Fresh 1.5-kg coarse-ground chicken breast, inoculated with $C$. jejuni (3-strain mixture), were moisture enhanced with $\mathrm{NaCl}(2.0 \%)+\mathrm{Na}$-tripolyphosphate $(0.5 \%)$ solutions to reach $1 \%, 5 \%$ or $11 \%$ pump rates. Inoculated samples were then manufactured into patties $(2.1 \mathrm{~cm}$ thick and $10.4 \mathrm{~cm}$ diameter) followed by aerobic storage at $4.5^{\circ} \mathrm{C}$ for $42 \mathrm{~h}$ before double pan-broiling for $0,30,60,90,120,150,180,210,240,300,330$, and $360 \mathrm{~s}$ with temperatures set at 200, 300, 400 or $425^{\circ} \mathrm{F}$. C. jejuni counts were analyzed on Brucella agars under microaerophilic condition.

\section{Results}

Cooking reduced $(P<0.05) C$. jejuni cells from 5.31-5.80 $\log \mathrm{CFU} / \mathrm{g}$ to $<0.3 \log \mathrm{CFU} / \mathrm{g}$ after $330-360\left(200^{\circ} \mathrm{F}\right), 210\left(300^{\circ} \mathrm{F}\right), 180-210\left(400^{\circ} \mathrm{F}\right)$, and $150-165 \mathrm{~s}\left(425^{\circ} \mathrm{F}\right)$ in all chicken samples. D-values (Weibull-model) of samples with $1 \%$ pump rate (118.2 and 112 s) were lower $(P<$ 0.05 ) than $11 \%$ samples ( 139.5 and $124 \mathrm{~s}$ ) when cooked at 400 and $425^{\circ} \mathrm{F}$, respectively.

\section{Conclusions}

These findings will be useful by USDA-FSIS to develop risk assessments of Campylobacter in moisture enhanced non-intact chicken products. 


\subsection{Introduction}

Campylobacter spp. are gram-negative, spiral curved shape bacteria growing under microaerophilic conditions ${ }^{1}$. According to the new Foodborne Disease Outbreak Surveillance System from the Centers for Disease Control and Prevention (FDOSS-CDC), Campylobacter is the third most common single confirmed etiology, responsible for $155(5 \%)$ of the reported outbreaks related to chicken meat from 2009 to $2015^{2}$. United States Department of AgricultureFood Safety and Inspection Service (USDA-FSIS) established the new performance standards in 2010 that requires routine testing for Campylobacter in all processing plants where the percentage of positive samples should be less than $10.4 \%{ }^{3}$. Among various Campylobacter species, Campylobacter jejuni is the most significant thermophilic species responsible for intestinal colonization in poultry and food-borne enteritis in humans and a significant cause of human enterocolitis if consuming undercooked poultry meat.

Non-intact chicken meat products including restructured products are grounded, flaked, tumbled, or chopped and then manufactured into steaks, chops, or roast-like products for retail food preparation ${ }^{4}$. Chicken meat are usually mixed or injected with brine solutions containing salt, polyphosphate and other favor ingredients to improve water-holding capacity, cooking yields and overall eating quality ${ }^{5}$. Salt and polyphosphate can solubilize myofibrillar proteins to ensure a stable meat product bind and formed into a desired shape after packaging for retail markets. The restructuring affords the use of quality meat that can be transformed into even more valuable products by the processor. For instance, breast meat is transformed into chicken rolls, patties, steaks, and nuggets from raw broiler carcasses ${ }^{6}$. However, microbiological safety concerns are raised possibly by that foodborne pathogens could translocate from the meat surface to internal 
tissue or entrapped in the tissue during restructuring, and they are protected from cooking process, especially if the products are undercooked ${ }^{7}$.

Thermal processing is recognized as the most effective and widely used technology to inactivate spoilage bacteria and foodborne pathogen during postharvest food processing using high temperatures ${ }^{8}$. Types of heat transferring into meat products include conduction, convention and radiation as applied by pan-broiling, roasting, and broiling, respectively ${ }^{9}$. Double pan-broiling (referred as contact grilling) is cooked on both the top and bottom sides simultaneously and widely applied for preparing commercial fast meat products especially for beef, pork and chicken burger patties, due to greatly reducing the cooking time ${ }^{10}$. The thermal inactivation activity of double pan-broiling against Escherichia coli $\mathrm{O} 157: \mathrm{H} 7$ has been well documented in nonintact beef and veal products ${ }^{7,10}$.

For Campylobacter, the thermal inactivation has been studied in brain heart infusion broth ${ }^{11}, 1 \%$ peptone solution ${ }^{12}$, fluid milk ${ }^{13}$, and chicken liver ${ }^{14}$. According to the World Health Organization (WHO), the published data on fried chicken breast and chicken breast fillets indicates unusual heat resistance of Campylobacter and there are not enough studies on home cooking practices such as double pan-broiling in grillers ${ }^{15}$. Therefore, the objectives of this study were to determine the thermal inactivation of $C$. jejuni in moisture enhanced reconstructed non-intact chicken patties with various pump rates and cooked by double pan-broiling set at different temperatures.

\subsection{Materials and methods}

\subsubsection{Bacteria inoculum preparation}

Three C. jejuni strains RM5032, RM1188, and RM1464 (kindly supplied by Dr. Nereus Gunther from USDA-ARS, Wyndmoor, PA, USA) were used in this study. Each individual C. jejuni 
strain was maintained on Brucella agar (Hardy Diagnostics, MD) at $4{ }^{\circ} \mathrm{C}$ in a $2.5-\mathrm{L}$

microaerophilic jar (Hardy Diagnostics) under microaerophilic conditions with $5.0 \% \mathrm{O}_{2}, 10 \%$ $\mathrm{CO}_{2}$, and $85 \% \mathrm{~N}_{2}$ by a gas generator (Hardy Diagnostics). The preparation of $C$. jejuni cells was followed a previous study in our lab (Jiang et al., 2018). For each individual strain, two single colonies from the Brucella agar plates were picked by sterilized plastic loops and added into 10 $\mathrm{mL}$ of Bolton's broth (Hardy Diagnostics) and incubated for $48 \mathrm{~h}$ at $42^{\circ} \mathrm{C}$ under the aforementioned microaerophilic conditions. The cultivated broth was then centrifuged (VWR Symphony 4417, VWR International, Radnor, PA) at 5,000 $\times \mathrm{g}$ for $15 \mathrm{~min}$, duplicate-washed in $0.1 \%$ buffered peptone water (BPW), centrifuged again, and re-suspended in fresh $0.1 \% \mathrm{BPW}$. After washing, the three strains were then combined and spread-plated onto Brucella agars to determine the initial concentration of the inoculum (7.5 $\log \mathrm{CFU} / \mathrm{ml})$. Colonies on the Brucella agars were verified for $C$. jejuni with agglutinated clumping from a Campy-latex Agglutination Test kit (Hardy Diagnostics).

\subsubsection{Manufacturing of chicken patties and inoculation}

Fresh bone-less chicken breasts were purchased from Young \& Stout, Inc., Bridgeport, West Virginia. Before experiment, the $1.5 \mathrm{~kg}$ of chicken breast was weighted and manually trimmed into small slices followed by coarse-grounding through a kidney plate $(0.95 \mathrm{~cm}$ diameter $)$ in a benchtop meat grinder before inoculation with $30 \mathrm{ml}$ of the prepared three-strain C. jejuni mixture to achieve the initial inoculation level of 5.5-6.0 $\log \mathrm{CFU} / \mathrm{g}$. The meat and inoculum were thoroughly mixed for 2 min in a bowl-lift stand mixer (KitchenAid ${ }^{\circledR}$, Professional 600, St. Joseph, MI) with the speed setting at "stir". The inoculated chicken samples were then mixed for an additional 2 min with 15, 75 or $150 \mathrm{~mL}$ of a sodium chloride (20\%) plus sodium tripolyphosphate (5\%) solution (BK Giulini Corporation, Simi Valley, CA) to reach the 1, 5 and 
$11 \%$ pump rate, respectively. Chicken samples moisture enhanced with 1,5 , and $11 \%$ pump rate contained sodium chloride and sodium tripolyphosphate concentrations (wt/wt) of $0.2 \%$ and $0.05 \%, 1.0 \%$ and $0.25 \%, 2.2 \%$ and $0.55 \%$, respectively. The chicken patties were then manufactured in a manual hamburger patty maker (Mainstays 6-ounce-patty maker, Walmart, Bentonville, AR) with $120 \pm 1.0 \mathrm{~g}$ of each sample. Chicken patties $(2.1 \mathrm{~cm}$ thick and $10.4 \mathrm{~cm}$ diameter) were then packaged aerobically in foam trays $(20 \times 25 \mathrm{~cm}$, Pactiv, Lake Forest, IL) with the absorbent pads, covered using air-permeable plastic film (Omni-film, Pliant Corporation, $\mathrm{OH})$ and stored at $4.5^{\circ} \mathrm{C}$ for $42 \mathrm{~h}$.

\subsubsection{Cooking of non-intact chicken patties}

After $42 \mathrm{~h}$ of aerobic storage, the non-intact chicken patties were cooked by double pan-broiling in a Farberware grill (Farberware 4-in-1 Grill, Fairfield, CA) with a set-up and pre-heated temperature of $200^{\circ} \mathrm{F}, 300^{\circ} \mathrm{F}, 400^{\circ} \mathrm{F}$, and $425^{\circ} \mathrm{F}$ for $0,30,60,90,120,150,180,210,240,300$, 330 , and $360 \mathrm{~s}$, respectively, to determine the pathogen survival populations and the thermal dynamic parameters ("shoulder-time" and D-value). The internal temperatures of each patty were monitoring throughout the cooking process by inserting a type-K thermocouple into the geometric center of the patty using a real-time data-recording software PicoLog (Pico Technology Ltd., Cambridge, UK).

\subsubsection{Microbiological and physicochemical analyses}

Un-cooked and cooked chicken samples were placed in a WhirlPak ${ }^{\circledR}$ filter bag $(19 \times 30 \mathrm{~cm}$, Nasco, Modesto, CA) with $100 \mathrm{~mL}$ refrigerated Bolton broth plus $0.1 \%$ sodium pyruvate (Fisher Scientific, Fair Lawn, NY) for better recovery of heat-injured cells, followed by homogenizing in a Masticator (IUL Instruments, Barcelona, Spain) for $2 \mathrm{~min}$, and then 10 or 100-fold serially diluted in Bolton broth, and finally spread-plated onto Brucella agars. Brucella agars were then 
incubated at the same microaerophilic conditions at $42.5^{\circ} \mathrm{C}$ for $48 \mathrm{~h}$ before manually counting the colonies after the confirmation with Campy-latex agglutination test. Cooking losses of chicken samples were determined by weighing samples before cooking and reweighing them immediately after cooking and calculated as (weight before - weight $\left.t_{\text {after }}\right) /$ weightbefore $\times 100 \%$. The $\mathrm{pH}$ of the chicken samples was tested after microbiological analysis using a digital $\mathrm{pH}$ meter with a glass electrode (Denver Instruments, Arvada, CO).

\subsubsection{Data analysis}

This study was repeated three times including three chicken patties per treatment per repeat with a total of nine samples. Each experiment was conducted with a completely randomized design with a $3 \times 4 \times 12$ factorial structure with 3 pump rates, 4 cooking set up temperatures, and 12 cooking time points. The USDA-Integrated-Predictive-Modeling-Program ${ }^{16}$ and USDA-Global-

Fit software ${ }^{17}$ was applied to calculate thermal kinetic parameters including "shoulder-time" and D-value of each individual treatment. The Mixed Model Procedure of SAS (version 9.2, SAS Institute, Cary, NC) was used to analyze the survival population and reduction of $C$. jejuni and thermal kinetic parameters with the individual factors and 2 or 3 interactions between them. The means were compared with an $\alpha=0.05$ significance level as determined by Tukey HSD.

\subsection{Results and discussion}

\subsubsection{Cooking curves, cooking losses, and $\mathrm{pH}$ values.}

The cooking curves of the moisture enhanced non-intact chicken patties are shown in Figure 1. The initial internal geometric center temperatures of chicken samples were ranged from 2.3 to $3.6^{\circ} \mathrm{C}$ after storing at the refrigerated temperature for $42 \mathrm{~h}$ (Figure 1). During cooking, the enhancement of internal temperatures was not different among samples with 1, 5 and $11 \%$ pump rates (data not shown in tabular form), therefore the temperature data point in Figure 1 are the 
averaged values across all pump rates. Cooking chicken patties on a double pan-broiling griller set at temperatures of $200,300,400$, and $425^{\circ} \mathrm{F}$ took $330,210,165$, and $165 \mathrm{~s}$, respectively, to achieve the internal temperatures of $73.8^{\circ} \mathrm{C}\left(165^{\circ} \mathrm{F}\right)$ as a microbiological safe temperature of poultry meat determined by the USDA-FSIS ${ }^{18}$.

Table 1 shows the cooking losses of chicken patties moisture enhanced with 1, 5, and $11 \%$ pump rates after double pan-broiling at $200,300,400$, and $425^{\circ} \mathrm{F}$ for 60 to $360 \mathrm{~s}$. The cooking losses of chicken patties increased $(P<0.05)$ with the increasing of cooking time, decreased $(P<0.05)$ with the increasing of pump rates, and their interactions were also significant $(P<0.05)$. Double pan-broiling chicken samples, across all pump rates, at temperatures of $200,300,400$, and $425^{\circ} \mathrm{F}$ increased $(P>0.05)$ the cooking losses from $0.23-0.61$ to $1.77-4.35 \%, 0.28-0.45$ to $3.44-9.57 \%$, $0.92-1.51$ to $4.27-10.82 \%, 0.61-1.95$ to $4.53-11.68 \%$ after $60 \mathrm{~s}$ to the end of cooking, respectively (Table 1), due to the longer cooking time causing the greater amount loss of chicken meat juice. As expected, cooking from $60 \mathrm{~s}$ to the end, chicken samples with 1, 5, and 11\% pump rate decreased $(P<0.05)$ the cooking losses from $0.23-4.35$ to $0.16-1.77 \%, 0.45-9.57$ to 0.28 $3.44 \%, 1.51-10.82$ to $0.92-4.27 \%$, and $1.95-11.68$ to $1.11-4.53 \%$ with temperatures set at 200 , 300,400 , and $425^{\circ} \mathrm{F}$, respectively. These results can be explained by the fact that the greater amounts of salt and tripolyphosphate decrease the cooking loss by increasing the amount of bound water ${ }^{19}$ through enhancing meat $\mathrm{pH}$ to shift the isoelectric point of the muscle myofibrillar proteins and create gaps between the actin myofilaments ${ }^{20,21}$.

Table 2 shows the $\mathrm{pH}$ values of chicken samples moisture enhanced with 1, 5, and $11 \%$ pump rates before and after cooking for 60 to $360 \mathrm{~s}$. Following cooking at temperatures of 200, 300, 400 , and $425^{\circ} \mathrm{F}$, the $\mathrm{pH}$ values did not significantly $(P>0.05)$ change with only slight increasing by 0.08 to 0.22 unit in 1 and $5 \%$ pump rate samples (Table 2) due to a slight decrease of free 
acidic groups as meat temperatures increase ${ }^{22}$. Among all chicken samples, the greater $(P<0.05)$ $\mathrm{pH}$ values ( 0.2 to 1.0 , Table 2$)$ of the $5 \%$ and $11 \%$ pump rate samples compared to the $1 \%$ samples can be explained by the higher amounts of salt and sodium tripolyphosphate increasing the net charge of the meat muscle ${ }^{19}$.

\subsubsection{Thermal inactivation of $C$. jejuni in chicken patties}

Data points in Figure 2 illustrates the survival curves of $C$. jejuni in moisture enhanced chicken patties under isothermal cooking set at $200,300,400$ and $425^{\circ} \mathrm{F}$. For all chicken samples, cooking did not significantly decrease the pathogen counts at the early stage of $\leq 60-90 \mathrm{~s}$ regardless of different set-up temperatures, however, the rate of reduction started to accelerate after the heating time exceeded $90 \mathrm{~s}$ (Figure 2). This result can be explained by the "shouldereffect" that the dimension of chicken patties causing the pathogen located at the geometric center were not significantly inactivated by the heating temperature due to the slow increasing of the geometric center temperature at the early cooking stage ${ }^{8}$.

As expected, double pan-broiling chicken samples decreased $(P<0.05)$ C. jejuni cells gradually with increasing of cooking time under isothermal conditions (Figure 2). The greater set-up temperature of the griller required shorter $(P<0.05)$ time to reduce the pathogen population below detect limit $(<0.3 \log \mathrm{CFU} / \mathrm{g})$. Specifically, cooking reduced $(P<0.05)$ C. jejuni cells from 5.31-5.80 $\log \mathrm{CFU} / \mathrm{g}$ to $<0.3 \log \mathrm{CFU} / \mathrm{g}$ after 330-360, 210, 180-210, and 150-165 s with the set-up temperatures of $200,300,400$, and $425^{\circ} \mathrm{F}$, respectively (Figure 2), when the internal temperatures of chicken samples has reached more than $73.8^{\circ} \mathrm{C}$ with various cooking set-up temperatures. Whyte et al. ${ }^{14}$ concluded that maintaining the internal temperatures of pan-fried chicken livers from $70-80^{\circ} \mathrm{C}$ for 2-3 min killed all naturally occurring C. jejuni cells. Gunsen ${ }^{23}$ also found that cooking chicken drumsticks in an oven set at $200^{\circ} \mathrm{C}$ for $3-5$ min reaching the 
internal temperatures of $70-80^{\circ} \mathrm{C}$ reduced $C$. jejuni cells below detect limit. Sampers et al. ${ }^{24}$ reported that frying chicken burgers for 4 minutes reaching the internal temperature of $57.5^{\circ} \mathrm{C}$ can reduce $C$. jejuni by $>3.5 \log \mathrm{CFU} / \mathrm{g}$. In agreement with these previous studies, results of this study confirmed that the thermal inactivation activity against $C$. jejuni cells on chicken meat products was determined by the internal temperature reached during cooking process. It was noticed that shorter time was needed to achieve $5-\log$ reduction of $C$. jejuni in chicken samples with $1.0 \%$ pump rate compared to the samples with $11.0 \%$ pump rate (except for the $300^{\circ} \mathrm{F}$ cooked samples) by showing 330 vs $360 \mathrm{~s}, 180 \mathrm{vs} 210 \mathrm{~s}$, and $150 \mathrm{vs} 165 \mathrm{~s}$ for the set-up temperatures of 200,400 , and $425^{\circ} \mathrm{F}$, respectively (Figure 2). These results might be explained by the protective effect of sodium chloride or tripolyphosphate against thermal inactivation of $C$. jejuni in $11.0 \%$ pump rate samples which containing 10 times more salt concentrations than the $1.0 \%$ pump rate ${ }^{25}$.

\subsubsection{Modeling of $C$. jejuni survival during double pan-broiling}

The four bacterial survival models in the USDA-IPMP software ${ }^{16}$ were used to predict the thermal inactivation kinetics of $C$. jejuni cells in chicken patties moisture enhanced by 1,5 , and $11 \%$ pump rates. Based on the RMSE and AIC values of each survival model, Mafart-Weibull model $(\mathrm{RMSE}=0.536$ to $0.967, \mathrm{AIC}=-5.46$ to -239.77$)$ and Buchanan Two-phase Model $(\mathrm{RMSE}=0.465$ to $0.823, \mathrm{AIC}=-23.028$ to -68.034$)$ was fit to the thermal kinetics of $C$. jejuni cells in chicken patties after exposure to heat treatment, therefore they were used to calculate the "shoulder-time" and D-values of the pathogen cells under isothermal conditions, respectively. The IPMP-Global fit software, containing Mafart-Weibull model, was applied to compare the difference of D-values of each set-up temperature under one pump rate $(1,5$, or $11 \%)$ simultaneously ${ }^{17}$. 
The Mafart-Weibull model includes two indexes $\mathrm{K}$ determining the concavity of survival curves and $\mathrm{D}$ as the time of first decimal reduction ${ }^{26}$. The $\mathrm{K}$ values of 1,5 , and $11 \%$ pump rate samples under isothermal dynamic conditions are $4.86 \pm 0.46,3.82 \pm 0.35$, and $3.49 \pm 0.32$, respectively. Since all these K values were $>1$, their survival curves were downwardly concaved and indicated "shoulder-effect" ${ }^{26}$. The "shoulder-time", calculated from the Buchanan Two-phase Model, was significantly $(P<0.05)$ affected by the cooking set-up temperatures. As the temperatures increased from 200 to $400^{\circ} \mathrm{F}$, the "shoulder-time" decreased $(P<0.05)$ from 179.7 to $109.8 \mathrm{~s}$, 237.6 to $106.2 \mathrm{~s}$, and 221.9 to $121.2 \mathrm{~s}$ for chicken samples with 1,5 , and $11 \%$ pump rate, respectively. The pump rates did not generate the difference $(P>0.05)$ of the "shoulder-time" when cooking at 200 and $300^{\circ} \mathrm{F}$. However, shorter $(P<0.05)$ "shoulder-times" were observed in 1 and $5 \%$ pump rate samples compared to the $11 \%$ ones when cooking temperatures increased from 300 to 400 or $425^{\circ} \mathrm{F}$. For example, the "shoulder-time" of samples with 5\% pump rate was 106.2 and $107 \mathrm{~s}$, which are not different $(P>0.05)$ to the $1 \%$ samples $(109.8$ and $113.6 \mathrm{~s})$ but shorter $(P<0.05)$ than the $11 \%$ samples $(212.2$ and $127.7 \mathrm{~s})$ when they were cooked at 400 and $425^{\circ} \mathrm{F}$, respectively.

Compared to other foodborne pathogens such as E. coli O157:H7 and Salmonella spp., the studies regarding D-values of $C$. jejuni in food systems are limited. An early study of Blankenship and Craven ${ }^{12}$ showed that the D-values of C. jejuni strain H-840 in 1\% peptone heating at 53,55 , and $57^{\circ} \mathrm{C}$ were $1.71,0.64$, and $0.25 \mathrm{~min}$, respectively. Al-Sakkaf and Jones ${ }^{11}$ reported that the D-values of 4 C. jejuni isolates of poultry and human from New Zealand were ranged from 8.0 to $24.1 \mathrm{~s}$ and 1.3 to $4.2 \mathrm{~s}$ at 56.5 and $60^{\circ} \mathrm{C}$ in brain heart infusion (BHI) broth, respectively. Nguyen et al. ${ }^{27}$ found that the D-values of the two C. jejuni strains from poultry feces in $\mathrm{BHI}$ broth at $55^{\circ} \mathrm{C}$ were as great as 4.6 to $6.6 \mathrm{~min}$ due to the folding of the $\alpha$ and $\beta$ 
subunits of RNA polymerase as heat resistant essential proteins. Since the huge variation of the D-values of $C$. jejuni cells in broth was reported in the above three studies, it is important to determine the D-values of the pathogen in poultry meat products. In this study, the calculated Dvalues of all samples across 3 different pump rates ranged from 112 to $264 \mathrm{~s}$ among 4 different set-up temperatures (Table 3). These relatively high D-values agree with two previous studies of C. jejuni in chicken products. Bergsma et al. ${ }^{28}$ reported that the greatest D-value for $C$. jejuni in fired chicken fillets with surface temperatures ranging from 109 to $127^{\circ} \mathrm{C}$ was $1.95 \min (117 \mathrm{~s})$. In a related study, de Jong et al. ${ }^{29}$ found that the D-value in boiled chicken fillet at $100^{\circ} \mathrm{C}$ was 1.9 $\min (114 \mathrm{~s})$. However, Blankenship and Craven ${ }^{12}$ found that the D-values of C. jejuni in ground chicken heating at $57^{\circ} \mathrm{C}$ were only $0.79 \mathrm{~min}(47 \mathrm{~s})$. The disparity of the results is due to the smaller amount (2 gram) of the ground chicken meat cooked in the study of Blankenship and Craven compared to a whole chicken patty and chicken fillet (>100 gram) used in this study and the studies of Bergsma et al. and de Jong et al..

In this study, the statistical analysis of D-values among all tested treatments shows a significant effect of cooking set-up temperatures $(P<0.05)$, margin effect of pump rates $(P=0.06)$, and no significant effect of the interaction $(P>0.05)$. D-values of cooking at $200^{\circ} \mathrm{F}$ were $246.8,239.7$, and $264 \mathrm{~s}(P>0.05)$, and at $300^{\circ} \mathrm{F}$ were $150.2,145.7$, and $141.0 \mathrm{~s}(P>0.05)$ for chicken patties with $1.0,5.0$, and $11.0 \%$ pump rate, respectively. When the cooking temperatures increased to $400^{\circ} \mathrm{F}$, the D-values of 5.0 and $11.0 \%$ pump rate samples were 132 and $139.5 \mathrm{~s}$, respectively, which were greater $(P<0.05)$ than the $1.0 \%$ ones $(118.2 \mathrm{~s})$. Cooking at $425^{\circ} \mathrm{F}$, the D-value of $1.0 \%$ pump rate sample was $112 \mathrm{~s}$, which was slightly lower $(P>0.05)$ than the $5.0 \%$ samples $(118 \mathrm{~s})$ but significantly lower $(P<0.05)$ than the $11.0 \%$ samples $(124 \mathrm{~s})$. These results, together with the previous microbiological data and results of "shoulder time", suggest that the $C$. jejuni 
cells in the $1 \%$ pump rate chicken patties cooked at 400 and $425^{\circ} \mathrm{F}$ are more sensitive (smaller Dvalues) to the heat than the $11 \%$ pump rate samples (Tables 4 and 5). Two possible reasons might be explained by this result. First, during cooking, the $1 \%$ pump rate chicken lost more moisture than $11 \%$ samples resulting greater fat content than the $11 \%$ samples. Kotrola and Conner ${ }^{25}$ reported that the ground turkey breast meat prepared with $8 \%$ salt and $0.5 \%$ polyphosphate containing 11\% fat resulted smaller D-values of E. coli $\mathrm{O} 157: \mathrm{H} 7$ than $3 \%$ fat samples when heating at $55(17.9$ vs $23 \mathrm{~s})$ and $57^{\circ} \mathrm{C}(6.1 \mathrm{vs} 10.8 \mathrm{~s})$, which was due to the fine mixing of the menstrua prior to cooking. Second, as mentioned early, compared to the $1 \%$ pump rate samples, the greater concentrations of sodium chloride or tripolyphosphate in $11.0 \%$ samples protected the pathogen from the heat due to enhanced membrane stabilization of bacteria during heating provided by the salts ${ }^{30}$. The study of Kotrola and Conner also reported that $\mathrm{D}$-values of 55,57 and $60^{\circ} \mathrm{C}$ from the ground turkey meat with $8 \%$ salt were greater than from turkey with no salt ingredients. Results of these study indicate that non-intact chicken products moisture enhanced with salt ingredients should be a critical consideration regarding safely cooking chicken meat products.

\subsection{Conclusions}

In summary, results of this study indicate that the double pan-broiling griller set at $>400$ to $425^{\circ} \mathrm{F}$ is efficiently to inactivate $C$. jejuni in moisture enhanced non-intact chicken patties. When cooking at $>400^{\circ} \mathrm{F}, C$. jejuni in chicken meat moisture enhanced with smaller pump rate is more vulnerable to heat than the greater pump rate. These results fill the data gap of cooking practices to inactivate Campylobacter in chicken meat, which will be useful for the USDA-FSIS to develop a risk assessment for non-intact chicken products. These results will also be useful to the food service personnel to select the effective chicken meat cooking protocols and develop 
manufacturing procedures to create moisture enhanced chicken products, also provide safe cooking instructions for consumers. 
Tables and Figures 
Table 1. Cooking losses (mean \pm standard deviation) of moisture enhanced non-intact chicken patties with 1,5 , and $11 \%$ pump rate after double pan-broiling at $200,300,400$, and $425^{\circ} \mathrm{F}$ for 60 to $360 \mathrm{~s}$

\begin{tabular}{ccccc}
\hline $\begin{array}{c}\text { Set-up Temperature } \\
\left({ }^{\circ} \mathrm{F}\right)\end{array}$ & $\begin{array}{c}\text { Cooking Time } \\
(\mathrm{sec})\end{array}$ & 1 & 5 & 11 \\
\hline 200 & 60 & $0.23 \pm 0.07 \mathrm{aA}$ & $0.31 \pm 0.07 \mathrm{aB}$ & $0.61 \pm 0.27 \mathrm{aC}$ \\
& 180 & $0.71 \pm 0.14 \mathrm{bA}$ & $0.55 \pm 0.37 \mathrm{aA}$ & $0.33 \pm 0.13 \mathrm{aB}$ \\
& 240 & $1.07 \pm 0.33 \mathrm{cA}$ & $1.14 \pm 0.40 \mathrm{bA}$ & $0.50 \pm 0.18 \mathrm{aB}$ \\
& 360 & $4.35 \pm 1.83 \mathrm{dA}$ & $2.66 \pm 0.22 \mathrm{cB}$ & $1.77 \pm 0.41 \mathrm{bC}$ \\
\hline 300 & 60 & $0.45 \pm 0.22 \mathrm{aA}$ & $0.28 \pm 0.27 \mathrm{aA}$ & $0.28 \pm 0.21 \mathrm{aA}$ \\
& 150 & $2.81 \pm 1.12 \mathrm{bA}$ & $1.91 \pm 0.36 \mathrm{bB}$ & $0.35 \pm 0.16 \mathrm{aC}$ \\
& 210 & $6.73 \pm 1.20 \mathrm{cA}$ & $4.58 \pm 0.25 \mathrm{cB}$ & $2.46 \pm 0.72 \mathrm{bC}$ \\
& 240 & $9.57 \pm 3.31 \mathrm{dA}$ & $6.31 \pm 0.62 \mathrm{~dB}$ & $3.44 \pm 0.66 \mathrm{cC}$ \\
\hline 400 & 60 & $1.51 \pm 0.57 \mathrm{aA}$ & $1.25 \pm 0.56 \mathrm{aA}$ & $0.92 \pm 0.70 \mathrm{aB}$ \\
& 120 & $5.75 \pm 1.03 \mathrm{bA}$ & $5.45 \pm 0.89 \mathrm{bA}$ & $1.82 \pm 0.79 \mathrm{bB}$ \\
& 150 & $7.92 \pm 3.19 \mathrm{bA}$ & $7.80 \pm 3.27 \mathrm{bA}$ & $2.92 \pm 0.55 \mathrm{cB}$ \\
& 180 & $10.82 \pm 1.86 \mathrm{cA}$ & $10.46 \pm 1.94 \mathrm{cA}$ & $4.27 \pm 0.37 \mathrm{~dB}$ \\
\hline 425 & 60 & $1.95 \pm 0.84 \mathrm{aA}$ & $1.15 \pm 0.48 \mathrm{aB}$ & $0.61 \pm 0.20 \mathrm{aC}$ \\
& 120 & $7.41 \pm 1.18 \mathrm{bA}$ & $3.57 \pm 0.62 \mathrm{bB}$ & $2.23 \pm 0.53 \mathrm{bC}$ \\
& 150 & $9.82 \pm 1.84 \mathrm{bA}$ & $5.28 \pm 1.23 \mathrm{cB}$ & $3.32 \pm 0.47 \mathrm{cC}$ \\
& 180 & $11.68 \pm 2.97 \mathrm{cA}$ & $7.27 \pm 1.34 \mathrm{~dB}$ & $4.53 \pm 1.05 \mathrm{dC}$ \\
\hline
\end{tabular}

Mean values within each set-up temperature different letters within a column are significantly different $(P<0.05)$; Mean values within each set-up temperature different capital letters within a row are significantly different $(P<0.05)$. 
Table 2. $\mathrm{pH}$ values (mean \pm standard deviation) of moisture enhanced non-intact chicken patties with 1,5 , and $11 \%$ pump rate after double pan-broiling at $200,300,400$, and $425^{\circ} \mathrm{F}$ for 0 to $360 \mathrm{~s}$

\begin{tabular}{ccccc}
\hline $\begin{array}{c}\text { Set-up Temperature } \\
\left({ }^{\circ} \mathrm{F}\right)\end{array}$ & $\begin{array}{c}\text { Cooking Time } \\
(\mathrm{sec})\end{array}$ & 1 & 5 & 11 \\
\hline 200 & 0 & $6.22 \pm 0.12 \mathrm{aA}$ & $6.87 \pm 0.08 \mathrm{aB}$ & $6.83 \pm 0.12 \mathrm{aB}$ \\
& 60 & $6.20 \pm 0.04 \mathrm{aA}$ & $6.81 \pm 0.11 \mathrm{aB}$ & $6.72 \pm 0.03 \mathrm{aB}$ \\
& 180 & $6.22 \pm 0.03 \mathrm{aA}$ & $6.85 \pm 0.05 \mathrm{aB}$ & $6.73 \pm 0.02 \mathrm{aB}$ \\
& 240 & $6.27 \pm 0.08 \mathrm{aA}$ & $6.98 \pm 0.13 \mathrm{aB}$ & $6.73 \pm 0.03 \mathrm{aB}$ \\
& 360 & $6.30 \pm 0.04 \mathrm{aA}$ & $7.00 \pm 0.10 \mathrm{aB}$ & $6.76 \pm 0.04 \mathrm{aB}$ \\
\hline 300 & 0 & $6.17 \pm 0.04 \mathrm{aA}$ & $7.20 \pm 0.08 \mathrm{aB}$ & $6.83 \pm 0.06 \mathrm{aC}$ \\
& 60 & $6.20 \pm 0.03 \mathrm{aA}$ & $7.25 \pm 0.10 \mathrm{aB}$ & $6.69 \pm 0.05 \mathrm{aC}$ \\
& 150 & $6.30 \pm 0.06 \mathrm{aA}$ & $7.32 \pm 0.09 \mathrm{aB}$ & $6.75 \pm 0.05 \mathrm{aC}$ \\
& 210 & $6.31 \pm 0.03 \mathrm{aA}$ & $7.28 \pm 0.10 \mathrm{aB}$ & $6.77 \pm 0.06 \mathrm{aC}$ \\
& 240 & $6.30 \pm 0.09 \mathrm{aA}$ & $7.30 \pm 0.10 \mathrm{aB}$ & $6.76 \pm 0.04 \mathrm{aC}$ \\
\hline 400 & 0 & $6.14 \pm 0.01 \mathrm{aA}$ & $6.81 \pm 0.10 \mathrm{aB}$ & $6.64 \pm 0.24 \mathrm{aC}$ \\
& 60 & $6.19 \pm 0.03 \mathrm{aA}$ & $6.88 \pm 0.08 \mathrm{aB}$ & $6.62 \pm 0.13 \mathrm{aC}$ \\
& 120 & $6.29 \pm 0.04 \mathrm{aA}$ & $6.95 \pm 0.07 \mathrm{aB}$ & $6.68 \pm 0.13 \mathrm{aC}$ \\
& 150 & $6.31 \pm 0.02 \mathrm{aA}$ & $6.95 \pm 0.05 \mathrm{aB}$ & $6.71 \pm 0.10 \mathrm{aC}$ \\
& 180 & $6.32 \pm 0.02 \mathrm{aA}$ & $6.94 \pm 0.05 \mathrm{aB}$ & $6.68 \pm 0.11 \mathrm{aC}$ \\
\hline 425 & 0 & $6.16 \pm 0.26 \mathrm{aA}$ & $6.76 \pm 0.09 \mathrm{aB}$ & $6.72 \pm 0.23 \mathrm{aB}$ \\
& 60 & $6.28 \pm 0.27 \mathrm{aA}$ & $6.81 \pm 0.06 \mathrm{aB}$ & $6.64 \pm 0.09 \mathrm{aB}$ \\
& 120 & $6.25 \pm 0.21 \mathrm{aA}$ & $6.86 \pm 0.07 \mathrm{aB}$ & $6.66 \pm 0.08 \mathrm{aC}$ \\
& 150 & $6.38 \pm 0.27 \mathrm{aA}$ & $6.86 \pm 0.04 \mathrm{aB}$ & $6.68 \pm 0.07 \mathrm{aB}$ \\
& 180 & $6.38 \pm 0.27 \mathrm{aA}$ & $6.91 \pm 0.03 \mathrm{aB}$ & $6.66 \pm 0.07 \mathrm{aC}$ \\
\hline
\end{tabular}

Mean values within each set-up temperature different letters within a column are significantly different $(P<0.05)$; Mean values within each set-up temperature different capital letters within a row are significantly different $(P<0.05)$ 
Table 3. "Shoulder-time" (mean \pm standard deviation) of Buchanan Two-phase Model for the inactivation of Campylobacter jejuni in chicken patties with 1, 5, and $11 \%$ pump rate after double pan-broiling at $200,300,400$, and $425^{\circ} \mathrm{F}$ for 0 to $360 \mathrm{~s}$

\begin{tabular}{cccc}
\hline & \multicolumn{3}{c}{ Pump rate $(\%)$} \\
\hline Temperature $\left({ }^{\circ} \mathrm{F}\right)$ & 1 & 5 & 11 \\
\hline 200 & $179.7 \pm 63.9 \mathrm{aB}$ & $237.6 \pm 33.4 \mathrm{aA}$ & $221.9 \pm 85.4 \mathrm{aA}$ \\
300 & $139.5 \pm 13.8 \mathrm{bA}$ & $136.2 \pm 12.7 \mathrm{bA}$ & $144.5 \pm 21.4 \mathrm{bA}$ \\
400 & $109.8 \pm 17.5 \mathrm{cB}$ & $106.2 \pm 4.4 \mathrm{cB}$ & $121.2 \pm 9.6 \mathrm{cA}$ \\
425 & $113.6 \pm 11.9 \mathrm{cB}$ & $107.0 \pm 15.9 \mathrm{cB}$ & $127.7 \pm 10.9 \mathrm{cA}$ \\
\hline
\end{tabular}

Mean values with different letters within a column are significantly different $(P<0.05)$

Mean values with different capital letters within a row are significantly different $(P<0.05)$ 
Table 4. D-values (mean \pm standard deviation) of Mafart-Weibull model for the inactivation of Campylobacter jejuni in chicken patties with 1, 5, and 11\% pump rate after double pan-broiling at $200,300,400$, and $425^{\circ} \mathrm{F}$ for 0 to $360 \mathrm{~s}$

\begin{tabular}{cccc}
\hline \multicolumn{4}{c}{ Pump rate $(\%)$} \\
\hline Temperature $\left({ }^{\circ} \mathrm{F}\right)$ & 1 & 5 & 11 \\
\hline 200 & $246.8 \pm 14.9 \mathrm{aA}$ & $239.7 \pm 22.6 \mathrm{aA}$ & $264.0 \pm 18.4 \mathrm{aA}$ \\
300 & $150.2 \pm 11.1 \mathrm{bA}$ & $145.7 \pm 12.8 \mathrm{bA}$ & $141.0 \pm 14.5 \mathrm{bA}$ \\
400 & $118.2 \pm 6.2 \mathrm{cB}$ & $132.0 \pm 32.2 \mathrm{bAB}$ & $139.5 \pm 15.0 \mathrm{bA}$ \\
425 & $112.0 \pm 6.0 \mathrm{cB}$ & $118.0 \pm 9.2 \mathrm{cAB}$ & $124.5 \pm 7.8 \mathrm{cA}$ \\
\hline
\end{tabular}

Mean values with different letters within a column are significantly different $(P<0.05)$

Mean values with different capital letters within a row are significantly different $(P<0.05)$ 
Figure 1. Temperature changes of the geometric center of moisture-enhanced non-intact chicken patties cooked at by double pan-broiling set at $200,300,400$, and $425^{\circ} \mathrm{F}$. Each point is averaged across all pump rates.

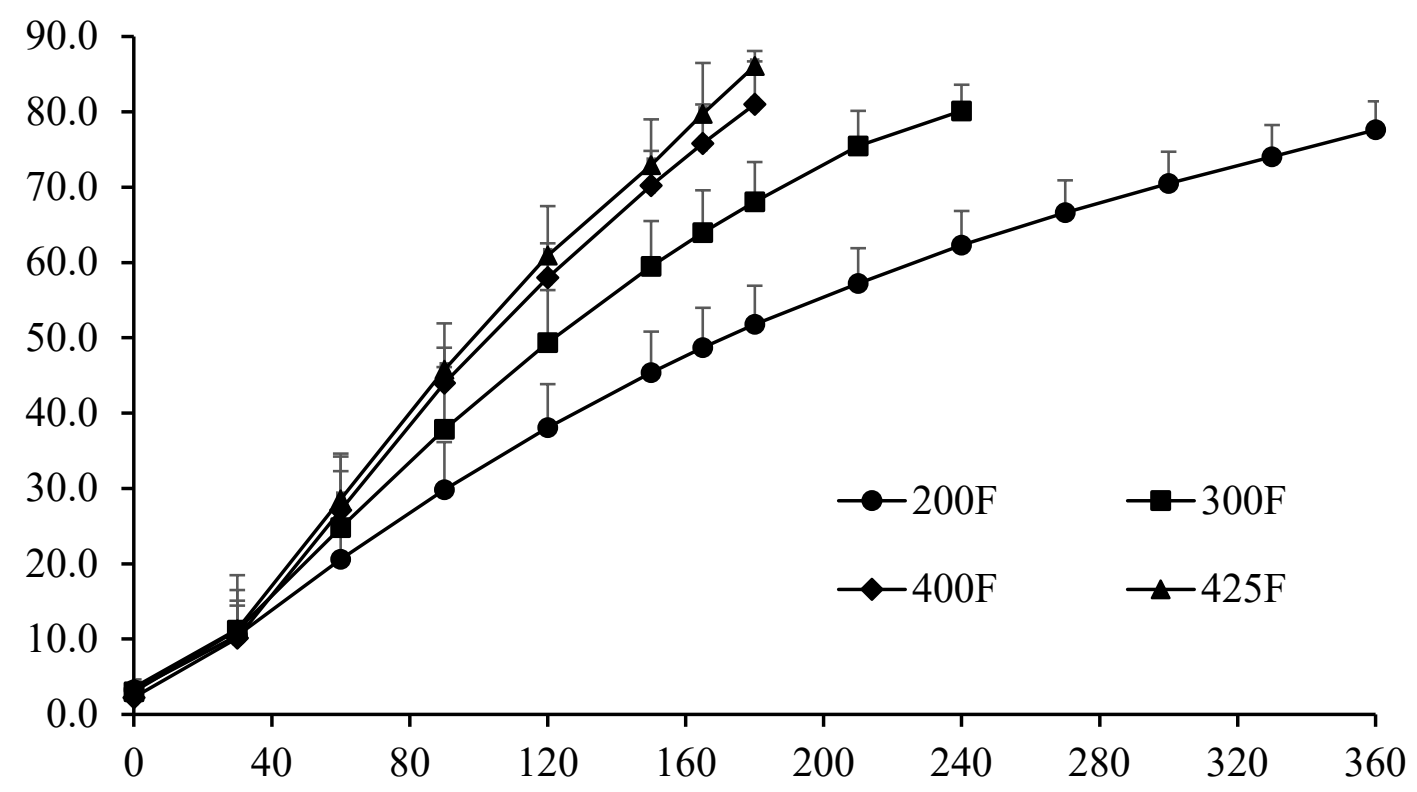


Figure 2. Survivals of Campylobacter jejuni in moisture enhanced non-intact chicken patties with 1,5 , and $11 \%$ pump rate that were cooked by double pan-broiling set at 200,300,400, and $425^{\circ} \mathrm{F}$
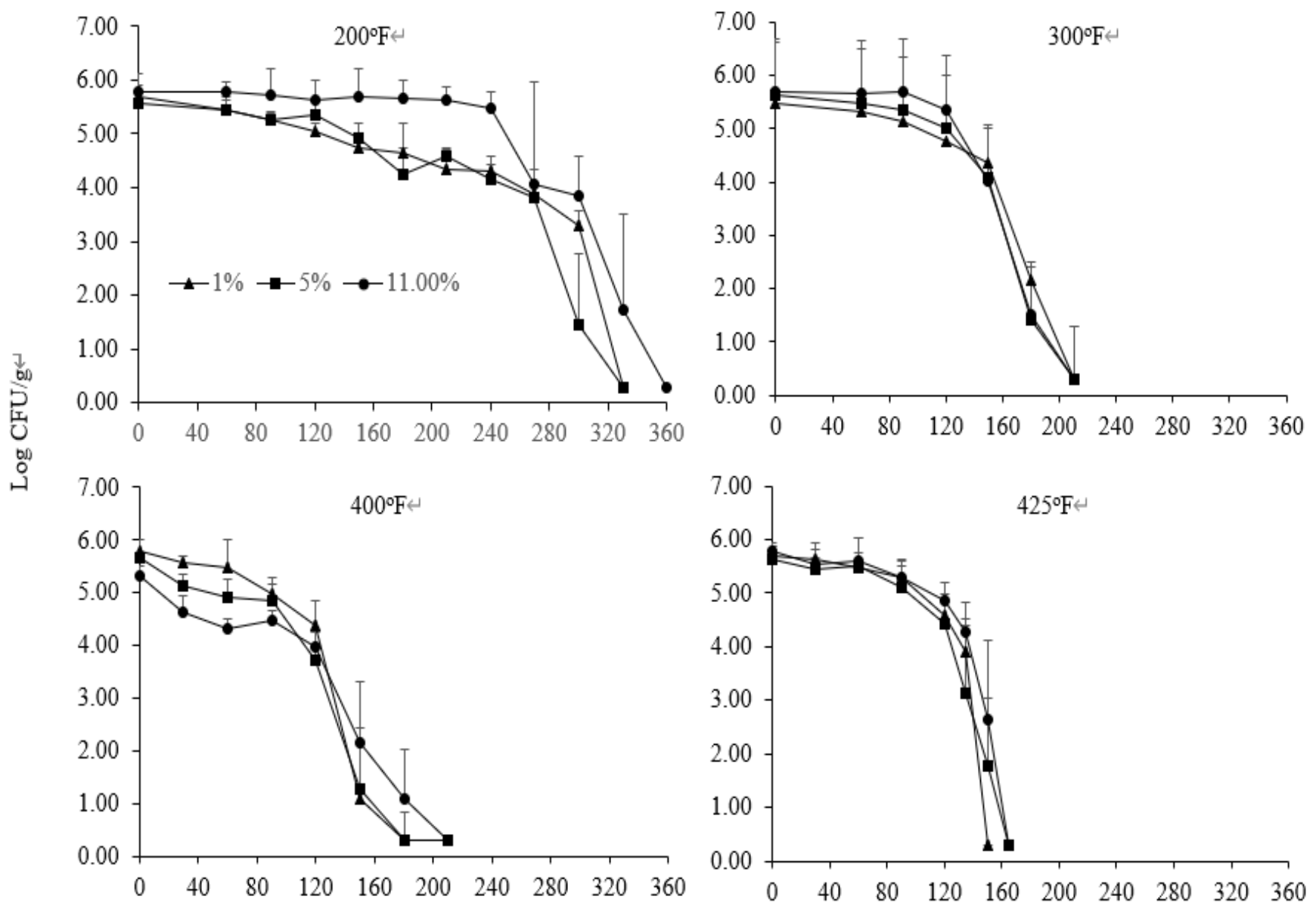

Cooking time (Sec) 


\section{References}

1. Humphrey T, O'Brien S, Madsen M. Campylobacters as zoonotic pathogens: a food production perspective. International journal of food microbiology. 2007;117(3):237-257.

2. Dewey-Mattia D, Manikonda K, Hall AJ, Wise ME, Crowe SJ. Surveillance for Foodborne Disease Outbreaks - United States, 2009-2015. Morbidity and mortality weekly report Surveillance summaries (Washington, DC : 2002). Jul 27 2018;67(10):1-11. doi:10.15585/mmwr.ss6710a1

3. FSIS U. New performance standards for Salmonella and Campylobacter in young chicken and turkey slaughter establishments: response to comments and announcement of implementation schedule. Fed Regist. 2011;76:15282-15290.

4. $\quad$ FSIS Product Categorization. United States Department of Agriculture-Food Safety and Inspection Service (USDA-FSIS). Accessed May 24th, 2020. https:/www.fsis.usda.gov/wps/wcm/connect/abbf595d-7fc7-4170-b7be-37f812882388/ProductCategorization.pdf?MOD=AJPERES

5. Gill CO, McGinnis JC, Barbut S, Young D, Lee N, Rahn K. Microbiological conditions of moisture-enhanced chicken breasts prepared at a poultry packing plant. J Food Prot. Dec 2004;67(12):2675-81. doi:10.4315/0362-028x-67.12.2675

6. Lonergan S, Topel D, Marple D. The science of animal growth and meat technology. Academic Press; 2019.

7. Shen C, Adler JM, Geornaras I, Belk KE, Smith GC, Sofos JN. Inactivation of Escherichia coli O157:H7 in nonintact beefsteaks of different thicknesses cooked by pan broiling, double pan broiling, or roasting by using five types of cooking appliances. J Food Prot. Mar 2010;73(3):4619. doi:10.4315/0362-028x-73.3.461

8. Huang L. Thermal inactivation of Listeria monocytogenes in ground beef under isothermal and dynamic temperature conditions. Journal of Food Engineering. 2009;90(3):380-387.

9. Association AMS. Research Guidelines for Cookery, Sensory Evaluation, and Instrumental Tenderness Measurements of Meat. Accessed Jan 23rd, 2021. https://meatscience.org/docs/default-source/publications-resources/amsa-sensory-andtenderness-evaluation-guidelines/research-guide/2015-amsa-sensory-guidelines-1$0 . p d f ?$ sfvrsn $=6$

10. Li K, McKeith AG, Shen C, McKeith R. A Comparison Study of Quality Attributes of Ground Beef and Veal Patties and Thermal Inactivation of Escherichia coli O157:H7 after Double Pan-Broiling Under Dynamic Conditions. Foods. Dec 26 2017;7(1)doi:10.3390/foods7010001

11. Al Sakkaf A, Jones G. Thermal inactivation of Campylobacter jejuni in broth. J Food Prot. Jun 2012;75(6):1029-35. doi:10.4315/0362-028X.JFP-11-518

12. Blankenship L, Craven S. Campylobacter jejuni survival in chicken meat as a function of temperature. Applied and environmental microbiology. 08/01 1982;44:88-92. doi:10.1128/AEM.44.1.88-92.1982

13. D'Aoust JY, Park CE, Szabo RA, Todd EC, Emmons DB, McKellar RC. Thermal inactivation of Campylobacter species, Yersinia enterocolitica, and hemorrhagic Escherichia coli O157:H7 in fluid milk. $J$ Dairy Sci. Dec 1988;71(12):3230-6. doi:10.3168/jds.s00220302(88)79928-2

14. Whyte R, Hudson J, Graham C. Campylobacter in chicken livers and their destruction by pan frying. Letters in applied microbiology. 2006;43(6):591-595.

15. WHO. Salmonella and campylobacter in chicken meat: meeting report. Accessed May 24th, 2020.

16. Huang L. IPMP 2013 - a comprehensive data analysis tool for predictive microbiology. 
International journal of food microbiology. 2014;171:100-107.

17. Huang L. IPMP Global Fit-A one-step direct data analysis tool for predictive microbiology. International journal of food microbiology. 2017;262:38-48.

18. United States Department of Agriculture-Food Safety and Inspection Service (USDAFSIS). Salmonella Questions and Answers. 2013;

19. Hedrick HB. Principles of meat science. Kendall/Hunt Publishing Company; 1994.

20. Alvarado C, McKee S. Marination to Improve Functional Properties and Safety of Poultry Meat. Journal of Applied Poultry Research. 2007/03/01/ 2007;16(1):113-120. doi:https://doi.org/10.1093/japr/16.1.113

21. Young $\mathrm{O}$, Zhang $\mathrm{S}$, Farouk M, Podmore $\mathrm{C}$. Effects of $\mathrm{pH}$ adjustment with phosphates on attributes and functionalities of normal and high $\mathrm{pH}$ beef. Meat science. 2005;70(1):133-139.

22. Lawrie RA, Ledward D. Lawrie's meat science. Woodhead Publishing; 2014:75-155.

23. Gunsen U. Inactivation of Campylobacter jejuni inoculated into baked drumsticks. Archiv fur Lebensmittelhygiene. 09/01 2008;59:175-179. doi:10.2376/0003-925X-59-175

24. Sampers I, Habib I, De Zutter L, Dumoulin A, Uyttendaele M. Survival of Campylobacter spp. in poultry meat preparations subjected to freezing, refrigeration, minor salt concentration, and heat treatment. International journal of food microbiology. 2010;137(2-3):147-153.

25. Kotrola JS, Conner DE. Heat Inactivation of Escherichia coli O157:H7 in Turkey Meat as Affected by Sodium Chloride, Sodium Lactate, Polyphosphate, and Fat Content ( $\dagger$ ). J Food Prot. Aug 1997;60(8):898-902. doi:10.4315/0362-028x-60.8.898

26. Albert I, Mafart P. A modified Weibull model for bacterial inactivation. Int J Food Microbiol. Apr 15 2005;100(1-3):197-211. doi:10.1016/j.ijfoodmicro.2004.10.016

27. Nguyen HT, Corry JE, Miles CA. Heat resistance and mechanism of heat inactivation in thermophilic campylobacters. Appl Environ Microbiol. 2006;72(1):908-913.

28. Bergsma Nynke J, Fischer Arnout RH, Van Asselt Esther D, Zwietering Marcel H, De Jong Aarieke EI. Consumer food preparation and its implication for survival of Campylobacter jejuni on chicken. British Food Journal. 2007;109(7):548-561. doi:10.1108/00070700710761536

29. de Jong AE, van Asselt ED, Zwietering MH, Nauta MJ, de Jonge R. Extreme Heat Resistance of Food Borne Pathogens Campylobacter jejuni, Escherichia coli, and Salmonella typhimurium on Chicken Breast Fillet during Cooking. International journal of microbiology. 2012;2012:196841. doi:10.1155/2012/196841

30. Mukherjee A, Yoon Y, Belk KE, Scanga JA, Smith GC, Sofos JN. Thermal inactivation of Escherichia coli O157:H7 in beef treated with marination and tenderization ingredients. $J$ Food Prot. Jul 2008;71(7):1349-56. doi:10.4315/0362-028x-71.7.1349 


\section{Chapter 4}


Chapter 4. Survival of Salmonella and the surrogate Enterococcus faecium in Cooking of Moisture Enhanced Reconstructed Comminuted Chicken Patties by Double Pan-broiling

\subsection{Abstract}

\section{Objective}

This study aims to compare kinetic parameters of Salmonella and Enterococcus faecium in moisture enhanced and reconstructed comminuted chicken patties with different pump rates during double pan-broiling with various set-up temperatures.

\section{Methods}

Fresh $1.5-\mathrm{kg}$ chicken breast meat was course grounded, inoculated with $S$. Typhimurium and Tennessee, or E. faecium, followed by adding $\mathrm{NaCl}(2.0 \%)+$ Na-tripolyphosphate $(0.5 \%)$ solutions to achieve pump rates of $1 \%, 5 \%$ or $11.1 \%$. Meat samples were manually manufactured into patties with the thickness of $2.1 \mathrm{~cm}$ and diameter of $10.4 \mathrm{~cm}$. Patties were packaged with polyvinyl chloride films in the foam-tray stored at $4{ }^{\circ} \mathrm{C}$ for $42 \mathrm{~h}$ before double pan-broiling set at 200, 300, or $425^{\circ} \mathrm{F}$ for 0 to $420 \mathrm{~s}$. Counts of pathogens were analyzed on XLT-4 and bile esculin agars with tryptic soy agar layers. Microbial data and kinetic parameters ( $n=9$, USDAIntegrated-Predictive-Modeling-Program/USDA-Global-Fit software) were analyzed by the Mixed Model Procedure (SAS).

\section{Results}

Double pan-broiling reduced $>5-\log \mathrm{CFU} / \mathrm{g}(P<0.05)$ of Salmonella after $360 \mathrm{~s}\left(200^{\circ} \mathrm{F}\right), 180$ $225\left(300^{\circ} \mathrm{F}\right)$, and $150-165 \mathrm{~s}\left(425^{\circ} \mathrm{F}\right)$, and of E. faecium after $270 \mathrm{~s}\left(300^{\circ} \mathrm{F}\right)$, and $180 \mathrm{~s}\left(425^{\circ} \mathrm{F}\right)$ across all samples. D-values (Mafart-Weibull model) of Salmonella and E. faecium in 1\% moisture enhanced samples cooked at $200-425^{\circ} \mathrm{F}(102.7-248.2$ and $115.5-271.0 \mathrm{~s})$ were lower $(P$ $<0.05)$ than $11.1 \%$ samples $(119.8-263.7$ and $122.5-298.3$ s). Salmonella were more susceptible 
$(P<0.05)$ to heat than E. faecium. "Shoulder-time" (Buchanan-Two-Phase model) of Salmonella cooking at $200-425^{\circ} \mathrm{F}$ increased $(P<0.05)$ from $82.3-229.0$ to $116.6-246.2 \mathrm{~s}$ as pump rate increased from 1 to $11.1 \%$, whereas this phenomenon was not shown for E. faecium.

\section{Conclusions}

Results indicate that Salmonella were resistant to heat in chicken patties with greater pump rate. E. faecium can be used as a surrogate for Salmonella in thermal inactivation validation studies of chicken products.

\subsection{Introduction}

Salmonella is Gram-negative, rods shape, non-endospore forming, facultative foodborne pathogen causing 905 outbreaks in the United States in 2018 with chicken products as the number 1 food category ( $>100)$ of outbreaks based on new surveillance data published by the U.S. Centers for

Disease Control and Prevention in December, $2020^{1}$. An early study of Morris et al. ${ }^{2}$ also confirms that Salmonella is responsible for approximately 35\% of the foodborne illnesses associated with poultry products. In February 2016, the U.S. Department of Agriculture-Food Safety and Inspection Service established a new performance standard in response to national surveillance baseline data from 2012 to $2015^{3}$. The new standard allowed the maximum acceptable positive rate of Salmonella up to $25 \%$ in comminuted chicken (325 g sample) and up to $15.4 \%$ in chicken parts (4 lb. sample).

Raw chicken carcasses are usually further processed through reduction of raw chicken particle size, extraction of meat proteins, binding meat pieces with salt and/or phosphate, and marination with commercial or domestic marinades. These techniques are followed by grinding, tumbling, or chopping for further manufacturing into retail chicken products such as ground chicken, chicken steaks, or bags of chicken roasts. Reconstructed, comminuted chicken meat is often 
mixing with brine solutions containing various salt and polyphosphate concentrations to increase water-holding capacity, decrease cooking losses, improve sensory tasting scores, and to maintain good quality of completed chicken products ${ }^{4}$. Applying appropriate concentrations of salt and tripolyphosphate into the chicken meat products can generate an optimal water-holding capacity value for solubilizing muscle myofibrillar proteins to form a stable and desired final product shape as shown in commercial retail packages ${ }^{5,6}$. Recently, new nationwide sampling results showed high prevalence of Salmonella (36.7-83.5\%) in comminuted chicken products, representing 1.6-2.3-fold increase of Salmonella prevalence compared to bone-in chicken parts and carcasses ${ }^{7}$. These data raised microbiological safety concerns of foodborne pathogens. The mild heat generated during grinding and possibly translocation of foodborne pathogens from the surface to internal tissues during restructuring, moisture enhancement and marination could add to the microbial safety risk, especially if the final products are undercooked ${ }^{8}$.

Cooking raw chicken to $74^{\circ} \mathrm{C}$ (internal target temperature) is expected to reach a $7-\log$ reduction of Salmonella ${ }^{9}$. However, studies on chicken breast fillets observed unexpected heat resistance to Salmonella ${ }^{10}$. The presence of chemical ingredients, size of the product, cooking method, water activity, fat content, and product $\mathrm{pH}$ are factors that affect pathogen heat resistance ${ }^{10}$. Furthermore, Salmonella may survive during the cooking of comminuted chicken manufactured products and cause subsequent illness in consumers, especially if the chemical ingredients interfere with thermal inactivation or increase the heat resistance of the pathogens. To date, there are no published studies that show the thermal inactivation activity of Salmonella in moisture enhanced reconstructed chicken products during common cooking practices. The lack of quantitative data relating chicken cooking practices for with the reduction of Salmonella in chicken products remain a large, unaddressed problem in food safety guidelines ${ }^{10}$. 
The common cooking practices to inactivate foodborne pathogens in chicken products including pan-broiling, double pan-broiling, and roasting (American Meat Science Association, 1995) should be evaluated in real commercial cooking settings, because that environment is expected to be much less controlled and much more dynamic than a laboratory setting. Almost no commercial chicken meat processors are willing to use a microbial foodborne pathogen in their cooking practices to determine the critical control points and critical limits of cooking temperatures in their Hazard-Analysis-Critical-Control-Point plan. Therefore, choosing a surrogate of pathogen and including that surrogate in laboratory validation studies before moving onto pilot plant or commercial testing is an appropriate method ${ }^{11}$. Enterococcus faecium, is a Gram-positive, cocci with chain shape arrangement, non-endospore forming, and facultative bacteria. Previous studies at our West Virginia University (WVU) poultry farm has included $E$. faecium as a Salmonella surrogate in the steaming ${ }^{12}$ and standard or aggressive thermal pelleting of chicken feeds ${ }^{13}$. Our previous study also confirmed that E. faecium is a promising Salmonella surrogate in antimicrobial dip testing for broiler carcasses ${ }^{14}$. However, E. faecium has not been studied on chicken meat products during cooking to verify that it is an ideal surrogate for

\section{Salmonella.}

Therefore, this study aims to conduct side-by-side comparison cooking studies of Salmonella verse E. faecium to compare their thermal inactivation kinetics in reconstructed, comminuted chicken patties moisture enhanced $(\mathrm{MH})$ with various pump rates and double pan-broiled with various setup temperatures.

\subsection{Materials and Methods}

\subsubsection{Bacteria strains}


Bacterial cultures used in this study include Salmonella Typhimurium American Type Culture Collection (ATCC) 14028, Salmonella Tennessee ATCC 10722, and the Salmonella surrogate bacteria Enterococcus faecium ATCC 8459. These same strains were used in our previous validation studies of antimicrobials on broiler carcasses ${ }^{14}$. Individual strains of Salmonella and Enterococcus was stored as frozen culture at $-80^{\circ} \mathrm{C}$ freezer and activated by streak-plating a loop of bacteria lawn onto xylose-lysine-Tergitol-4 (XLT-4) (Hardy Diagnostics, MD, USA) and bile esculin agar (BEA, Hardy Diagnostics) followed by incubating at $35 \mathrm{C}$ for $48 \mathrm{~h}$ to obtain the single colonies of Salmonella and E. faecium, respectively. The XLT-4 agars of Salmonella were stored at $4^{\circ} \mathrm{C}$ ready for the preparation of the experimental inoculum. Since natural background bacteria of chicken meat can be grown on bile esculin agar which interferes with the numeration of inoculated E. faecium (unpublished data), a nalidixic acid (NaL)-resistant strain of E. faecium was prepared prior to the experiment.

\subsubsection{Preparation of NaL-resistant E. faecium strain}

Two single colonies from the BEA were transferred into a $10 \mathrm{ml}$ of tryptic soy broth (TSB, Hardy Diagnostics) and incubated at $35 \mathrm{C}$ for $24 \mathrm{~h}$, followed by spread plating $0.3 \mathrm{ml}$ of the $24 \mathrm{~h}$ culture solution onto a BEA containing $100 \mathrm{ppm}$ of $\mathrm{NaL}$ (BEA-NaL, Hardy Diagnostics) and incubated at $35^{\circ} \mathrm{C}$ for $48 \mathrm{~h}$. A single colony from the BEA-NaL was transferred into a fresh $10 \mathrm{ml}$ of TSB plus $100 \mathrm{ppm}$ of NaL (TSB-NaL) incubated for $24 \mathrm{~h}$. Then, the $100 \mathrm{ul}$ of the $24 \mathrm{~h}$ solution was continuously sub-cultured into a fresh $10 \mathrm{ml}$ of TSB-NaL for 5 times. The final sub-culture solution was streak-plated onto a new BEA-NaL and incubated at $35^{\circ} \mathrm{C}$ for $48 \mathrm{~h}$ to create a NaLresistant E. faecium. Since this NaL-resistant E. faecium was created by "point-mutation", the culturing of NaL-resistant E. faecium in this study were accompanied with $100 \mathrm{ppm}$ of $\mathrm{NaL}$ in broth or agar plates. 


\subsubsection{Preparation of bacterial inoculum}

Two single colonies from the XLT-4 (Salmonella) or BEA-NaL (E. faecium) agars were pickedup by a sterilized plastic loop and transferred into a $10 \mathrm{ml}$ of TSB and TSB-NaL followed by incubating at $35 \mathrm{C}$ for $24 \mathrm{~h}$, respectively. The fresh $24 \mathrm{~h}$ culture broth were then washed twice in $0.1 \%$ buffered peptone water (BPW, Hardy Diagnostics) by centrifuging for $15 \mathrm{~min}$ in a microcentrifuge (VWR Symphony 4417, VWR International, Radnor, PA) with the speed of 5,000 × g, resuspending in $10 \mathrm{ml}$ of $0.1 \% \mathrm{BPW}$, centrifuging again, and resuspending again in a fresh sterilized $0.1 \% \mathrm{BPW}$. After completing the washing process of bacterial cultures, the two Salmonella strains were mixed and spread plated onto XLT-4 agars with 100-fold serial dilution in $0.1 \% \mathrm{BPW}$ to determine the concentration of the inoculum $(\sim 7.4 \log \mathrm{CFU} / \mathrm{ml})$. The NaL-

resistant E. faecium solution was also numerated on BEA-NaL to calculate the concentration of that inoculum $(\sim 8.0 \log \mathrm{CFU} / \mathrm{ml})$.

\subsubsection{Manufacturing of chicken patties and inoculation}

Frozen bone-less chicken breasts used in this study were purchased from Young \& Stout, Inc., Bridgeport, West Virginia and shipped to the West Virginia University Food Science Core Lab. The frozen chicken meat was thawed overnight at $4 \mathrm{C}$ before the experiment. On the day of experiment, the thawed meat was manually cut into small slices with knives and distributed into $1.5 \mathrm{~kg}$ batches. Each batch was then coarse grounded in a small benchtop scale meat grinder with a kidney plate $(0.95 \mathrm{~cm}$ diameter $)$ followed by adding $30 \mathrm{~mL}$ of the prepared inoculum of Salmonella or NaL- resistant E. faecium to reach the initial bacterial concentration of $\sim 6.0 \pm 0.4$ $\log \mathrm{CFU} / \mathrm{g}$. The inoculation process was conducted by mixing the chicken meat $(1.5 \mathrm{~kg})$ and the prepared inoculum $(30 \mathrm{ml})$ thoroughly and stirring for $2 \mathrm{~min}$ in a bowl-lift standard mixer (KitchenAid $^{\circledR}$, St. Joseph, MI, U.S.A) with the slowest speed set at "stir". Then, the inoculated 
chicken meat was $\mathrm{MH}$ to reach 1,5 and $11.1 \%$ of pump rates by adding 15,75 or $150 \mathrm{~mL}$ of a $\mathrm{NaCl}(2.0 \%)$ plus Na-tripolyphosphate $(0.5 \%)$ solution (BK Giulini Corporation, Simi Valley, CA, U.S.A.) into the meat, respectively, followed by mixing with the same "stir" speed for another 2 min. Therefore, the MH chicken meat with the final pump rates of 1, 5, and 11.1\% containing 0.2 and $0.05 \%, 1.0$ and $0.25 \%, 2.0$ and $0.50 \%$ of $\mathrm{NaCl}$ and Na-tripolyphosphate $(\mathrm{wt} / \mathrm{wt})$, respectively. The chicken meat portion was then weighted $(120 \pm 1.0 \mathrm{~g})$ and manufactured manually into a chicken patty using a hamburger patty maker (Mainstays 6-ouncepatty maker, Walmart, Bentonville, AR, U.S.A). Each chicken patty was $2.1 \mathrm{~cm}$ thick with a $12.4 \mathrm{~cm}$ diameter. Two chicken patties were finally placed into a foam tray $(20 \times 25 \mathrm{~cm}$, Pactiv, Lake Forest, IL, U.S.A) containing the absorbent pads, manually packaged by covering the tray with polyvinyl chloride films (Omni-film, Pliant Corporation, OH, U.S.A) using a film wrapping dispenser and stored in a refrigerated incubator at $4.2 \pm 0.3 \mathrm{C}$ for $42 \mathrm{~h}$.

\subsubsection{Cooking of non-intact chicken patties}

After $42 \mathrm{~h}$ storage, chicken patties were aseptically removed from the tray under a biosafety hood and cooked on a grill (Farberware ${ }^{\circledR}$ 4-in-1 Grill, Fairfield, CA, U.S.A) for 0, 30, 60, 90, 120, 150, $180,210,240,300,330,360,390$, and $420 \mathrm{~s}$, respectively. The grill was set at "grill" referred as double pan-broiling with heated top and bottom plates touching meat samples and pre-heated with the temperatures set at 200,300 , and $425 \mathrm{~F}$, respectively. This procedure was used to determine the microbial populations of Salmonella or E. faecium and their related thermal dynamic parameters including D-values and "shoulder time" of each set-up cooking temperature. The internal temperature of each patty during heating were monitored and recorded in a software of PicoLog (Pico Technology Ltd., Cambridge, U.K) after inserting a type-K thermocouple into the patty's geometric center and automatically recording changes of temperatures for every $10 \mathrm{~s}$. 


\subsubsection{Microbiological analyses}

After cooking, chicken samples were immediately placed in a WhirlPak ${ }^{\circledR}$ food sample filter bag $(19 \times 30 \mathrm{~cm}$, Nasco, Modesto, CA, U.S.A) containing $100 \mathrm{~mL}$ of refrigerated TSB plus $0.1 \%$ sodium pyruvate (Fisher Scientific, Fair Lawn, NY, U.S.A) for enumeration of bacteria survival populations including heat injured cells. The sample bags with chicken meat were homogenized in a blender (Microbiology International, Frederick, MD, U.S.A) for $2 \mathrm{~min}$. The liquid solution from the filtered side of sample bags was then 10- or 100-fold serial diluted in 9.0 or $9.9 \mathrm{ml}$ of $0.1 \% \mathrm{BPW}$. One tenth $\mathrm{mL}$ of this solution was spread-plated onto XLT-4 and BEA-NaL agars for Salmonella and E. faecium, respectively. After spread-plating, a thin layer of $12 \mathrm{ml}$ of melted tryptic soy agar (Hardy Diagnostics) was added overlaid on the surface of each agar before incubating at $35 \mathrm{C}$ for $48 \mathrm{~h}$ to manually count the colonies to recover heat injured cells. All bacterial cells counts were transformed to $\log _{10} \mathrm{CFU} / \mathrm{g}$ with the detection limit of $0.3 \log _{10} \mathrm{CFU} / \mathrm{g}$.

\subsubsection{Statistical analysis}

After preliminary tests, the whole cooking experiments were conducted using 3 replicates with 3 chicken patties (120 g per sample unit) in each treatment generating a total of 9 samples. Experimental design is a completely randomized $(3) \times(3) \times(6-14)$ factorial structure with 3 different pump rates, 3 different set-up temperatures, and 6-14 different cooking times. Survival and reduction data of the two bacterial cells were first analyzed using the SAS mixed model procedure (version 9.2, SAS Institute, Cary, NC) with individual factors and interactions between them. After that, thermal kinetic parameters of "shoulder-time" and D-values of each cooking treatment were calculated using the United States Department of Agriculture (USDA)Integrated-Predictive-Modeling-Program (IPMP) and the USDA-Global-Fit software according to the procedures described in Huang ${ }^{15,16}$, respectively. Finally, calculated "shoulder-times" and 
D-values of each treatment were also analyzed use the same mixed model procedure of SAS and a pair-wised t-test was used to compare parameter differences between Salmonella and its surrogate $E$. faecium. The differences of each individual comparison were determined by Tukey's HSD with the significance level at $\alpha=0.05$.

\subsection{Results}

\subsubsection{Temperature changes of the geometric center}

Figure 1 shows the temperature changes at the geometric center of chicken patties cooked at different set-up temperatures. Preliminary investigation indicated that various pump rates $(1,5$ and 11.1\%) did not affect $(P>0.05)$ temperature of chicken samples during cooking, therefore Figure 1 depicts the average values of 6 cooked samples across the three pump rates. After aerobic storage at $4.2^{\circ} \mathrm{C}$ for $42 \mathrm{~h}$, the initial temperatures were ranged from 2.3 to $3.6^{\circ} \mathrm{C}$ among all chicken samples before cooking (Figure 1). Double pan-broiling chicken patties with the griller temperatures set at 200,300 , and $425^{\circ} \mathrm{F}$ took 300,255 , and $165 \mathrm{~s}$, respectively, to reach the geometric temperature of $73.8^{\circ} \mathrm{C}$, the target internal temperature of cooked chicken meat products without causing microbial safety risks ${ }^{17}$. Internal temperatures of chicken samples reached as high as $84.7,80.4$, and $86.5^{\circ} \mathrm{C}$ with set-up cooking temperatures at 200,300 , and $425^{\circ} \mathrm{F}$, respectively, by the end of the cooking period (Figure 1).

\subsubsection{Survivals of microbial population during cooking}

Survival curves of Salmonella and E. faecium cell populations in MH reconstructed comminuted chicken patties under isothermal cooking conditions set at 200,300 , and $425^{\circ} \mathrm{F}$ were shown in Figure 2 and Figure 3, respectively. Among all chicken samples, cooking did not reduce significantly $(P<0.05)$ Salmonella or E. faecium at the early period $(0$ to 150 s). Cellular reductions accelerated after the early period. Under isothermal conditions, as expected, cooking 
chicken samples by double pan-broiling gradually reduced $(P<0.05)$ the bacterial cells with increasing of cooking time (Figures 2 and 3) with a higher set-up temperature reducing cells at a greater rate (Figures 2 and 3).

For Salmonella, double pan-broiling decreased $(P<0.05)$ cell counts from 5.97-6.33 $\log _{10} \mathrm{CFU} / \mathrm{g}$ to below the detect limit $\left(0.3 \log _{10} \mathrm{CFU} / \mathrm{g}\right)$ or achieved reductions of $>5.5 \log _{10} \mathrm{CFU} / \mathrm{g}$ after 360 , 180-225, and 150-165 s after cooking chicken patties at 200,300, and $425 \mathrm{~F}$, respectively, regardless of pump rates (Figure 2). For E. faecium, double pan-broiling chicken patties across all pump rates at 200,300 , and $425 \mathrm{~F}$ reduced the cell counts by $3.71-4.73,4.67-5.48$, and 5.56-6.14 $\log _{10} \mathrm{CFU} / \mathrm{g}$, respectively, by the end of the cooking period (Figure 3). Compared to Salmonella, the surrogate E. faecium in chicken samples was resistant $(P<0.05)$ to heat treatments because no samples were reduced $>5.5 \log _{10} \mathrm{CFU} / \mathrm{g}$ when cooked at 200 and $300 \mathrm{~F}$ (Figures 2 and 3). For Salmonella, less $(P<0.05)$ time was required to achieve the reduction of $5.5 \log _{10}$ in chicken patties MH with $1.0 \%$ pump rate compared with those of 5.0 and $11.1 \%$ pump rates, as shown by the 180 vs 210 and $225 \mathrm{~s}$, and 150 vs 165 and $165 \mathrm{~s}$ times cooking at 300 and $425 \mathrm{~F}$, respectively (Figure 2). A greater $(\mathrm{P}<0.05)$ reduction in E. faecium was shown in chicken samples with $1.0 \%$ pump rate compared with those from the 5.0 and $11.1 \%$ ones, as shown as 4.73 vs 4.29 and 3.71 $\log _{10} \mathrm{CFU} / \mathrm{g}, 5.48$ vs 4.74 and $4.67 \log _{10} \mathrm{CFU} / \mathrm{g}$, and 6.14 vs 5.56 and $5.99 \log _{10} \mathrm{CFU} / \mathrm{g}$, when cooked at 200, 300, and $425 \mathrm{~F}$, respectively (Figure 3).

\subsubsection{Modeling of bacterial survivals during cooking}

The USDA-IPMP software ${ }^{15}$, containing 4 survival mathematical models, were used in this study to calculate "shoulder-times" (Buchanan Two-phase Model) and D-values (Mafart-Weibull model) of Salmonella and E. faecium in chicken patties prepared with three different pump rates. The IPMP-Global fit software ${ }^{16}$ was also used to compare the D-values of Salmonella and E. faecium 
in chicken samples cooked at three different set-up temperatures using a single pump rate $(1.0,5.0$, or $11.1 \%$ ) simultaneously.

As expected, the calculated values of "shoulder-time" of Salmonella and E. faecium in chicken patties decreased $(P<0.05)$ with increasing set-up temperatures (Table 1). When the set-up temperatures increased from 200 to $425 \mathrm{~F}$, the "shoulder-time" of Salmonella and E. faecium in chicken samples across all pump rates decreased $(P<0.05)$ from $229.0-247.8$ to $82.3-118.0 \mathrm{~s}$ and 234.8-259.4 to 128.3-130.9 s (Table 1), respectively. For Salmonella, the pump rates had a significant effect on $(P>0.05)$ the "shoulder-times" in chicken patties during cooking. When cooked at $300 \mathrm{~F}$, the "shoulder-times" of samples with $1.0 \%$ and $5 \%$ pump rate were 128.0 and $133.4 \mathrm{~s}$, respectively, which were shorter $(P<0.05)$ than the $11 \%$ samples $(158.6 \mathrm{~s}$, Table 1$)$. When the set-up temperature was increased to $425 \mathrm{~F}$, a "shoulder-time" in samples with $1 \%$ pump rate $(82.3 \mathrm{~s})$ was significantly shorter $(P<0.05)$ than those of the $5.0(118.0 \mathrm{~s})$ and $11.1 \%$ pump rates (116.6 s, Table 1). In contrast to Salmonella, "shoulder-times" of E. faecium in chicken patties did not differ significantly $(P>0.05)$ regardless of various pump rates. The "shouldertimes" of chicken patties with $1.0 \%$ pump rate were $235.6,136.2$, and $128.3 \mathrm{~s}$, which were similar $(P>0.05)$ to the $5.0 \%$ samples $(259.4,130.1$, and $128.6 \mathrm{~s})$ and the $11.1 \%$ samples $(234.8,151.5$, and 130.9 s) when cooked at 200, 300 and $425 \mathrm{~F}$, respectively (Table 1).

The D-values of Salmonella and E. faecium (Table 2) in chicken patties were significantly affected by the set-up temperatures $(P<0.05)$ and pump rates $(P<0.05)$ but the interaction was not significant $(P=0.05$ to 0.06$)$. The Salmonella, D-values of chicken patties with $1.0 \%$ pump rate cooked at 200,300, and $425 \mathrm{~F}$ were $248.2,127.0$, and $102.7 \mathrm{~s}$, respectively, which were lower $(P$ $<0.05)$ than to the $5.0 \%$ samples $(260.3,157.7$, and $115.3 \mathrm{~s})$ and the $11.1 \%$ samples $(263.7,156.7$, and $119.8 \mathrm{~s}$ ) (Table 2). The Salmonella, D-values of E. faecium in chicken samples with 1.0\% 
pump rate of 200,300, and $425 \mathrm{~F}$ were $271.0,168.0$, and $115.5 \mathrm{~s}$, respectively, which were similar $(P>0.05)$ to the $5.0 \%$ samples $(284.7,172.7$, and $119.3 \mathrm{~s})$, but lower $(P<0.05)$ than the $11.1 \%$ samples $(298.3,185.0,122.5$ s). Figure 4 shows the pair-wise comparisons between the D-values of Salmonella and E. faecium in all samples with all combinations of set-up temperatures and pump rates. D-values of Salmonella were lower $(P<0.05)$ than the surrogate E. faecium in almost all cooked chicken patties except for the samples with 5 and $11.1 \%$ pump rates cooked at $425 \mathrm{~F}$, which showed similar D-values between the two bacteria (Figure 4).

\subsection{Discussion}

Studies related to thermal inactivation of Salmonella in chicken products have been initiated about 2 decades ago. In two early studies of Murphy ${ }^{18,19}$ reported that heating ground chicken breast meat in a $70^{\circ} \mathrm{C}$ water bath reduced Salmonella by $7-\log _{10} \mathrm{CFU} / \mathrm{g}$ after approximately $2.1 \mathrm{~min}$ (126 s). In the current study, the manufacturing, packaging, storage and cooking of $\mathrm{MH}$ reconstructed comminuted chicken patties stimulated the retail commercial processing. Results indicated that double pan-broiling with the set-up temperature of $425^{\circ} \mathrm{F}$ achieved $>5.5 \log _{10} \mathrm{CFU} / \mathrm{g}$ reduction after cooking of 2-3 min, suggesting that double pan-broiling with two heating plates, employed by most fast food restaurant kitchens, is a very efficient approach for thorough cooking of chicken patties.

For double pan-broiling of chicken patties at 200, 300 and $425^{\circ} \mathrm{F}$, the population of Salmonella and E. faecium did not decrease significantly at the early stage of cooking indicating a "shoulder effect", which agree with previous studies of Huang ${ }^{20}, \mathrm{Li}$ et al. ${ }^{14}$ and Jiang et al. ${ }^{21}$. The internal temperatures of the chicken patties did not increase rapidly enough to kill bacterial cells at the early stage due to the geometric dimension of chicken patties ${ }^{20}$. The "shoulder effect" observed 
in this study was expressed as "shoulder time" of each cooked sample calculated from Buchanan Two-phase Model in the USDA-IPMP software ${ }^{15}$. The "shoulder-times" of Salmonella in chicken patties decreased with increasing pump rates at each cooking set-up temperature. In these samples, the higher phosphate immobilized more water in the muscle myofibril lattices which decreased the rate of heat transfer inside of the chicken patties during cooking ${ }^{22}$. The D-value, defined as the time required to kill $90 \%(1.0-\log )$ of the organism at a specific heating temperature, is used commonly to measure the death rate an organism during thermal inactivation process ${ }^{23}$. Juneja et al. ${ }^{24}$ reported that the D-values of Salmonella heating at 58 to $65^{\circ} \mathrm{C}$ ranging from 7.08 to $0.59 \mathrm{~min}(424.8$ to $35.4 \mathrm{~s}$ ) in ground chicken with $3 \%$ fat. Murphy et al. (2002) found that the D-values of Salmonella at the temperatures of 60 to $70^{\circ} \mathrm{C}$ in a commercially manufactured ground chicken patties ( $5 \%$ fat) were 8.09 to $0.32 \mathrm{~min}$ ( 485.4 to 19.2 s). In a related study, Murphy et al. (2003) also reported that the D-values of Salmonella in ground chicken breast meat heating at 60 to $70^{\circ} \mathrm{C}$ ranged from 3.83 to $0.10 \mathrm{~min}(229.8$ to $6 \mathrm{~s}$ ). Comparing the current D-values with previous findings is limited by three factors. First, the current study used commercial size $\mathrm{MH}$ chicken patties rather than 10 to $100 \mathrm{~g}$ ground chicken meat. Second, the cooking method was commercial double pan-broiling compared with immersion heating in a circulated water bath. Third, D-values were calculated from MafartWeibull model which includes the "should-effect" of the cooking process in this study instead of linear or linear regression models used in all previous studies. The current D-values calculated for Salmonella are similar to the previous studies even with the above limitations. In this study, Salmonella cells in chicken patties MH with 1.0\% pump rate were more susceptible to heating as shown by shorter cooking times to reach $>5.5 \log _{10}$ reduction, shorter "shoulder times" and lower D-values compared with the samples with greater pump rates. Our most recent 
study $^{21}$ also found that Campylobacter jejuni in the chicken patties with $1.0 \%$ pump rate is more sensitive to the heat than the $11 \%$ pump rate samples when cooked at 400 and $425^{\circ} \mathrm{F}$. These results could be explained by the following two reasons, 1) compared to the $11 \%$ pump rate samples, chicken samples $\mathrm{MH}$ with 1\% pump rate higher moisture loss during cooking increases the fat content; and 2) compared to the $1.0 \%$ pump rate samples, the $11 \%$ samples higher sodium chloride and tripolyphosphate protect bacterial cells from heating by stabilizing bacterial cell membrane ${ }^{25}$. Kotrola and Conner ${ }^{26}$ reported that the D-values of Escherichia coli O157:H7 in ground turkey breast $\left(8 \%\right.$ salt and $0.5 \%$ polyphosphate) with $11 \%$ fat heating at 55 and $57^{\circ} \mathrm{C}$ were smaller than the samples with $3 \%$ fat as shown as $17.9 \mathrm{vs} 23 \mathrm{~s}$ and $6.1 \mathrm{vs} 10.8 \mathrm{~s}$, respectively. The same study found that D-values of E. coli $\mathrm{O} 157: \mathrm{H} 7$ in the ground turkey with 8\% salt heating at 55 (25.1-27.2 vs 7.7-11.0 s), $57(11.0-12.7$ vs $2.7-3.4 \mathrm{~s})$ and $60^{\circ} \mathrm{C}(2.9-4.8$ vs $0.7 \mathrm{~s})$ were greater than the samples with no salt ingredients ${ }^{26}$. These results indicate that cooking protocols for chicken products need to consider salt content.

Evaluating the behavior of surrogate bacteria in food processing treatments become more popular in recent years ${ }^{11}$. An ideal surrogate organism should be non-pathogenic, easy to prepare, generally stable, survive in various environmental conditions, and behave equally well or resistant to interventions (i.e. antimicrobials or thermal treatments) compared with its target pathogen ${ }^{11,27}$. E. faecium fulfills these requirements as a surrogate of Salmonella due to its survival in wide temperature ranges of 5 to $65^{\circ} \mathrm{C}, \mathrm{pH}$ ranges of 4.5 to 10.0 , and high salt concentrations $(6.5 \%)^{28}$. For chicken products, our previous study found that unstressed or coldstressed E. faecium on chicken carcasses behaved similar or resistant to four different antimicrobial solutions (peroxyacetic acid, lactic acid, lactic/citric acid blend, and chlorine water) than Salmonella ${ }^{14}$. Results of this study indicated that E. faecium is less susceptible to 
heat treatment than Salmonella in MH chicken patties because of fewer reductions after same cooking period, longer "shoulder times", and greater D-values. Bianchini ${ }^{29}$ found that E. faecium is more resistant to heat than Salmonella in a complex carbohydrate-protein meal by showing a higher temperature requirement to reach 5-log reduction $\left(73.7\right.$ vs $\left.60.6^{\circ} \mathrm{C}\right)$ and complete elimination of bacterial cells $\left(80.3\right.$ vs $\left.68^{\circ} \mathrm{C}\right)$. Ceylan and Bautista ${ }^{30}$ also reported that D-values of E. faecium in thermal processed pet food with $9 \%$ moisture were greater than the tested 7 Salmonella strains at $76.7^{\circ} \mathrm{C}(11.7$ vs $6.5 \mathrm{~min}), 82.2^{\circ} \mathrm{C}(4.1$ vs $2.7 \mathrm{~min})$, and $87.8^{\circ} \mathrm{C}(1.7$ vs 1.1 $\mathrm{min})$. The thermal resistance of E. faecium is mainly associated with its growth phase, membrane structure, amount of lipid and fatty acid and sigma factors. First, E. faecium growing at $35^{\circ} \mathrm{C}$ in this study, compared to the growth at 40 and $45^{\circ} \mathrm{C}$, this relatively low temperature may cause the increase of saturated fatty acid and decrease of unsaturated fatty acids and further decrease the fluidity of the cell membrane therefore increase thermal resistance ${ }^{28,31}$. Second, in same to previous studies ${ }^{29,30}$, E. faecium was at the stationary phase and might initiate an alternative sigma factor mediated programming adaptation which directing RNA polymerase to transcribe many genes that can be translated into proteins designated to protect bacterial cells from thermal treatments ${ }^{31}$.

In conclusion, results of this study suggested that increasing the pump rates of $\mathrm{MH}$ reconstructed comminuted chicken patties could cause Salmonella heat resistance during double pan-broiling. E. faecium could be an appropriate surrogate for Salmonella used in the thermal validation studies of chicken meat products. Further studies are needed to validate the behavior of E. faecium verse Salmonella in different formulations with various chemical ingredients such as antimicrobials or antioxidants. 
Tables and Figures 
Table 1. Buchanan Two-phase Model calculated "shoulder-times" (mean \pm standard deviation) of Salmonella Typhimurium and Tennessee and Enterococcus faecium in reconstructed comminuted chicken patties moisture-enhanced with $1.0,5.0$, and $11.1 \%$ pump rate and double pan-broiling at 200, 300, and $425 \mathrm{~F}$.

\begin{tabular}{cccc}
\hline & \multicolumn{3}{c}{$2.0 \% \mathrm{NaCl}+0.5 \%$ Na-tripolyphosphate } \\
\hline & & Pump rate $(\%)$ & \\
\hline Salmonella & 1 & 5 & 11.1 \\
Temperature (F) & $229.0 \pm 36.4 \mathrm{aA}$ & $247.8 \pm 28.2 \mathrm{aB}$ & $246.2 \pm 12.4 \mathrm{aB}$ \\
200 & $128.0 \pm 13.6 \mathrm{bA}$ & $133.4 \pm 16.3 \mathrm{bA}$ & $158.6 \pm 27.4 \mathrm{bB}$ \\
300 & $82.3 \pm 16.0 \mathrm{cA}$ & $118.0 \pm 6.8 \mathrm{cB}$ & $116.6 \pm 17.8 \mathrm{cB}$ \\
425 & & & \\
& & & \\
Enterococcus & & $259.4 \pm 6.0 \mathrm{aB}$ & $234.8 \pm 29.5 \mathrm{aA}$ \\
Temperature (F) & $235.6 \pm 9.7 \mathrm{aA}$ & $130.1 \pm 14.9 \mathrm{bA}$ & $151.5 \pm 13.6 \mathrm{bB}$ \\
200 & $136.2 \pm 10.8 \mathrm{bA}$ & $128.6 \pm 10.6 \mathrm{bA}$ & $130.9 \pm 7.0 \mathrm{cA}$ \\
300 & $128.3 \pm 8.5 \mathrm{cA}$ &
\end{tabular}

Mean values with different letters within a column differ significantly $(P<0.05)$

Mean values with different capital letters within a row differ significantly $(P<0.05)$ 
Table 2. Mafart-Weibull model calculated D-values (mean \pm standard deviation) of Salmonella Typhimurium and Tennessee and Enterococcus faecium in reconstructed comminuted chicken patties moisture-enhanced with $1.0,5.0$, and $11.1 \%$ pump rate of double pan-broiling at 200, 300 , and $425 \mathrm{~F}$.

\begin{tabular}{cccc}
\hline & \multicolumn{3}{c}{$2.0 \% \mathrm{NaCl}+0.5 \%$ Na-tripolyphosphate } \\
\hline \multicolumn{3}{c}{ Pump rate $(\%)$} \\
Salmonella & 1 & 5 & 11.1 \\
Temperature (F) & $248.2 \pm 12.7 \mathrm{aA}$ & $260.3 \pm 6.0 \mathrm{aB}$ & $263.7 \pm 9.6 \mathrm{aB}$ \\
200 & $127.0 \pm 8.4 \mathrm{bA}$ & $157.7 \pm 5.6 \mathrm{bB}$ & $156.7 \pm 10.8 \mathrm{bB}$ \\
300 & $102.7 \pm 5.6 \mathrm{cA}$ & $115.3 \pm 6.9 \mathrm{cB}$ & $119.8 \pm 6.7 \mathrm{cB}$ \\
425 & & & \\
& & & \\
Enterococcus & & $284.7 \pm 8.8 \mathrm{aB}$ & $298.3 \pm 16.5 \mathrm{aC}$ \\
Temperature (F) & $271.0 \pm 10.1 \mathrm{aA}$ & $172.7 \pm 10.1 \mathrm{bA}$ & $185.0 \pm 10.4 \mathrm{bB}$ \\
200 & $168.0 \pm 6.8 \mathrm{bA}$ & $119.3 \pm 7.5 \mathrm{cA}$ & $122.5 \pm 5.4 \mathrm{cA}$ \\
300 & $115.5 \pm 5.1 \mathrm{cA}$ &
\end{tabular}

Mean values with different letters within a column differ significantly $(P<0.05)$

Mean values with different capital letters within a row differ significantly $(P<0.05)$ 
Figure 1. Time-temperature profiles of the geometric center of moisture-enhanced reconstructed comminuted chicken patties double pan-broiling set at 200,300, and $425^{\circ} \mathrm{F}$. Each data point is the average value across all pump rates.

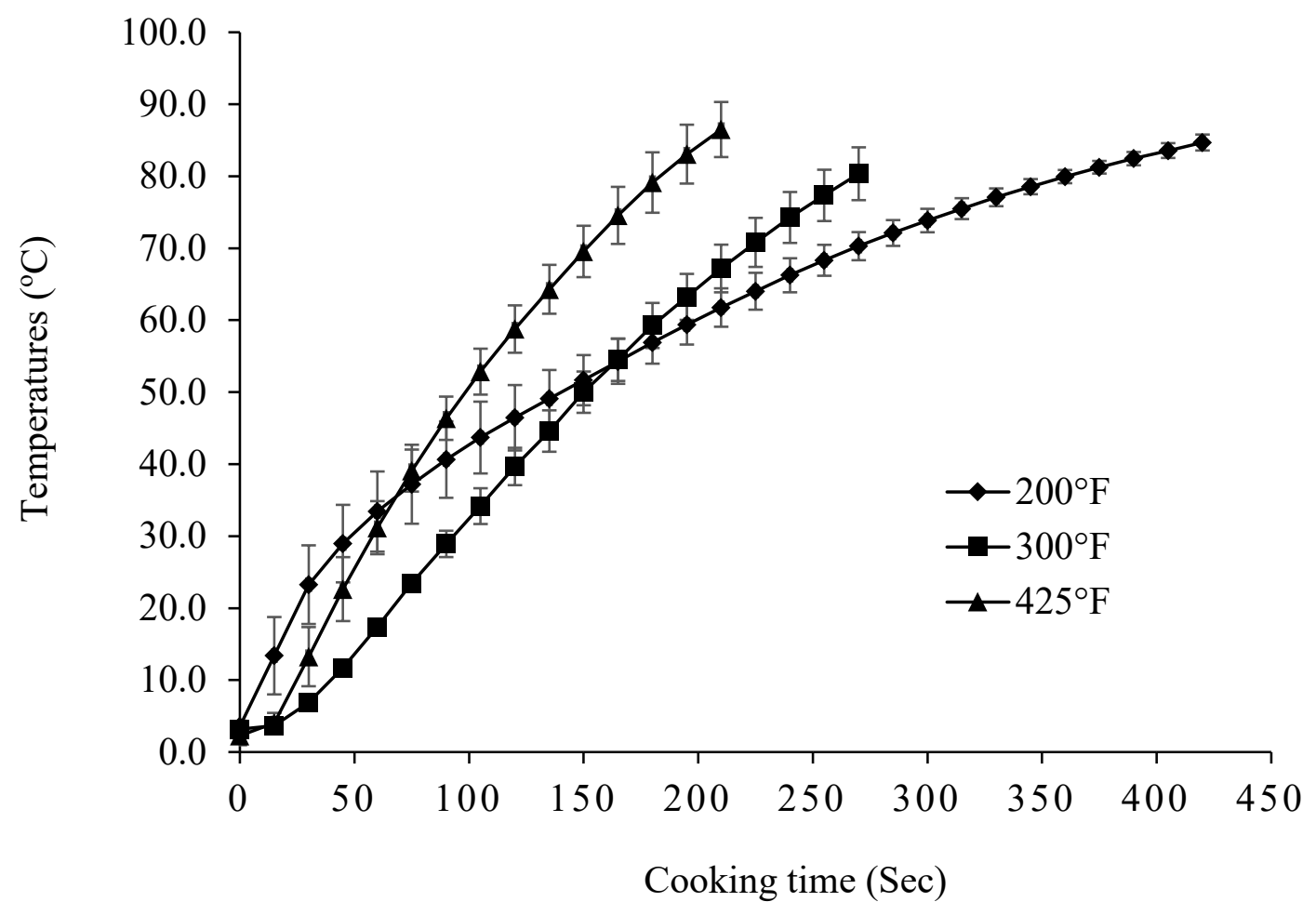


Figure 2. Survival-temperature profiles of Salmonella Typhimurium and Tennessee in reconstructed comminuted chicken patties moisture-enhanced with 1.0, 5.0, and $11.1 \%$ pump rate during double pan-broiling at 200,300 , and $425^{\circ} \mathrm{F}$.
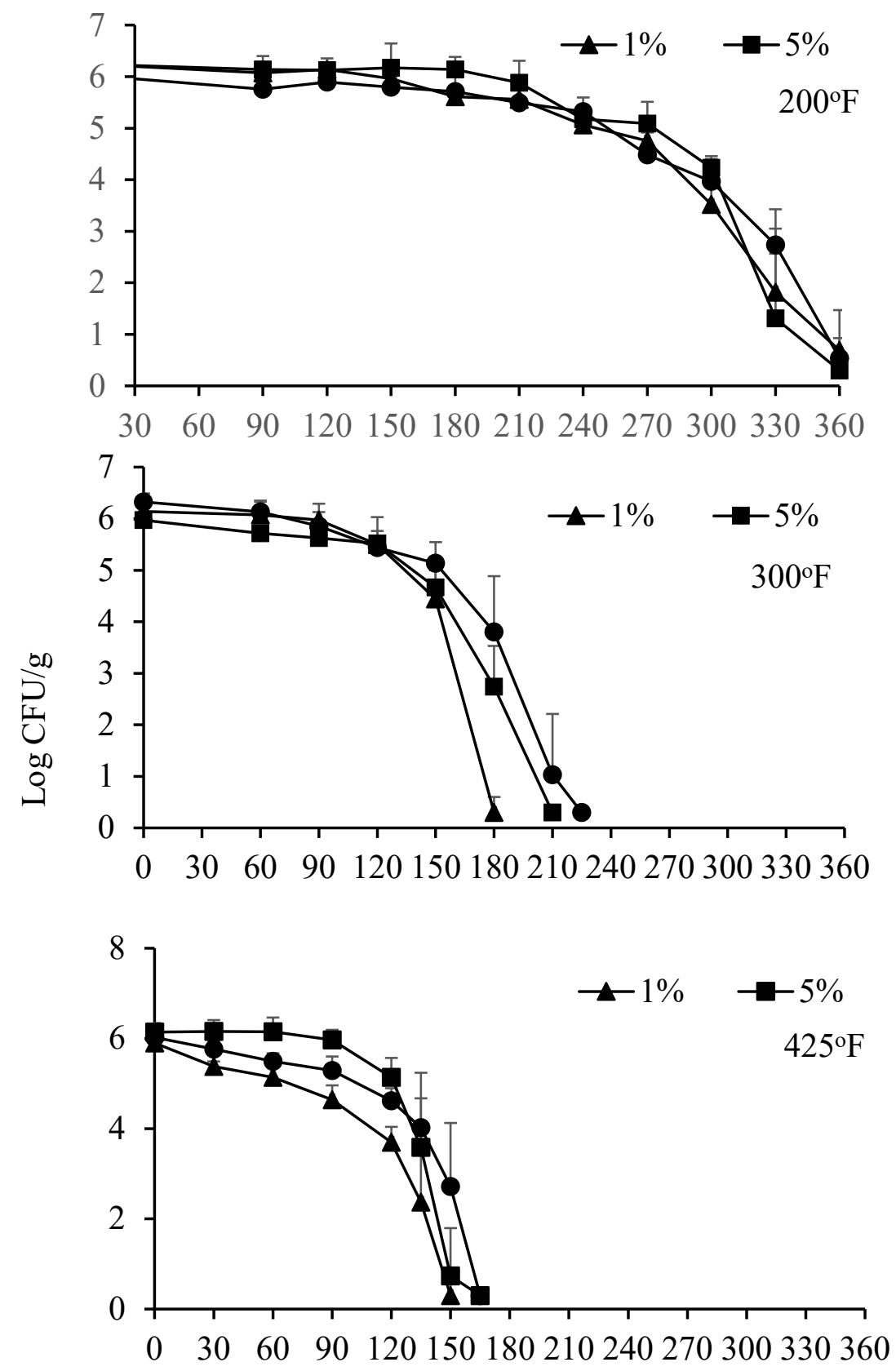

Cooking time (Sec) 
Figure 3. Survival-temperature profiles of the surrogate Enterococcus faecium in reconstructed comminuted chicken patties moisture-enhanced with 1.0, 5.0, and 11.1\% pump rate during double pan-broiling at 200,300 , and $425^{\circ} \mathrm{F}$.
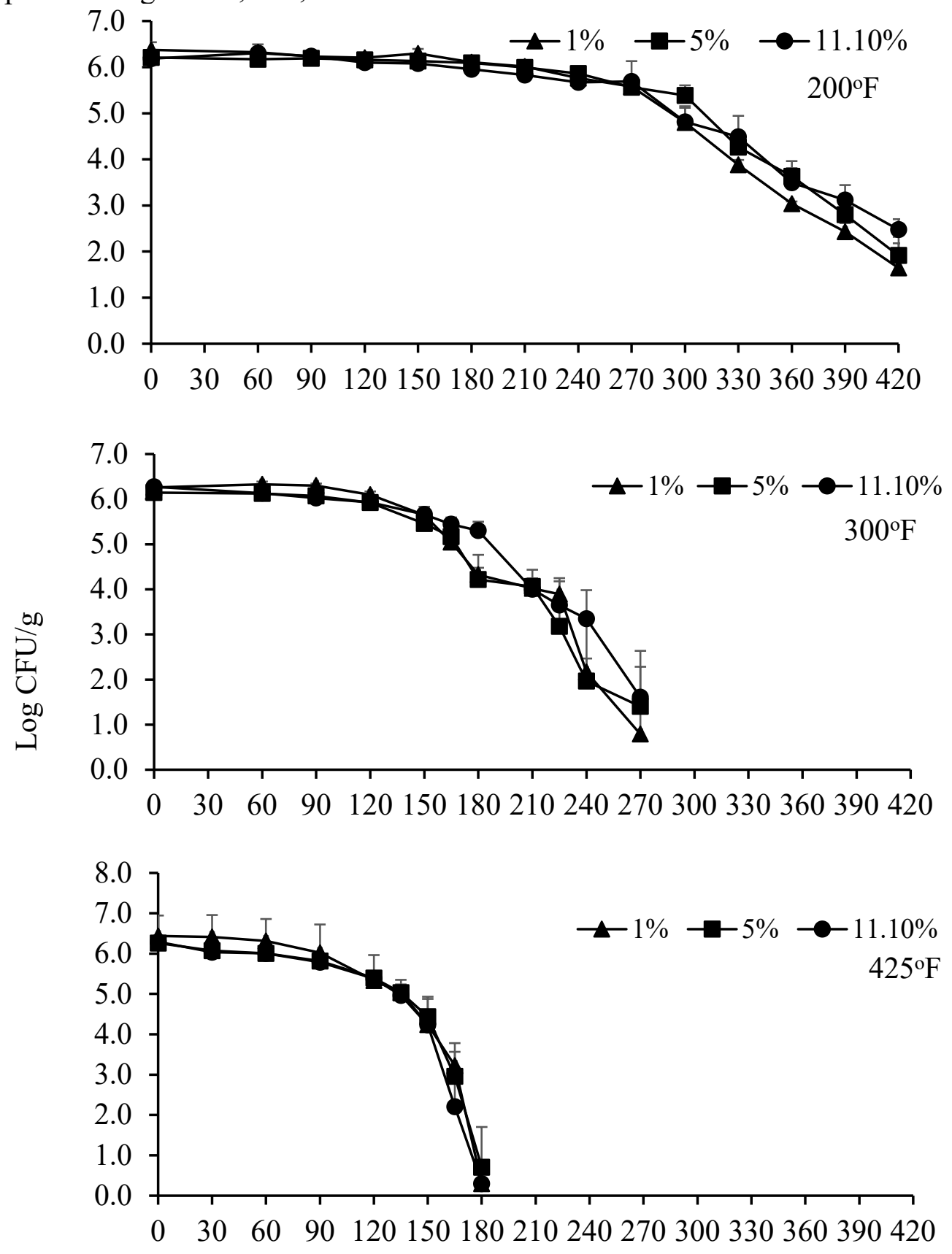

Cooking time (Sec) 
Figure 4. Pair-wised comparison of D-values of Salmonella Typhimurium and Tennessee and the surrogate Enterococcus faecium in reconstructed comminuted chicken patties moisture-enhanced with $1.0,5.0$, and $11.1 \%$ pump rate by double pan-broiling at 200,300 , and $425^{\circ} \mathrm{F}$. Different letters indicate significant difference $(P<0.05)$.
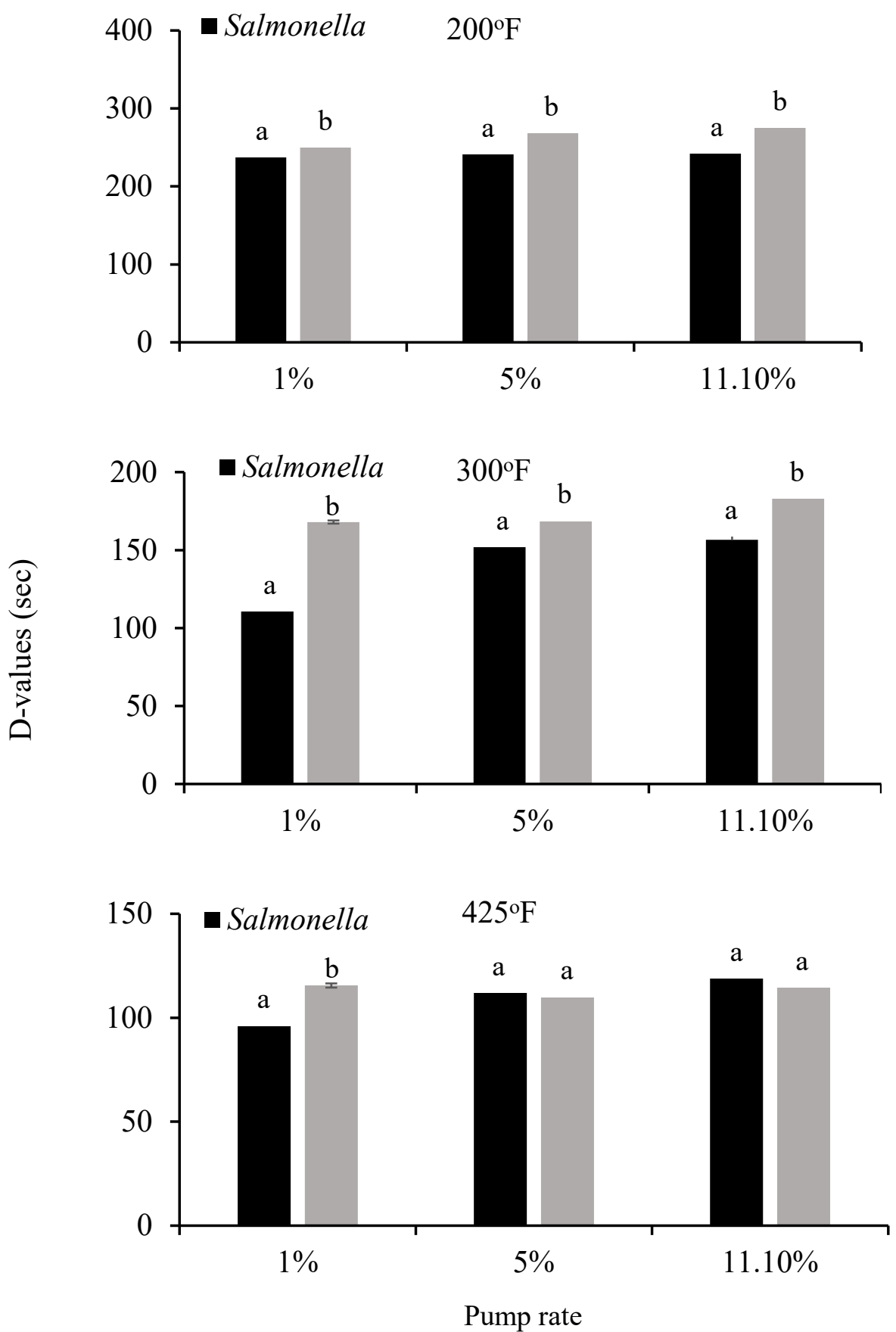


\section{References}

1. Collaboration TIFSA. Foodborne illness source attribution estimates for 2018 for Salmonella, Escherichia coli O157, Listeria monocytogenes, and Campylobacter using multiyear outbreak surveillance data, United States. Accessed Jan 23rd, 2021. https:/www.cdc.gov/foodsafety/ifsac/pdf/P19-2018-report-TriAgency-508.pdf

2. Morris JGJH, Sandra ; Batz, B. Ranking the Risks: The 10 Pathogen-Food Combinations With the Greatest Burden on Public Health. Accessed Feb 1st, 2021. https://folio.iupui.edu/bitstream/handle/10244/1022/72267report.pdf

3. FSIS U. New performance standards for Salmonella and Campylobacter in young chicken and turkey slaughter establishments: response to comments and announcement of implementation schedule. Fed Regist. 2011;76:15282-15290.

4. Gill CO, McGinnis JC, Barbut S, Young D, Lee N, Rahn K. Microbiological conditions of moisture-enhanced chicken breasts prepared at a poultry packing plant. J Food Prot. Dec 2004;67(12):2675-81. doi:10.4315/0362-028x-67.12.2675

5. Young LL, Hamm D, Ang CYW, Wilson R, Lyon CE. Research Note: Effect of Carcass Size and Sodium Pyrophosphate on Moisture Absorption and Retention by Marinated Broiler Halves. Poultry Science. 1988/03/01/ 1988;67(3):510-512. doi:https://doi.org/10.3382/ps.0670510

6. Young LL, Lyon CE. Effect of postchill aging and sodium tripolyphosphate on moisture binding properties, color, and Warner-Bratzler shear values of chicken breast meat. Poultry Science. 1997/11/01/ 1997;76(11):1587-1590. doi:https://doi.org/10.1093/ps/76.11.1587

7. USDA Food Safety and Inspection Service (USDA-FSIS). FSIS Salmonella Compliance Guidelines for Small and Very Small Meat and Poultry Establishments that Produce Ready-toEat (RTE) Products and Revised Appendix A. Accessed Feb 10th, 2021. https://www.fsis.usda.gov/wps/portal/fsis/topics/regulatory-compliance/guidelines/2017-0008

8. Shen C, Adler JM, Geornaras I, Belk KE, Smith GC, Sofos JN. Inactivation of Escherichia coli O157:H7 in nonintact beefsteaks of different thicknesses cooked by pan broiling, double pan broiling, or roasting by using five types of cooking appliances. J Food Prot. Mar 2010;73(3):461-9. doi:10.4315/0362-028x-73.3.461

9. Foods NACoMCf. Analytical utility of Campylobacter methodologies. J Food Prot. Jan 2007;70(1):241-50. doi:10.4315/0362-028x-70.1.241

10. Organization WH. Salmonella and Campylobacter in chicken meat: meeting report. vol 19. World Health Organization; 2009.

11. Hu M, Gurtler JB. Selection of Surrogate Bacteria for Use in Food Safety Challenge Studies: A Review. J Food Prot. Sep 2017;80(9):1506-1536. doi:10.4315/0362-028x.Jfp-16-536

12. Boney JW, Jaczynski J, Weidhaas JL, Bergeron AN, Moritz JS. The effects of steam conditioning and antimicrobial inclusion on feed manufacturing and inactivation of Enterococcus faecium, a Salmonella surrogate. Journal of Applied Poultry Research. 2018/12/01/ 2018;27(4):472-482. doi:https://doi.org/10.3382/japr/pfy052 
13. Boltz TP, Boney JW, Shen C, Jaczynski J, Moritz JS. The Effect of Standard Pelleting and More Thermally Aggressive Pelleting Utilizing a Hygieniser on Feed Manufacture and Reduction of Enterococcus faecium, a Salmonella Surrogate. Journal of Applied Poultry Research. 2019/12/01/ 2019;28(4):1226-1233. doi:https://doi.org/10.3382/japr/pfz088

14. Li K, McKeith AG, Shen C, McKeith R. A Comparison Study of Quality Attributes of Ground Beef and Veal Patties and Thermal Inactivation of Escherichia coli O157:H7 after Double Pan-Broiling Under Dynamic Conditions. Foods. Dec 26 2017;7(1)doi:10.3390/foods7010001

15. Huang L. IPMP 2013 - a comprehensive data analysis tool for predictive microbiology. International journal of food microbiology. 2014;171:100-107.

16. Huang L. IPMP Global Fit-A one-step direct data analysis tool for predictive microbiology. International journal of food microbiology. 2017;262:38-48.

17. United States Department of Agriculture-Food Safety and Inspection Service (USDAFSIS). Salmonella Questions and Answers. 2013;

18. Murphy RY, Marks BP, Johnson ER, Johnson MG. Inactivation of Salmonella and Listeria in ground chicken breast meat during thermal processing. J Food Prot. Sep 1999;62(9):980-5. doi:10.4315/0362-028x-62.9.980

19. Murphy RY, Marks BP, Johnson ER, Johnson MG. Thermal Inactivation Kinetics of Salmonella and Listeria in Ground Chicken Breast Meat and Liquid Medium. Journal of Food Science. 2000;65(4):706-710. doi:https://doi.org/10.1111/j.1365-2621.2000.tb16076.x

20. Huang L. Thermal inactivation of Listeria monocytogenes in ground beef under isothermal and dynamic temperature conditions. Journal of Food Engineering. 2009;90(3):380387.

21. Jiang W, Li K, Chiu Y-C, Waldman C, Shen C. Inactivation of Campylobacter jejuni in moisture enhanced non-intact chicken patties by double pan-broiling as affected by cooking setup temperature and pump rate. $L W T$. 2020/11/01/ 2020;133:109938. doi:https://doi.org/10.1016/j.lwt.2020.109938

22. Offer G, Trinick J. On the mechanism of water holding in meat: The swelling and shrinking of myofibrils. Meat Sci. 1983;8(4):245-81. doi:10.1016/0309-1740(83)90013-x

23. Jay JM, Loessner MJ, Golden DA. Modern Food Microbiology. Food Science Text Series. New York: Springer; 2005.

24. Juneja V, Eblen BS, Ransom G. Thermal Inactivation of Salmonella spp. in Chicken Broth, Beef, Pork, Turkey, and Chicken: Determination of D- and Z-values. Journal of Food Science. 2001;66:146-152.

25. Mukherjee A, Yoon Y, Belk KE, Scanga JA, Smith GC, Sofos JN. Thermal inactivation of Escherichia coli O157:H7 in beef treated with marination and tenderization ingredients. $J$ Food Prot. Jul 2008;71(7):1349-56. doi:10.4315/0362-028x-71.7.1349 
26. Kotrola JS, Conner DE. Heat Inactivation of Escherichia coli O157:H7 in Turkey Meat as Affected by Sodium Chloride, Sodium Lactate, Polyphosphate, and Fat Content $(\dagger)$. J Food Prot. Aug 1997;60(8):898-902. doi:10.4315/0362-028x-60.8.898

27. Liu B, Schaffner DW. Mathematical modeling and assessment of microbial migration during the sprouting of alfalfa in trays in a nonuniformly contaminated seed batch using Enterobacter aerogenes as a surrogate for Salmonella Stanley. J Food Prot. Nov 2007;70(11):2602-5. doi:10.4315/0362-028x-70.11.2602

28. Fisher K, Phillips C. The ecology, epidemiology and virulence of Enterococcus. Microbiology (Reading, England). Jun 2009;155(Pt 6):1749-1757. doi:10.1099/mic.0.026385-0

29. Bianchini A, Stratton J, Weier S, et al. Use of Enterococcus faecium as a surrogate for Salmonella enterica during extrusion of a balanced carbohydrate-protein meal. J Food Prot. Jan 2014;77(1):75-82. doi:10.4315/0362-028x.Jfp-13-220

30. Ceylan E, Bautista DA. Evaluating Pediococcus acidilactici and Enterococcus faecium NRRL B-2354 as Thermal Surrogate Microorganisms for Salmonella for In-Plant Validation Studies of Low-Moisture Pet Food Products. J Food Prot. May 2015;78(5):934-9. doi:10.4315/0362-028x.Jfp-14-271

31. Martínez S, López M, Bernardo A. Thermal inactivation of Enterococcus faecium: effect of growth temperature and physiological state of microbial cells. Lett Appl Microbiol. 2003;37(6):475-81. doi:10.1046/j.1472-765x.2003.01431.x 


\section{Chapter 5}


Chapter 5. Survey of Locally Small Produce Growers' Perception of Antibiotic Resistance Issues at Farmers Markets

\subsection{Abstract}

\section{Objective}

Antibiotic resistance (AR) has been identified in bacteria isolated from fresh produce from local farmers markets (FMs). This study determines local produce growers' awareness and attitude toward AR risks from produce sold at FMs.

\section{Methods}

Surveys were conducted at five FMs in WV, PA, and MI from May-2019 to March-2020.

Questions asked include demographic information, awareness and concerns of AR risks, on-farm practice of antibiotics, field rotation between produce and livestock, type of fertilizers, source of irrigation water, and interest to take AR training. Data were analyzed using Chi-square tests of independence in R-software to examine bivariate relationships between categorical variables (P $=0.05)$.

\section{Results}

The survey response rate was $41 \%(76 / 185)$ and no location variation $(\mathrm{P}>0.05)$ was observed in answers to each question. There are $92 \%$ of participants have heard of AR risks, although AR is their least concerned (28\%) risk regardless of the farm size $(\mathrm{P}>0.05)$. There are $70 \%$ of respondents believed that AR was caused by use of antibiotics in humans and farms, whereas $43 \%$ thought it was caused by AR-bacteria on produce. There are $60 \%$ of the respondents used manure or plant compost vs. $30 \%$ used chemicals as fertilizers $(\mathrm{P}<0.05)$. Source of irrigation water evenly (P > 0.05) distributed among municipal (34\%), surface (34\%), well (34\%), and rainwater (39\%). There are $29 \%$ of the participants using antibiotics to treat their animals 
compared to $40 \%$ that did not. There are $85 \%$ of the participants never converted to growing produce in the same fields in which livestock were raised previously, while $15 \%$ did $(\mathrm{P}<0.05)$. There are $68 \%$ of the participants interested in the training of AR prevention, especially for farmers owning 1-24 acres $(\mathrm{P}<0.05)$.

\section{Conclusions}

The survey results allow local government agencies to make better-informed decisions regarding AR risks related to food safety policies.

\subsection{Introduction}

A farmers' market (FM) is a public and recurring assembly of farmers selling the products directly to consumers. FMs contribute to an increasing share of US agricultural production. In 2017, farm outputs totaled $\$ 132.8$ billion, accounting for $1 \%$ of the US gross domestic product $(\mathrm{GDP})^{1}$. The number of farmers markets has increased approximately three-fold from 2,863 in 2000 to 8,771 in $2019^{2}$. The expansion of FMs has helped revitalize rural and urban communities by increasing household income and providing job opportunities. Meanwhile, it has also enabled consumers to develop better diet habits. For example, FM shoppers tend to consume more fruits and vegetables in North Carolina and Kentucky3.

However, the safety and qualities of food products from FMs are not always better than food from retail stores. It is known that FMs are loosely regulated compared to grocery store chains. Many microbial studies indicated that the microbial levels in products from FMs were higher than in retail establishments ${ }^{4-7}$ found that there is a positive relationship between FMs and reported total outbreaks and foodborne illness. Although few reported foodborne illness outbreaks directly link to foods sold at FMs, it is important to recognize that many foodborne illnesses went unreported due to limited traceability of produce and other food items sold at FMs. 
Another food safety issue related to FM products is antibiotic resistance (AR), a global public health challenge that compromises the successful treatment of infectious diseases ${ }^{8}$. More than 2.8 million AR infections and more than 35,000 deaths occur in the United States each year ${ }^{9,10}$. One of the main reasons for rising AR is the excessive usage or misusage of antibiotics to treat animal and plant diseases in agriculture ${ }^{11}$. Antibiotics used for growth promotion in food animals also play an important role in rising $\mathrm{AR}^{12}$. Antibiotic-resistant bacterial could horizontally transfer from animal to soil and then from soil to food. Antibiotic-resistant bacteria can be shed in fecal matter and move to other animals, humans, and spread in the environment through manure and drainage ${ }^{13}$.

There are many risk factors for AR during the agricultural process. Water harvest systems and the application of pesticides with contaminated water are considered the main avenues for resistant bacteria to spread into the field ${ }^{14}$. AR can also originate from the plant metabolites, which result in the generation of multidrug efflux systems ${ }^{15}$. The produce from FMs may play a role as a carrier and reservoir of AR bacteria. Blau ${ }^{15}$ found self-transmissible multiple resistance plasmids in Escherichia coli isolated from mixed salad, arugula, and cilantro. Similarly, AR E. coli was found in lettuce collected from FMs in Canada ${ }^{16}$. The AR problem is particularly critical for the local food sector because most of the produce from FMs are in a ready-to-eat state, which means consumers will be directly exposed to resistant bacteria. To reduce the spread of AR, World Health Organization (WHO) announced a plan to improve global awareness and understanding of AR through effective communication, education, and training in May $2015^{17}$. This study aims to determine local small produce growers' awareness and attitude toward food safety and AR risks from fresh produce sold at FMs. Results from the study will help identify risk factors for microbial contamination and $\mathrm{AR}$ risks in the local food sector, enabling 
policymakers to make more informed decisions regarding food safety policies with AR risk in FMs.

\subsection{Materials and Methods}

\subsubsection{Survey questionnaire development}

The initial survey questionnaire was designed by the authors after several group meetings and was subsequently distributed to selected extension agents and faculty members at West Virginia University (WVU) and Wayne State University (WSU) for further revision. The questionnaire was approved by the WVU Institutional Review Board (IRB, WVU protocol \#: 2005997264). Before conducting the formal survey, the questionnaire was pre-tested by three farmers market vendors from Charleston, West Virginia, in the 2019 WV Small Farm Conference to ensure that the survey respondents can easily understand the questions. The questionnaire consists of 20 questions, including basic demographic information such as age, gender, and education level, and questions on the awareness and concerns of antibiotic-resistant (AR) risks, production practices, and interest in taking AR training.

The survey was conducted between May 2019 and March 2020 via a face-to-face method. Survey respondents include vendors from various farmers markets in Morgantown, WV, Washington, PA, Detroit, MI, and farmers at the 2020 WV Small Farm Conference at Charleston, WV. Only produce growers who sold fruits and vegetables at farmer's markets during the data collection period were recruited. Prior to answering the questionnaire, all survey participants were required to sign a consent form, informing them that the survey was voluntary and anonymous and that they were free to withdraw at any point in time. The participants who cannot complete onsite could mail back their answers or send their answers electronically through a bar-code in the questionnaire. In total, we collected 76 completed survey responses. 


\subsubsection{Data Analysis}

Data were analyzed using R-software. We first compare whether the answers differ significantly across locations. Since no statistical difference $(P>0.05)$ is found for answers to any of the questions among various locations, the 76 completed surveys were analyzed together without being categorizing into different groups. Chi-square tests of independence were employed to examine bivariate relationships between categorical variables $(P=0.05)$.

\subsection{Results and discussion}

\subsubsection{Response Rate}

A total of $76(76 / 185,41.1 \%)$ survey responses were returned. The response rates were $80 \%$ (16/20), 85.4\% (35/41), 62.5\% (15/24), and 10\% (10/100) for WV Morgantown and WVU Health Science Center farmers markets, WV Small Farm Conference exhibition, western PA farmers market, and MI Detroit farmers market, respectively. The response rates of individual questions ranged from 19.5 to $23.5 \%$. Detroit's response rate was low because most of the vendors are hired and do not own the farms. Most of the respondents grow vegetables while raising live animals on the farm.

\subsubsection{Demographics}

The demographics of the participants are shown in Table 1. The participants were mostly females $(53 \%)$, obtained some levels of higher education $(40 \%$ with a bachelor's degree and $22 \%$ with a graduate degree), and were young to middle-aged ( $26 \%$ both being $26-35$ and $36-45$, Table 1). The demographic distribution in this study differs from a previous study of GAP survey of farmers market vendors in Kentucky, of which $54.4 \%$ of the participants were male and nearly $30 \%$ aged $50-59^{18}$. Similar to this study, Sinke ${ }^{18}$ reported that more than $60 \%$ of the participants had a bachelor's or graduate degree, suggesting that farmers market vendors are highly educated. Hunt ${ }^{19}$ also reported $63.6 \%$ of vendors were highly educated among Maine 
farmers' market vendors. Another study that investigated food safety perceptions of farmers markets managers and vendors in Texas and Arkansas by Mohammad ${ }^{20}$ indicated that the participants were mostly female (68\%), had some levels of higher education (35.2\% bachelor's degree, $24.6 \%$ graduate degree, $4.9 \%$ post-graduate degree), and aged 52 years and above (only $26.8 \%$ and $21.1 \%$ of the participants aged $37-51$ and $18-36$ ). The growers used a wide variety of land sizes for fresh produce, with $53 \%$ of respondents growing on $1-24$ acres, followed by $17 \%$ with less than 1 acre and 14\% with 24-49 acres (Table 1). More than one-third of farmers had 610 years (39\%) of farming experience, followed by less than five years of experience (33\%), which is similar to the study of Sinkel ${ }^{18}$.

\subsubsection{Major concerns regarding local food production}

Participants were asked to select their main food safety concerns of local food products at farmers' market, with options consisting of "bacteria contamination", "fertilizer", "antibiotic resistance", "soil contamination" and "water quality." Results are presented in Table 2. There are $54 \%(37 / 39)$ of the respondents indicating that soil contamination and water quality were the top concerns, followed by bacteria contamination (42.9\%) and fertilizers (35\%) (Table 2). In contrast, only $28 \%$ (19/69) expressed concerns about AR, the lowest among the five possible risks. Among respondents whose major concerns include either soil contamination, bacteria contamination, or fertilizers, a statistically significant difference $(P<0.05)$ was found between growers with different land areas (Table 2). A significant relationship $(P<0.05)$ was found within the 1-24 acres farm, which the soil contamination (23\%) and water quality (22\%) were of the greatest concerns among 1-24 acres of the farm group compared to the others. The sample number of the other two groups ( $<1$ acre and $\geq 25$ acres) lack statistical power within each group. 


\subsubsection{Fertilizer and irrigation water resource}

Fecal samples from domestic animals and livestock could contain commensal or pathogenic bacteria resistant to certain antibiotics and transferred into plant/farm soils ${ }^{21}$. The various AR genes may also be distributed through multiple farm management practices, including applying plant fertilizer and water from different irrigation sources. Furthermore, the recycling of manure during crop production can potentiate and disseminate resistance to crops intended for human consumption $^{22}$.

Since fertilizer and irrigation water are highly correlated with AR, the participants were next asked about fertilizer and irrigation water use on their farms, the results of which are shown in Table 3. Approximately $60 \%$ of the respondents use manure (61\%) and plant compost (59\%) as their farm field fertilizer, followed by $45 \%$ choose mulch and $30 \%$ use chemical fertilizers, and $11 \%$ use other types of fertilizers, including fish emulsion, seaweed powder, and chick litters

(Table 3). Harrison et al. (2013) reported that of 226 farmers from Georgia, Virginia, and South Carolina, more than $56 \%$ used manures as the primary fertilizer type. We further find a significant difference between the types of fertilizer used by 1-24 acres farm $(P<0.05)$. Plant compost (31\%), manure $(28 \%)$, and mulch $(26 \%)$ were the most $(P<0.05)$ common types of fertilizers applied by farmers of 1-24 acres size group (Table 3). There is a lack of statistical power among different types of fertilizers for the other two groups ( $<1$ acre and $\geq 25$ acres). Among the respondents who applied manure, plant compost, and mulch, the majority of them (49-62\%) are from the farm size group with $1-24$ aces, which are greater $(P<0.05)$ than the vendors from $<1$ acre (13-17\%) and $>25$ acres (21-36\%) (Table 3). According to Lupton ${ }^{23}$, in 1986-2011 over 50\% of selected organic material consumption in the U.S. are dried manure. Lupton also points out that farmers choose organic fertilizers mostly based on their prices. The 
U.S. Department of Agriculture (USDA) shows the price of manure was relatively stable in 2000-2008, while the price of chemical fertilizers drastically increased during this period. This could be one reason why farmers mostly use manure and compost as fertilizer.

For irrigation water, $34 \%, 34 \%$, and $38 \%$ of farmers used municipal, surface, and well water, respectively. Additionally, $39 \%$ of the local farmers use rainwater for irrigation, while none $(0 \%)$ use wastewater (Table 3$)$. No significant $(P>0.05)$ correlation is found between farm size and the type of irrigation water. A significant difference $(P<0.05)$ of the irrigation water types was found within the 1-24 acres farm. No statistical difference is found between the various types of irrigation methods (except wastewater) for farms in the 1-24 acres category $(P>0.05)$. The percentage of farmers using surface water for irrigation in the current study is higher than that found in previous surveys. For instance, Harrison ${ }^{24}$ found that 9.7, 14.6, 12.4, and $11 \%$ of farmers used municipal water, untested well water, surface water and rainwater for irrigation, respectively in a survey of farmers in Georgia, Virginia, and South Carolina. In a survey of Kentucky farmers, Sinkel ${ }^{18}$ reported that municipal water was the most common choice of farm use water (70.3\%), followed by rainwater (53.6\%) and surface water (15.9\%). However, Bihn ${ }^{25}$ found that $57 \%$ of produce growers in New York used surface water for irrigation. Surface water, likely contaminated with raw human and animal wastes, sewage water discharges, manure storage, and waste disposal, is well known as the reservoir of foodborne pathogens and is required to be routinely tested for microbial quality (Escherichia coli or Salmonella) according to the Food Safety Modernization Act (FSMA) produce safety rules ${ }^{26}$. Studies found that water from a lake in Connecticut contained the Shiga toxin-producing E. coli $\mathrm{O} 121: \mathrm{H}_{1}{ }^{27}$, and the $E$. coli O157: H7 and Shigella sonnei were isolated from a lake in Oregon ${ }^{28}$. Furthermore, antibiotic-resistant bacteria from fecal runoff, agricultural and animal husbandry practices, and 
local hospitals can be directly transmitted into surface water ${ }^{29-31}$, resulting in a high level of antibiotic-resistant genes in irrigation water systems around urban wastewater and agricultural effluent inflow points ${ }^{30,32,33}$.

Compared to surface water, less research has focused on harvested rainwater. However, a study on rainwater-harvesting tanks in South Africa revealed that $76 \%$ of the pathogenic E. coli isolates were resistant to cephalothin with $52 \%$ demonstrating multiple-antibiotic resistance ${ }^{34}$. This raised concern about antibiotic resistance in crops due to rainwater exposure. Therefore, it is necessary to expand our current FSMA training program by including antibiotic-resistant and soil microbial safety content in the plant fertilizer and irrigation water section, which will help local produce growers address the immerging antibiotic-resistant issue.

\subsubsection{Basic knowledge of antibiotic resistance issues}

According to the U.S. Centers for Disease Control and Prevention (CDC), more than 2.8 million antibiotic-resistant infections occur in the US each year, resulting in more than 35,000 deaths $^{9}$. Table 4 shows the survey results on the basic knowledge of antibiotic resistance issues among the survey respondents. More than $90 \%$ of respondents have heard about "Antibiotic Resistant", followed by $80 \%$ heard of "Superbugs", and nearly half heard of "Antimicrobial Resistant" (53\%) and "Antimicrobial Resistant Bacteria" (49\%) (Table 4). Results suggest that antibioticresistant issue has been widely recognized among most small produce growers. A 2015 survey from World Health Organization (WHO) on public antibiotics awareness in 12 countries indicated of 9,772 participants, 70\% had heard of the term "antibiotic resistance", followed by "drug resistance" (68\%) and "antibiotic-resistant bacteria" (66\%), while "AMR" is the least familiar term (21\%). The proportion of all participants who had never heard any of the terms is 
$14 \%$. Although the WHO study was conducted on the general public, it is interesting to note that more than 8 in 10 respondents in North America are familiar with the terms ${ }^{35}$.

We asked survey respondents to identify the factors they believe have contributed to antibiotic resistance in humans from a list of possible factors. Close to $70 \%$ of the respondents picked antibiotics used in humans (73\%) and farms (67\%) as major factors, followed by $43 \%$ identifying the presence of antibiotic-resistant bacteria on fresh produce, and $11 \%$ on other factors including overdose and unnecessary distribution (Table 4). A recent review study on riskassessment of AR indicates that fresh produce, especially vegetables, is a potential carrier for antibiotic-resistant bacteria, including extended-spectrum beta-lactamase-producing Enterobacteriaceae, mcr1-positive E. coli, colistin- and carbapenem-resistant Pseudomonas aeruginosa, linezolid-resistant enterococci and staphylococci, and vancomycin-resistant enterococci ${ }^{36}$. Antibiotic-resistant carriers can be bacteria, as well as bacteriophage in the soil of the farm. The presence of antibiotic-resistant genes (blaTEM, blaCTX-M-1 group, blaCTX-M-9 group, blaOXA-48, blaVIM, mecA, sul1, qnrA, qnrS and armA) in a fraction of phage-packaged DNA in fresh produce (Lettuce, Cucumber, Spinach) and soil were confirmed by Larranaga ${ }^{37}$. Therefore, farm soil and fresh vegetables could be optimistic reservoirs for antibiotic-resistance genes.

\subsubsection{Attitude on antibiotic-resistant (AR) issue}

Table 5 shows there is a significant relationship between participants' level of education and their attitudes toward the antibiotic-resistant issue $(P<0.05)$. The majority of the respondents $(85 \%)$ disagree that we should take antibiotics to treat the common cold, while only $15 \%$ think we should (Table 5). This result contradicts a large-scale survey conducted in Hong Kong, China, which found that $54 \%$ of all respondents mistakenly identified the cold and flu as being treatable 
with antibiotics ${ }^{38}$. A similar result was found in other studies, such as the cross-sectional survey on public knowledge of antibiotics in Italy, which found that only $9.8 \%$ of respondents knew the definition of antibiotic resistance and $21.2 \%$ knew when it was appropriate to use antibiotics ${ }^{39}$. Another cross-sectional survey about public knowledge of antibiotics in Sweden found 19.1\% of respondents agreed that antibiotics cure common colds more quickly ${ }^{40}$. Both surveys indicated that the right answers to antibiotics knowledge are more likely to come from people who are better-educated, employed, and with a family member working in the health care sector. We show a similar finding — among those who disagree that we should take antibiotics to treat the common cold, more than half (62\%) hold at least a college degree. However, regarding whether antibiotics are safe drugs, the participants split the response with $48 \%$ agreeing and $51 \%$ disagreeing with the argument. Only $23 \%$ of the respondents believe that skipping 1-2 doses will not contribute to AR compared to $77 \%$ disagreeing (Table 5). When asked about who should be responsible for the rising AR risks, half of the respondents believe that government, including food safety inspectors and health inspectors, should take major responsibility. This is followed by $37 \%$ who thought clinicians and less than one-third believed vendors (20\%), farmers (30\%), and consumers (26\%) should hold accountable for AR risks (Table 5).

\subsubsection{Farm practice of antibiotic treatment}

Table 6 shows the relationship between farm size and antibiotic treatment practices. $29 \%$ of the participants use antibiotics to treat animals, including livestock on their farms, compared to $40 \%$ not using antibiotics. $31 \%$ of respondents did not answer the question. A significant relationship $(P<0.05)$ was observed between the size of the farm and antibiotic treatment practices. 55\% of the participants who own 1-24 acres of farm use antibiotics, as compared to only $5 \%$ for less than 1 acre and 38\% for more than 25 acres $(P<0.05)$ growers (Table 6). Meanwhile, among the 
respondents who did not apply antibiotics, $52 \%$ have $1-24$ acres of farm, $12 \%$ with less than 1 acre, and 36\% have more than 25 acres $(P<0.05)$ (Table 6$)$.

Among respondents who use antibiotics, no significant $(P>0.05)$ difference exists between the types of antibiotics used on participants' farms for treating livestock. 35\% use feed-grade antibiotics, $27 \%$ use prescription injectable antibiotics, and $38 \%$ choose nonprescription injectable antibiotics (Table 6). A significant relationship $(P<0.05)$ was found within 1-24 acres farm for respondents who use antibiotics. Of the 1-24 acres farm size group, most farmers using antibiotics to treat animals used limited (55\%) antibiotics (Table 6). Overall, nearly $70 \%$ of the respondents who use antibiotics on their farm believed their dose was either limited (51\%) or in line with the veterinarian's recommendations. Only $7 \%$ of the respondents believed they sometimes overdosed and 23\% were unsure about their application levels. When asked about whether applying antibiotics affect farms' outputs, $31 \%$ of the participants thought it is "very heavily" to "heavily" affected, followed by $48 \%$ believe it is slightly affected and $21 \%$ think there is no effect, regardless of the size of farms (Table 6).

The mixed farming practice with livestock-crop production rotation is important in the sustainable agricultural system, in particular the efficient nutrient flow. Recycling and applying manure from livestock to crop production not only reduces the wasteful loss of nutrients, protects the surface and subsurface water quality, mitigates emissions of nitric oxide and nitrous oxide to the detriment of air quality, but also minimizes the need to purchase costly mineral fertilizers ${ }^{41}$. However, antibiotics in manure from livestock can be very stable and increased due to the retransformation of metabolites back to the parent compound ${ }^{42}$. The aggregation of "polluted" manure and bioactive metabolites will eventually reach the farm fields and persist for months and even years depending on their structure ${ }^{43}$. Moreover, previous studies indicate that AR genes 
entrained in manure can contaminate the crop, causing an increased risk of human consumption

of these genes ${ }^{44,45}$. Our survey results show that only $15 \%$ of the respondents have grown produce in the same fields previously used for raising livestock (Table 6). Among the 11 respondents who did mixed farming, 4 rotated every 6 months, and the rest changed every 1 to 4 years (Table 6). Results indicate that the potential of mixed farming in transferring antibiotic resistance genes from manure to produce might not be a major concern at local farmer's markets.

\subsubsection{Concerns about antibiotic resistance (AR) issue}

The relationship between farm size and the concerns of AR issue is further explored in Table 7 . Results show that respondents were split about their concerns on AR risk. A total of $44 \%$ were either "very to extremely" (16\%) or "slightly to moderately" (28\%) concerned about the risk, while $42 \%$ of the participants were "not concerned at all" (Table 7). A survey of antibiotic use on dairy farms in South Carolina found that only $30 \%$ of the respondents were familiar with "antibiotic resistance" and $86 \%$ of them worried that the overuse of antibiotics in animals could result in AR issue ${ }^{46}$. One possible reason for the low levels of concern on AR risk is the absence of any rules and regulations at the federal, state, or local government levels regarding antibiotics use in fresh produce and small-scale local animal production.

Survey results further show that the majority of the respondents (68\%) are interested in obtaining AR prevention training in addition to the Good Agriculture Pratices (GAP)/FSMA training, especially for the farmers who own 1-24 acres of land $(P<0.05)$ (Table 7). However, only $21 \%$ of the participants are willing to apply interventions to reduce AR risks even if they are affordable (Table 7). There is a CDC training on antibiotic use which offers over 10 hours of free continuing education course $\mathrm{e}^{47}$. However, not many farmers or vendors know the existence of such free training opportunities. $44 \%$ of participants would love to increase the price of their 
products (by $1-2 \%(7 \%), 3-5 \%(18 \%)$, or more than $5 \%(19 \%))$ if applying new technologies to reduce AR risks would increase the cost of production by $5 \%$ (Table 7 ). Meanwhile, $10 \%$ of the respondents would not increase the price, and $40 \%$ were not sure (Table 7).

When asked about the choices to assist local growers in adopting technologies that reduce AR risks, the responses were averagely split among certification programs, free personal consultation, new regulations, and community education website (Table 7). In 2013, officials from the U.S.-CDC pointed out that overuse of antibiotics can promote antibiotic-resistant bacteria in the food supply chain and ultimately cause resistant infections in humans. They further estimated that at least two million illnesses come from an AR infection every year, 22\% of which would be linked to foodborne pathogens including Clostridium difficile, Campylobacter, Salmonella, Shigella and Staphylococcus aureus ${ }^{48}$. AR training is currently more focused on medical or clinical areas and has not been widely presented to food processors, especially at small scale local levels. Developing certification programs with in-person classroom settings or online community education websites as a supplement to the current GAP/FSMA training program is an important approach to mitigate AR risks among small processors at local levels.

\subsection{Conclusions}

Based on the results from the survey, respondents from local farmers market appeared to have some understanding of food safety practices regarding AR issues, especially for farmers with 124 acres size of farm. Results indicate that respondents are not concerned and have knowledge on farm practices that may lead to increasing AR risks, including contamination in irrigation water and management of manure. The results of this study provide the necessary information to county extension specialists/agents in West Virginia, Pennsylvania, and Michigan and nearby 
states, in developing produce safety training programs that include AR risks in addition to the FSMA training. These survey results can also contribute to the development of training materials for farmers market managers by local farmers market associations. 
Tables and Figures 
Table 1. Demographics of survey participants

\begin{tabular}{|c|c|c|}
\hline & Frequency & $\%$ \\
\hline \multicolumn{3}{|l|}{ Gender } \\
\hline Male & 34 & $47(34 / 73)$ \\
\hline Female & 39 & $53(39 / 73)$ \\
\hline \multicolumn{3}{|l|}{ Age } \\
\hline $18-25$ & 7 & $10(7 / 73)$ \\
\hline $26-35$ & 19 & $26(19 / 73)$ \\
\hline $36-45$ & 19 & $26(19 / 73)$ \\
\hline $46-55$ & 14 & 19(14/73) \\
\hline $56-65$ & 8 & $11(8 / 73)$ \\
\hline $66+$ & 6 & $8(6 / 73)$ \\
\hline \multicolumn{3}{|l|}{ Education } \\
\hline Fewer than 12 years of schooling & 3 & $4(3 / 72)$ \\
\hline High school graduate or GED & 13 & $18(13 / 72)$ \\
\hline Associates or technical degree & 11 & $15(11 / 72)$ \\
\hline Bachelor's degree & 29 & $40(29 / 72)$ \\
\hline Graduate degree (Master's, Professional, or Ph.D.) & 16 & $22(16 / 72)$ \\
\hline \multicolumn{3}{|l|}{ Years at farmers market as a vendor/farmer } \\
\hline Less than 5 years & 22 & $33(22 / 67)$ \\
\hline 6 to 10 years & 26 & $39(26 / 67)$ \\
\hline 11 to 20 years & 8 & $12(8 / 67)$ \\
\hline More than 20 years & 11 & $16(11 / 67)$ \\
\hline \multicolumn{3}{|c|}{ Size of your farm are in production of livestock/produce } \\
\hline Less than 1 acre & 11 & $17(11 / 64)$ \\
\hline 1-24 Acres & 34 & $53(34 / 64)$ \\
\hline
\end{tabular}




\begin{tabular}{|l|l|l|}
\hline $25-49$ Acres & 9 & $14(9 / 64)$ \\
\hline $50-74$ Acres & 3 & $5(3 / 64)$ \\
\hline $75-99$ Aces & 0 & $0(0 / 64)$ \\
\hline More than 100 Aces & 7 & $11(7 / 64)$ \\
\hline
\end{tabular}


Table 2. Relationship between size of farm with major concerns regarding local food production

\begin{tabular}{|c|c|c|c|c|c|}
\hline \multirow[b]{3}{*}{ Major concerns } & \multicolumn{5}{|c|}{ Size of farm (acres) } \\
\hline & $<1$ & $1-24^{b}$ & $\geqslant 25$ & Total $(\mathrm{N}=69)$ & \\
\hline & $\mathrm{n}(\%)$ & $\mathrm{n}(\%)$ & $\mathrm{n}(\%)$ & $\mathrm{n}(\%)$ & P-value of $\mathrm{Chi}^{2}$ \\
\hline Bacteria contamination & $4(13)$ & $16(53)$ & $10(33)$ & $30(43)$ & 0.03 \\
\hline Fertilizers & $3(13)$ & $15(63)$ & $6(25)$ & $24(35)$ & 0.01 \\
\hline Antibiotic Resistance & $3(16)$ & $8(42)$ & $8(42)$ & $19(28)$ & 0.27 \\
\hline Soil contamination & $7(19)$ & $19(51)$ & $11(30)$ & $37(54)$ & 0.05 \\
\hline Water quality & $8(22)$ & $18(49)$ & $11(30)$ & $37(54)$ & 0.12 \\
\hline None of them & $1(14)$ & $2(29)$ & $4(57)$ & $7(10)$ & $\begin{array}{l}\text { No statistical } \\
\text { power }\end{array}$ \\
\hline Others $^{\mathrm{a}}$ & $0(0)$ & $5(100)$ & $0(0)$ & $5(7)$ & $\begin{array}{l}\text { No statistical } \\
\text { power }\end{array}$ \\
\hline
\end{tabular}

Note: a: Soil nutrition depletion; Sharing health farm microbes; Safe handling practice; Chemical Sewage; Young farmer. b: The major concerns of 1-24 acres size of farm shows a statistically significant relationship $(P<0.05)$ within group. 
Table 3. Relationship between size of farm with fertilizer and irrigation water resource

\begin{tabular}{|l|l|l|l|l|l|l|}
\hline & & \multicolumn{5}{|l}{ Size of farm (acres) } \\
\hline & & $<1$ & $1-24^{\mathrm{b}, \mathrm{c}}$ & $\geqslant 25$ & $\begin{array}{l}\text { Total } \\
(\mathrm{N}=64)\end{array}$ & $\begin{array}{l}\text { P-value } \\
\text { of Chi }^{2}\end{array}$ \\
\hline & & $\mathrm{n}(\%)$ & $\mathrm{n}(\%)$ & $\mathrm{n}(\%)$ & $\mathrm{n}(\%)$ & \\
\hline Fertilizer & Manure & $6(15)$ & $19(49)$ & $14(36)$ & $39(61)$ & 0.04 \\
\hline & Plant compost & $5(13)$ & $21(55)$ & $12(32)$ & $38(59)$ & 0.01 \\
\hline & Mulch & $5(17)$ & $18(62)$ & $6(21)$ & $29(45)$ & 0.01 \\
\hline & Chemical fertilizers & $2(11)$ & $8(42)$ & $9(47)$ & $19(30)$ & 0.10 \\
\hline & Others & $1(14)$ & $2(29)$ & $4(57)$ & $7(11)$ & 0.37 \\
\hline & Municipal water & $6(27)$ & $10(45)$ & $6(27)$ & $22(34)$ & 0.48 \\
\hline & $\begin{array}{l}\text { Surface water (river, } \\
\text { lake, pond etc.) }\end{array}$ & $2(9)$ & $10(45)$ & $10(45)$ & $22(34)$ & 0.05 \\
\hline & Rainwater & $5(20)$ & $12(48)$ & $8(32)$ & $25(39)$ & 0.23 \\
\hline & Wastewater & $0(0)$ & $0(0)$ & $0(0)$ & $0(0)$ & N/A \\
\hline & Well water & $5(21)$ & $10(42)$ & $9(38)$ & $24(38)$ & 0.42 \\
\hline
\end{tabular}

Note: a: Fish emulsion, seaweed powder, chicken litter, a chemical named Triple 90, urea. b: The fertilizer resource of 1-24 acres size of farm shows a statistically significant relationship $(P<$ $0.05)$ within group. c: The irrigation water resource of 1-24 acres size of farm shows a statistically significant relationship $(P<0.05)$ within group. 
Table 4. Basic knowledge of antibiotic resistant issue

\begin{tabular}{|c|c|c|}
\hline & $\begin{array}{l}\text { Frequency } \\
(\mathrm{N}=76)\end{array}$ & $\%$ \\
\hline \multicolumn{3}{|l|}{ Ever heard of the following ${ }^{a}$} \\
\hline Antibiotic Resistance & 68 & 92 \\
\hline Superbugs & 59 & 80 \\
\hline Antimicrobial Resistance & 39 & 53 \\
\hline Antimicrobial Resistant Bacteria & 36 & 49 \\
\hline \multicolumn{3}{|l|}{ Factors influence antibiotic resistance in human ${ }^{a}$} \\
\hline $\begin{array}{l}\text { Use of antibiotics administered to humans when a health issue } \\
\text { occurs }\end{array}$ & 51 & 73 \\
\hline Use of antibiotics in farms & 47 & 67 \\
\hline $\begin{array}{l}\text { Ingestion of resistant bacteria present in contaminated fresh } \\
\text { products }\end{array}$ & 30 & 43 \\
\hline Others $^{\mathrm{b}}$ & 8 & 11 \\
\hline
\end{tabular}

Note: a: Respondents could indicate more than one response. b: "Other" answers are noted as: 1. over usage of antibiotics; 2 . Use of unnecessary distribution of antibiotics when medically unnecessary; 3. Clinics. 
Table 5. Relationship of level of education and attitude of antibiotic resistant (AR) issue

\begin{tabular}{|c|c|c|c|c|c|}
\hline & $\begin{array}{l}\text { High school } \\
\text { or less }\end{array}$ & $\begin{array}{l}\text { Some } \\
\text { degree }\end{array}$ & $\begin{array}{l}\text { College } \\
\text { degree } \\
\text { or } \\
\text { above }\end{array}$ & Total & \multirow[t]{2}{*}{$\mathrm{P}$-value of $\mathrm{Chi}^{2}$} \\
\hline & $n(\%)$ & $\mathrm{n}(\%)$ & $\mathrm{n}(\%)$ & $\mathrm{n}(\%)$ & \\
\hline \multicolumn{6}{|c|}{ Should take antibiotics when have cold $(\mathrm{N}=71)$} \\
\hline Agree & $3(27)$ & $1(9)$ & $7(64)$ & $11(15)$ & $\begin{array}{l}\text { No statistical } \\
\text { power }\end{array}$ \\
\hline Disagree & $13(22)$ & $10(17)$ & $37(62)$ & $60(85)$ & 0.01 \\
\hline \multicolumn{6}{|l|}{ Antibiotics are safe drugs $(\mathrm{N}=70)$} \\
\hline Agree & $10(29)$ & $6(18)$ & $18(53)$ & $34(48)$ & 0.04 \\
\hline Disagree & $6(17)$ & $4(11)$ & $26(72)$ & $36(51)$ & 0.01 \\
\hline \multicolumn{6}{|c|}{ Skipping 1-2 doses does not contribute to $A R(N=65)$} \\
\hline Agree & $4(27)$ & $1(7)$ & $10(67)$ & $15(23)$ & 0.02 \\
\hline Disagree & $10(20)$ & $9(18)$ & $31(62)$ & $50(77)$ & 0.04 \\
\hline \multicolumn{6}{|l|}{ Most responsible for AR Risk $(\mathrm{N}=70)$} \\
\hline Vendors & $3(21)$ & $1(7)$ & $10(71)$ & $14(20)$ & $\begin{array}{l}\text { No statistical } \\
\text { power }\end{array}$ \\
\hline Farmers & $3(14)$ & $3(14)$ & $15(71)$ & $21(30)$ & 0.01 \\
\hline Consumers & $3(17)$ & $2(11)$ & $13(72)$ & $18(26)$ & 0.01 \\
\hline $\begin{array}{l}\text { Government, including Food Safety } \\
\text { Inspectors and Health Inspectors }\end{array}$ & $8(23)$ & $3(9)$ & $24(69)$ & $35(50)$ & 0.03 \\
\hline Clinicians & $6(23)$ & $3(12)$ & $17(65)$ & $26(37)$ & 0.01 \\
\hline Others ${ }^{\mathrm{a}}$ & $3(33)$ & $2(22)$ & $4(44)$ & $9(13)$ & $\begin{array}{l}\text { No statistical } \\
\text { power }\end{array}$ \\
\hline
\end{tabular}

Note: a: Uninformed people (High school or less), Publics, People who works on antibiotics (Some degree), GMO producing, Chemical company, Corporations that mandate farming progress (College degree or above). 
Table 6. Relationship between size of farm with practice of antibiotic treatment

\begin{tabular}{|c|c|c|c|c|}
\hline & & \multicolumn{3}{|c|}{ Size of farm (acres) } \\
\hline & & $<1$ & $1-24^{a, b}$ & $\geqslant 25$ \\
\hline & & $n(\%)$ & $n(\%)$ & $n(\%)$ \\
\hline \multirow{3}{*}{$\begin{array}{l}\text { Use antibiotics to treat animals (livestock) } \\
(\mathrm{N}=62)\end{array}$} & No & $3(12)$ & $13(52)$ & $9(36)$ \\
\hline & Yes & $1(5)$ & $10(55)$ & $7(38)$ \\
\hline & N/A & $7(36)$ & $9(47)$ & $3(15)$ \\
\hline \multirow[t]{3}{*}{ If YES, what antibiotics are used $(\mathrm{N}=26)$} & Feed grade antibiotics & $0(0)$ & $7(77)$ & $2(22)$ \\
\hline & Prescription injectable antibiotics & $0(0)$ & $3(42)$ & $4(57)$ \\
\hline & $\begin{array}{l}\text { Nonprescription injectable } \\
\text { antibiotics }\end{array}$ & $2(20)$ & $4(40)$ & $4(40)$ \\
\hline \multirow{4}{*}{$\begin{array}{l}\text { If YES, quantity of antibiotics used in the } \\
\text { farm is }(N=33)\end{array}$} & Limited & $1(4)$ & $12(54)$ & $9(40)$ \\
\hline & $\begin{array}{l}\text { Fair, in line with veterinarian's } \\
\text { recommendations }\end{array}$ & $2(25)$ & $4(50)$ & $2(25)$ \\
\hline & Sometimes excessive & $1(33)$ & $2(66)$ & $0(0)$ \\
\hline & Unknown & $3(30)$ & $4(40)$ & $3(30)$ \\
\hline \multirow{4}{*}{$\begin{array}{l}\text { If YES, Antibiotic treatment affects the } \\
\text { output of the farm }(\mathrm{N}=42)\end{array}$} & Not at all & $0(0)$ & $6(66)$ & $3(33)$ \\
\hline & Only slightly & $3(15)$ & $9(45)$ & $8(40)$ \\
\hline & Heavily & $1(12)$ & $5(62)$ & $2(25)$ \\
\hline & Very heavily & $1(20)$ & $3(60)$ & $1(20)$ \\
\hline \multirow{2}{*}{$\begin{array}{l}\text { In the past } 3 \text { years, did you convert to } \\
\text { growing produce in the same fields in } \\
\text { which you were previously raising } \\
\text { livestock? }(N=62)\end{array}$} & No & $\begin{array}{l}10 \\
(18)\end{array}$ & $27(50)$ & $16(30)$ \\
\hline & Yes & $1(11)$ & $5(55)$ & $3(33)$ \\
\hline
\end{tabular}




\begin{tabular}{|c|c|c|c|c|}
\hline \multirow{4}{*}{$\begin{array}{l}\text { If YES, how long ago did you change? } \\
(\mathrm{N}=11)\end{array}$} & 6 months & $0(0)$ & $2(50)$ & $2(50)$ \\
\hline & 1 year & 1 (33) & $1(33)$ & 1 (33) \\
\hline & 2 years & $0(0)$ & $1(100)$ & $0(0)$ \\
\hline & 4 years or more & $0(0)$ & $3(100)$ & $0(0)$ \\
\hline
\end{tabular}

Note: a: The quantity of antibiotics used in 1-24 acres size of farm shows a statistically significant relationship $(P<0.05)$ within group; b: The field conversion of 1-24 acres size of farm shows a statistically significant relationship $(P<0.01)$ within group. 
Table 7. Relationship between size of farm with concerns of antibiotic resistant (AR) issue

\begin{tabular}{|c|c|c|c|c|}
\hline & & \multicolumn{3}{|c|}{ Size of farm (acres) } \\
\hline & & $<1$ & $1-24^{a, b}$ & $\geqslant 25$ \\
\hline & & $\mathrm{n}(\%)$ & $\mathrm{n}(\%)$ & n (\%) \\
\hline \multirow[t]{3}{*}{ Concerns about AR issue in your products $(\mathrm{N}=67)$} & Not at all & $4(14)$ & $16(57)$ & $8(29)$ \\
\hline & Slightly to moderately & $5(26)$ & $8(42)$ & $6(31)$ \\
\hline & Very to extremely & $2(18)$ & $6(55)$ & $3(27)$ \\
\hline \multirow{2}{*}{$\begin{array}{l}\text { Interested in AR Prevention Training in addition to } \\
\text { GAP/FSMA? }(\mathrm{N}=69)\end{array}$} & Yes & $7(15)$ & $27(57)$ & $13(28)$ \\
\hline & No & $3(23)$ & $5(38)$ & $5(38)$ \\
\hline \multirow{2}{*}{$\begin{array}{l}\text { Apply interventions to reduce AR Risks if they are } \\
\text { affordable? }(N=67)\end{array}$} & Yes & $3(21)$ & $8(57)$ & $3(21)$ \\
\hline & No & $7(15)$ & $23(50)$ & $16(35)$ \\
\hline \multirow{5}{*}{$\begin{array}{l}\text { Suppose applying new technologies to reduce AR } \\
\text { risks would increase the cost of production by } 5 \% \text {, } \\
\text { how much will you increase the price of your } \\
\text { products? }(N=67)\end{array}$} & No increase & $1(14)$ & $2(29)$ & $4(57)$ \\
\hline & $1-2 \%$ & $0(0)$ & $4(80)$ & $1(20)$ \\
\hline & $3-5 \%$ & $2(17)$ & $6(50)$ & $4(33)$ \\
\hline & More than 5\% & $2(15)$ & $8(62)$ & $3(23)$ \\
\hline & Not sure & $6(22)$ & $13(48)$ & $8(30)$ \\
\hline \multirow{4}{*}{$\begin{array}{l}\text { Other than training sessions, what would help you } \\
\text { adopt technologies that reduce AR? (Choose all } \\
\text { answers that apply) }(\mathrm{N}=58)\end{array}$} & A certification program & $3(14)$ & $13(59)$ & $6(27)$ \\
\hline & Free personal consultation & $6(21)$ & $14(50)$ & $8(29)$ \\
\hline & New state/local regulations & $7(30)$ & $8(35)$ & $8(35)$ \\
\hline & $\begin{array}{l}\text { A community education } \\
\text { website }\end{array}$ & $3(17)$ & $12(67)$ & $3(17)$ \\
\hline
\end{tabular}

Note: a: The interest in antibiotic resistance training in addition to GAP/FSMA in 1-24 acres size of farm shows a statistically significant relationship $(P<0.05)$ within group. b: The willingness 
to apply interventions to reduce AR risks in 1-24 acres size of farm shows a statistically significant relationship $(P<0.05)$ within group 


\section{References}

1. USDA ERS - Ag and Food Sectors and the Economy. Accessed May 19, 2020.

https://www.ers.usda.gov/data-products/ag-and-food-statistics-charting-the-essentials/ag-andfood-sectors-and-the-economy/

2. Farmers Markets and Direct-to-Consumer Marketing|Agricultural Marketing Service. Updated Monday, May 04, 2020. Accessed May 19, 2020.

https://www.ams.usda.gov/services/local-regional/farmers-markets-and-direct-consumermarketing

3. Jilcott Pitts SB, Gustafson A, Wu Q, et al. Farmers' market use is associated with fruit and vegetable consumption in diverse southern rural communities. Nutr J. 2014;13:1-1. doi:10.1186/1475-2891-13-1

4. Levy DJ, Beck NK, Kossik AL, et al. Microbial safety and quality of fresh herbs from Los Angeles, Orange County and Seattle farmers' markets. J Sci Food Agric. 2015/10// 2015;95(13):2641-2645. doi:10.1002/jsfa.6996

5. Scheinberg JA, Doores S, Cutter CN. A Microbiological Comparison of Poultry Products Obtained from Farmers' Markets and Supermarkets in Pennsylvania. Journal of Food Safety. 2012;33:259-264.

6. Sirsat SA, Neal JA. Microbial Profile of Soil-Free versus In-Soil Grown Lettuce and Intervention Methodologies to Combat Pathogen Surrogates and Spoilage Microorganisms on Lettuce. Foods. Nov 11 2013;2(4):488-498. doi:10.3390/foods2040488

7. Bellemare MF, Nguyen N. Farmers Markets and Food-Borne Illness*. American Journal of Agricultural Economics. 2018;100(3):676-690. doi:10.1093/ajae/aay011

8. Nathwani D, Jamieson C, Barlow G. Editorial: JAC-Antimicrobial Resistance (JACAMR) a novel open access journal for research and education. JAC-Antimicrobial Resistance. 2019;1(1)doi:10.1093/jacamr/dlz001

9. $\quad$ Antibiotic resistance threats in the United States, 2019. Report. 2019;

10. Antibiotic-resistant Germs: New Threats. Accessed May 23, 2020.

https://www.cdc.gov/drugresistance/biggest-

threats.html?CDC AA refVal=https $\% 3 \mathrm{~A} \% 2 \mathrm{~F} \% 2 \mathrm{Fwww} . \mathrm{cdc} . g 0 \mathrm{\%} \% 2 \mathrm{Fdrugresistance} \% 2 \mathrm{Fbiggest}$ threats.html

11. Schwaiger K, Helmke K, Hölzel CS, Bauer J. Antibiotic resistance in bacteria isolated from vegetables with regards to the marketing stage (farm vs. supermarket). International journal of food microbiology. 2011/08// 2011;148(3):191-196.

doi:10.1016/j.ijfoodmicro.2011.06.001

12. Marston HD, Dixon DM, Knisely JM, Palmore TN, Fauci AS. Antimicrobial Resistance. Jama. Sep 20 2016;316(11):1193-1204. doi:10.1001/jama.2016.11764

13. Graham DW, Bergeron G, Bourassa MW, et al. Complexities in understanding antimicrobial resistance across domesticated animal, human, and environmental systems. Annals of the New York Academy of Sciences. Apr 2019;1441(1):17-30. doi:10.1111/nyas. 14036

14. Brandl MT. Fitness of Human Enteric Pathogens on Plants and Implications for Food Safety. Annual Review of Phytopathology. 2006;44(1):367-392.

doi:10.1146/annurev.phyto.44.070505.143359

15. Blau K, Bettermann A, Jechalke S, et al. The Transferable Resistome of Produce. mBio. 2018;9(6):e01300-18. doi:10.1128/mBio.01300-18 
16. WOOD JL, CHEN JC, FRIESEN E, DELAQUIS P, ALLEN KJ. Microbiological Survey of Locally Grown Lettuce Sold at Farmers' Markets in Vancouver, British Columbia. Journal of Food Protection. 2015;78(1):203-208. doi:10.4315/0362-028x.Jfp-14-199

17. Prigitano A, Romanò L, Auxilia F, Castaldi S, Tortorano AM. Antibiotic resistance:

Italian awareness survey 2016. Journal of infection and public health. Jan-Feb 2018;11(1):30-34. doi:10.1016/j.jiph.2017.02.010

18. Sinkel DJ, Khouryieh H, Daday J, Stone M, Shen C. Knowledge and Implementation of Good Agricultural Practices among Kentucky Fresh Produce Farmers. Food protection trends. 2018;38:111-121.

19. Hunt AR. Consumer interactions and influences on farmers' market vendors. Renewable Agriculture and Food Systems. 2007;22(1):54-66. doi:10.1017/s1742170507001597

20. Mohammad ZH, Yu H, Neal JA, Gibson KE, Sirsat SA. Food Safety Challenges and Barriers in Southern United States Farmers Markets. Foods. Dec 21 2019;9(1)doi:10.3390/foods9010012

21. Yost CK DM, Topp E. Animals and Humans as Sources of Fecal Indicator Bacteria. The Fecal Bacteria. 2011:67-91.

22. Gaze WH, Krone SM, Larsson DGJ, et al. Influence of humans on evolution and mobilization of environmental antibiotic resistome. Emerg Infect Dis. 2013;19(7):e120871. doi:10.3201/eid1907.120871

23. Lupton S. Markets for waste and waste-derived fertilizers. An empirical survey. Journal of Rural Studies. 2017;55:83-99. doi:10.1016/j.jrurstud.2017.07.017

24. Harrison JA, Gaskin JW, Harrison MA, Cannon JL, Boyer RR, Zehnder GW. Survey of food safety practices on small to medium-sized farms and in farmers markets. J Food Prot. Nov 2013;76(11):1989-93. doi:10.4315/0362-028x.Jfp-13-158

25. Bihn EA, Smart CD, Hoepting CA, Worobo Rw. Use of Surface Water in the Production of Fresh Fruits and Vegetables: A Survey of Fresh Produce Growers and Their Water Management Practices. Food Protection Trends. 2013;33(No.5):307-314.

26. Efficacy Protocol for Reduction of Foodborne Bacteria in Preharvest Agricultural Water. U.S.-Food and Drug Administration. Accessed December 6th, 2020.

https://www.fda.gov/food/food-safety-modernization-act-fsma/efficacy-protocol-reductionfoodborne-bacteria-preharvest-agricultural-water

27. McCarthy TA, Barrett NL, Hadler JL, et al. Hemolytic-Uremic Syndrome and Escherichia coli O121 at a Lake in Connecticut, 1999. Pediatrics. Oct 2001;108(4):E59. doi:10.1542/peds.108.4.e59

28. Keene WE, McAnulty JM, Hoesly FC, et al. A swimming-associated outbreak of hemorrhagic colitis caused by Escherichia coli O157:H7 and Shigella sonnei. N Engl J Med. Sep 1 1994;331(9):579-84. doi:10.1056/NEJM199409013310904

29. Zhang XX, Zhang T, Fang HH. Antibiotic resistance genes in water environment. Applied microbiology and biotechnology. Mar 2009;82(3):397-414. doi:10.1007/s00253-008-1829-z

30. Pruden A, Arabi M, Storteboom HN. Correlation between upstream human activities and riverine antibiotic resistance genes. Environmental science \& technology. Nov 6 2012;46(21):11541-9. doi:10.1021/es302657r

31. Rizzo L, Manaia C, Merlin C, et al. Urban wastewater treatment plants as hotspots for antibiotic resistant bacteria and genes spread into the environment: a review. The Science of the total environment. Mar 1 2013;447:345-60. doi:10.1016/j.scitotenv.2013.01.032 
32. Czekalski N, Gascón Díez E, Bürgmann H. Wastewater as a point source of antibioticresistance genes in the sediment of a freshwater lake. The ISME journal. 2014/07/01 2014;8(7):1381-1390. doi:10.1038/ismej.2014.8

33. Hsu C-Y, Hsu B-M, Ji W-T, et al. A Potential Association Between Antibiotic Abuse and Existence of Related Resistance Genes in Different Aquatic Environments. Water, Air, \& Soil Pollution. 2014/12/18 2014;226(1):2235. doi:10.1007/s11270-014-2235-z

34. Malema MS, Abia ALK, Tandlich R, Zuma B, Mwenge Kahinda J-M, Ubomba-Jaswa E. Antibiotic-Resistant Pathogenic Escherichia Coli Isolated from Rooftop Rainwater-Harvesting Tanks in the Eastern Cape, South Africa. Int J Environ Res Public Health. 2018;15(5):892. doi:10.3390/ijerph15050892

35. World Health O. Antibiotic resistance: multi-country public awareness survey. World Health Organization; 2015.

36. Hölzel CS, Tetens JL, Schwaiger K. Unraveling the Role of Vegetables in Spreading Antimicrobial-Resistant Bacteria: A Need for Quantitative Risk Assessment. Foodborne pathogens and disease. Nov 2018;15(11):671-688. doi:10.1089/fpd.2018.2501

37. Larranaga $\mathrm{O}$, Brown-Jaque $\mathrm{M}$, Quiros $\mathrm{P}$, et al. Phage particles harboring antibiotic resistance genes in fresh-cut vegetables and agricultural soil. Environ Int. Jun 2018;115:133-141. doi:10.1016/j.envint.2018.03.019

38. General Public's Knowledge, Attitude and Practice Survey on Antimicrobial Resistance 2016/17. Social Sciences Research Centre The University of Hong Kong. Accessed December 6th, 2020. https://www.chp.gov.hk/files/pdf/kap_on_amr_main_report.pdf

39. Napolitano F, Izzo MT, Di Giuseppe G, Angelillo IF. Public knowledge, attitudes, and experience regarding the use of antibiotics in Italy. PloS one. 2013;8(12):e84177.

doi:10.1371/journal.pone.0084177

40. André M, Vernby A, Berg J, Lundborg CS. A survey of public knowledge and awareness related to antibiotic use and resistance in Sweden. The Journal of antimicrobial chemotherapy. Jun 2010;65(6):1292-6. doi:10.1093/jac/dkq104

41. Marti R, Tien YC, Murray R, Scott A, Sabourin L, Topp E. Safely coupling livestock and crop production systems: how rapidly do antibiotic resistance genes dissipate in soil following a commercial application of swine or dairy manure? Appl Environ Microbiol. May 2014;80(10):3258-65. doi:10.1128/aem.00231-14

42. Heuer H. Fate of sulfadiazine administered to pigs and its quantitative effect on the dynamics of bacterial resistance genes in manure and manured soil. Soil biology \& biochemistry. 2008-07 2008;v. 40(no. 7):pp. 1892-1900-2008 v.40 no.7. doi:10.1016/j.soilbio.2008.03.014 43. Jechalke S, Heuer H, Siemens J, Amelung W, Smalla K. Fate and effects of veterinary antibiotics in soil. Trends in microbiology. Sep 2014;22(9):536-45.

doi:10.1016/j.tim.2014.05.005

44. Heuer H, Schmitt H, Smalla K. Antibiotic resistance gene spread due to manure application on agricultural fields. Current Opinion in Microbiology. 2011/06/01/ 2011;14(3):236243. doi:https://doi.org/10.1016/j.mib.2011.04.009

45. Zhu Y-G, Johnson TA, Su J-Q, et al. Diverse and abundant antibiotic resistance genes in Chinese swine farms. Proceedings of the National Academy of Sciences. 2013;110(9):3435. doi:10.1073/pnas.1222743110

46. Friedman DB, Kanwat CP, Headrick ML, Patterson NJ, Neely JC, Smith LU. Importance of prudent antibiotic use on dairy farms in South Carolina: a pilot project on farmers' knowledge, 
attitudes and practices. Zoonoses and public health. 2007;54(9-10):366-75. doi:10.1111/j.18632378.2007.01077.x

47. Continuing Education and Informational Resources $\mid$ Community $\mid$ Antibiotic Use $\mid$ CDC. Accessed August 10, 2020. https://www.cdc.gov/antibiotic-use/community/for-hcp/continuingeducation.html

48. Antibiotic resistance threats in the United States. Centers for Disease Control and

Prevention (CDC). Accessed December 6th, 2020. https://www.cdc.gov/drugresistance/threatreport-2013/pdf/ar-threats-2013-508.pdf 